\title{
Uncertainty and Error in Complex Plasma Chemistry Models
}

\author{
Miles M. Turner \\ School of Physical Sciences and National Centre for Plasma Science and Technology, \\ Dublin City University, Dublin 9, Ireland \\ E-mail: miles.turner@dcu.ie
}

\begin{abstract}
Chemistry models that include dozens of species and hundreds to thousands of reactions are common in low-temperature plasma physics. The rate constants used in such models are uncertain, because they are obtained from some combination of experiments and approximate theories. Since the predictions of these models are a function of the rate constants, these predictions must also be uncertain. However, systematic investigations of the influence of uncertain rate constants on model predictions are rare to non-existent. In this work we examine a particular chemistry model, for helium-oxygen plasmas. This chemistry is of topical interest because of its relevance to biomedical applications of atmospheric pressure plasmas. We trace the primary sources for every rate constant in the model, and hence associate an error bar (or equivalently, an uncertainty) with each. We then use a Monte Carlo procedure to quantify the uncertainty in predicted plasma species densities caused by the uncertainty in the rate constants. Under the conditions investigated, the range of uncertainty in most species densities is a factor of two to five. However, the uncertainty can vary strongly for different species, over time, and with other plasma conditions. There are extreme (pathological) cases where the uncertainty is more than a factor of ten. One should therefore be cautious in drawing any conclusion from plasma chemistry modelling, without first ensuring that the conclusion in question survives an examination of the related uncertainty.
\end{abstract}

PACS numbers: 


\section{Introduction}

The aim of computational science is to make accurate predictions, in some sense. At the extreme, grave social and economic consequences may flow from actions based on erroneous prediction [98]. However, we assume that some consequences follow from all predictions. Otherwise, why would they be made? That erroneous prediction is all too likely has been shown by recent investigations into the integrity of computational science [48, 47]. These alarming discoveries have directed attention towards techniques and practices that tend to reduce the likelihood of mistakes [114, 98, 99, 115]. This evolving collection of ideas goes under the general classification of "verification and validation" or "V\&V." "Verification" is concerned with the correctness of computer programs, while "validation" is about testing physical models. In this context, the purpose of a computer program is to find a solution to a particular physical model. Consequently, one should show that the computer program correctly solves the physical model before comparing the model predictions with any experiments. In other words, verification should precede validation. Even if our predictions are made with a certifiably correct computer program, some uncertainty remains, for two reasons. First, the solution of the physical model will usually be discrete (for example, in time or space or both), and therefore discretization errors will occur. Second, the physical model usually incorporates parameters that are known only within some margin of error, and these errors necessarily infect the solution. There is, therefore, invariably uncertainty in the computed solutions, and we should not compare these solutions with experiments, or use them for any other predictive purpose, without understanding the magnitude of the uncertainties that they embody. Consequently, "uncertainty quantification" is an essential element of good practice in computational science. The present paper is concerned with uncertainty quantification in the context of plasma chemistry modelling. In plasma modelling in general, there are many sources of uncertainty, arising, for example, from the many assumptions that may be made when constructing a particular model, but in this paper we focus exclusively on uncertainty caused by a fallible knowledge of rate constants.

Uncertainty is obviously a concern in the case of chemistry models in lowtemperature plasma physics. Such models may involve dozens of chemical species and thousands of reactions [117, 41, 95]. Each reaction is characterized by a rate constant, and these are are never known with certainty. The amount of uncertainty in each varies depending on the provenance of the data. In this context, a cursory review of a selection of recent literature $[132,139,77,81,100,142,50,117,41,95]$ dealing with plasma chemistry modelling reveals two striking features. First, as an ordinary practice, no information is supplied to characterize the margin of error in rate constant data, although processes considered especially sensitive or uncertain may be discussed. Second, the majority of rate constants are chosen on the authority of previously published chemistry models, and not by reference to a primary source. This practice often conceals a convoluted process of transmission between the primary source and the recent literature, with the effect that locating the primary source starting 
from a recent paper may be difficult or even impossible. This means that most authors do not know the primary authority for their data, and consequently cannot put an error bar on most of their rate constants. Under these conditions, not only the authors, but also the community more generally, cannot know what error bars to associate with the predictions of plasma chemistry models. Without this information, we cannot be sure that predictions made with plasma chemistry models are fit for purpose, whatever that purpose might be. A further confounding issue is that the convoluted pathways by which data are transmitted facilitate a variety of errors and misunderstandings, with the effect that a subset of the rate coefficients in common use is clearly incorrect. When considering these concerns, we should note that in other communities facing similar problems, such as combustion science, much better practice is evident $[143,118,125,70,94]$.

The specific aim of the present paper is to quantify the predictive uncertainty in a particular plasma chemistry model, the one for mixtures of helium and oxygen. This is a model of middling complexity, by recent standards, with some tens of chemical species and a few hundred reactions. Our procedure is in essence to associate a probability distribution with each rate coefficient in the model, and hence, by using a Monte Carlo procedure in which random rate coefficients are generated from the indicated probability distributions, we create an ensemble of predictions from the model. This procedure can be used to investigate how uncertainty in rate coefficients leads to uncertainty in prediction. Of course, in order to use this approach, we must characterize the uncertainty in the rate coefficients, and, as we have noted, this information is not customarily presented in the recent literature. So a major part of the present study is an investigation of the sources of the rate data for the helium-oxygen system, so that the uncertainty in this data can be characterised. We will then show that the uncertainty in the rate data causes appreciable uncertainty in the model predictions, typically of the order of a factor between two and five, but sometimes much larger. This is comparable with or even in excess of the error typically claimed for high quality experimental measurements of plasma species densities, for instance.

The structure of the remainder of this paper is as follows. In section 2, we discuss general concerns affecting the transmission and selection of rate data. In section 3 , we describe the chemistry model developed in the present work, and we discuss the particular rate constants selected by us, and the reason for those selections. In section 4 , we describe our computational procedure. The results of the calculations are presented in section 5, and various issues arising from the results are discussed in section 6 . Some concluding reflections are in section 7 .

\section{Transmission of rate constants}

As we have already remarked, a chemistry model consists of a set of reactions, and each reaction is characterized by a rate constant. The rate constants are determined by the convolution of a cross section with the energy or speed distribution of the reacting 
species, at least for binary processes. Ternary processes typically are a convenient representation of a chain of binary processes involving transient intermediate states, so there may not be an underlying cross section in the same sense. When all the reacting species are "heavy," or non-electronic, there is usually a presumption that the reacting species have a Maxwell-Boltzmann distribution of energies with a common temperature, and the rate constant may then be expressed as a parametric function of this temperature. The form usually chosen is of the extended Arhenius type:

$$
k(T)=A T^{B} \exp \left(-\frac{C}{T}\right),
$$

where $T$ is the temperature, and $A, B$ and $C$ are coefficients to be determined. Most experimental determinations of rate constants give a result in this form, or a form that is translatable into this one. Clearly, gathering these data for a complex chemistry model is a formidable task, since the number of primary sources involved is likely to be at least of the same order as the number of reactions in the model. Partly for this reason, most complex chemistry models in use today are the outcome of a historical process, in which older models are augmented and otherwise adjusted through several generations of development. An attempt to reach a primary source by following a chain of citation from a recent paper can involve consulting four or five intermediate works. Consequently, if we are seeking primary sources, the number of papers to be consulted may be several times larger than the number of rate constants of interest. This complex process of transmission is economical in the sense that previous work is not needlessly repeated, but there are disadvantages. One is that contact with the primary sources is lost, and when this connection is lost, so is any sense of the quality of the original data. Another is that when (as has usually been the case in the past) the mechanism of transmission is transcription of a printed source, opportunities are created for corruption of the data, or confusion as to its significance.

The process of tracing primary sources for rate data is difficult not just because of the number of sources that must be consulted, but also because of the common practice of citing authorities that are not readily acccessible. These include unpublished theses, unpublished technical reports, and books that are not widely available. Hence the primary sources cannot easily be found by starting with the reference list of a recently published model. However, the experience of constructing the model to be discussed below suggests that the original source for rate constant data is almost never in obscurity, and is usually a refereed journal in the open (indeed English language) literature, even though this may be hard to locate. In particular, it seems that the Russian language sources that some authors cite extensively are usually if not always of a secondary character. Not infrequently however, there is no primary source, and a rate constant has been estimated in some way, by someone, at some time. This is a legitimate and sometimes unavoidable procedure, but the common practice of subsequent authors treating such estimates as authorities indistinguishable from a primary source is unhelpful. This practice, and others discussed above, has the consequence that not only does the typical presentation of a chemistry model in 
the recent literature give no sense of the sources for or quality of the rate data being used, but also that it is difficult for readers to discover this information for themselves. In recent years these difficulties have decreased, because most refereed journals are available in digital form, and many hitherto obscure technical documents have been published digitally and are freely available. Important examples of this nature include the extensive compilations by Baurer and Bortner [11] and Ikezoe [55]. The resources required to pursue archival enquiries into the primary sources for rate data have therefore been reduced, and this has facilitated the present study.

\section{Chemistry model}

In this section we describe the chemistry model used in the present work. We begin by discussing the principles that have been adopted in selecting rate data. These principles are, of course, influenced by the considerations discussed in the previous section. Our central concern in seeking the sources for rate data is to associate an uncertainty with each rate constant. For this reason, the search for a source was concluded when this data was found, and this has been deemed the "primary source." Therefore the category of primary sources includes compilations, when these provide sufficient information to assign an uncertainty. Indeed, the best of all primary sources are critical compilations that present a detailed discussion of all the available data, accompanied by a recommended value with an uncertainty (e.g., Atkinson et al. [7] and Sander et al. [119]). Only a minority of the rate constants in the present model have been so treated, those mostly processes important in atmospheric chemistry. When there is a single experimental authority, we have accepted the uncertainty suggested by the experimenters, and when there is a sequence of experiments that are not critically reviewed, we have usually accepted the most recent value. More difficult is the case where there are only theoretical estimates. In these cases, where there are several calculations, we have treated the disagreement between them as indicative of the likely uncertainty, and when there is only a single calculation, we have assumed the uncertainty from some similar process. Not all these procedures are entirely satisfactory, but they will usually give results of the right order of magnitude.

A more complex concern is the treatment of electron impact processes. A high quality set of electron impact cross sections for any molecular or atomic species should be shown to be consistent with transport data, such as drift velocities, diffusion coefficients, and ionization coefficients [104]. This is not always possible (such data is not always available), but it is desirable. In principle, the uncertainties associated with a set of electron impact processes should be consistent with the transport coefficients, which themselves are experimentally uncertain. In practice, we have not attempted to impose this condition explicitly, and electron impact processes have been treated as any other process. This may be entirely appropriate, but a more detailed study of the problem would be desirable. We note that a characteristic problem in this context is that the total excitation cross section is better known that the cross sections for specific states. 
However, the total excitation rate is of course the sum of these other rates, and the sum of a set of random variables has smaller uncertainty than the component terms. Therefore, one can expect that reasonable choices for uncertainties in partial excitation rates will lead to an appropriate uncertainty in the total excitation rate, and hence to equally appropriate uncertainties in the transport coefficients (for example).

As these remarks suggest, the primary sources are varied in character. This variety cannot be conveyed completely in any simple scheme of classification, but to provide some guidance to readers, we have assigned the rate constants in the model to one of three categories. Category A rate constants have been the subject of at least one specific investigation, which may be either experimental or theoretical. The quality of the primary sources for category A reactions varies widely. Some are based on excellent critical evaluations of multiple independent experiments; others depend on a single theoretical study. Category B rate constants are determined from some theoretical or semi-empirical formula. The typical situation for rate constants in this category is that the formulae involved have been tested against experiments for particular instances, but not for the cases involved in the present model. The uncertainties assigned are based on such experimental tests. Category $\mathrm{C}$ rate constants have no specific experimental or theoretical foundation, and are assigned by analogy with other similar processes. In these cases, the uncertainties have been assigned by considering the range of rate constants found for similar processes in category A. As we will see, a substantial subset of reactions in the present model are assigned to category C. Although it is tempting to characterize these values as "guesses," this would not be altogether fair. Most category $\mathrm{C}$ reactions are exothermic processes, where closely related reactions are known to occur at nearly gas kinetic rates. The assumption that these category $\mathrm{C}$ processes also proceed at nearly gas kinetic rates therefore appears fairly well founded. There is some risk that inadequate understanding of the reaction mechanism leads to an overestimate of the rate constant in these cases, of course (see Appendix A.4, for an example). We have not cited earlier papers as authorities for category $\mathrm{C}$ rate constants, even when the same or similar choices have been made, on the grounds that such citation attaches spurious authority to weakly based data. Naturally, we urge future authors not to cite the present paper in this connection either, for the same reason.

The set of processes included in the present model has, of course, been influenced by earlier works, even though these are not cited as authorities for rate data below, because they are not primary sources. Recent interest in helium-oxygen chemistry has been stimulated by applications in chemical lasers (where excitation of the $\mathrm{O}_{2}\left(a^{1} \Delta_{u}\right)$ state is the primary concern) and biomedicine $[132,139,77,81,100,142,50,95]$. As we have already noted, plasma chemistry models are typically derived by complicated paths, and we will not try to follow these historical developments in detail. Nevertheless some comment may be of interest. Generally speaking, Stafford and Kushner [132] and Vidmar and Stalder [139] have been highly influential on subsequent works, which have often imported a substantial subset of their rate data from one or other of these papers (or both). Stafford and Kushner [132] and Vidmar and Stalder [139] in turn depend 
heavily on antecedent works, such as studies of the oxygen-nitrogen system by Kossyi et al. [69] and Gordiets et al. [42], and of oxygen by Eliasson et al. [33]. This latter group of papers cite primary sources extensively, but they also make considerable use of sources that are now inaccessible, and at this point difficulties arise in following the chain of citation. As already noted, the situation in this respect has been greatly eased by the electronic publication of compilations by Baurer and Bortner [12] and Ikezoe [55], which important and useful sources have thus been removed from the category of "obscure literature." The policy of the present work is to include all reactions that can be identified as potentially relevant, recognising that some of these are of minor importance. In practice, this means that the set of reactions included in the present model is almost the union of those mentioned in the works cited above. A small number of reactions have been discarded as clearly erroneous, or lacking any credible authority.

A list of the species included in the model appears as table 1. A complete list of the reactions included in the present model is presented in table 2. Electronic supplements to this paper contain the same list of reactions (in a less legible form), together with further commentary on the choice of some rate constants. Table 2 includes a reference number for each reaction, the reaction rate in the form of equation (1), and a dimensionless measure of the uncertainty, i.e. $\Delta A / A$, where $A$ is the first coefficient in the Arhenius rate equation (1). We thus allow that only the parameter $A$ is uncertain. For rates derived from cross sections, this is equivalent to assuming that the shape of the cross section is better known that the absolute magnitude, as is often the case for data originating from beam measurements [97]. Moreover, when a rate constant is reported directly in the form of equation (1), estimates of uncertainty for parameters $B$ and $C$ are rarely included. The assumption that only $A$ is uncertain is therefore both convenient, and responsive to the character of the data practically available. We explain below how we use $\Delta A$ in Monte Carlo calculations.

It will be evident that vibrational kinetics are not treated in detail. As is wellknown, vibrationally excited molecules are often much more reactive than those in the ground state. However, in the present work we are concerned with dilute mixtures of oxygen in helium, and in this case vibrational-translational processes involving helium quench vibrationally excited molecular states before they participate in other reactions. A single vibrationally excited level of each molecular species has been included both for completeness and so that we can verify that the density of vibrationally excited molecules is indeed small compared to ground state molecules. If this were not so, one would of course need a more detailed vibrational kinetics model [80]. We assume that the properties of these vibrationally excited levels are the same as those of the corresponding ground state, unless there is contrary evidence. In particular, a reaction involving a vibrationally excited molecule listed as category $\mathrm{C}$ in table 2 is assumed to have the same rate as the same reaction with a ground state molecule.

Only when a temperature dependence is specified by the primary source has this been included in table 2. (Some authors, such as Stafford and Kushner [132], introduce conjectural temperature dependencies when none are specified in their sources. This 
is avoided in the present work because it obscures what the sources say, without demonstrably improving the quality of prediction.)

In the next sections, we discuss the choice of rate constants for a subset of processes that present points of particular interest or difficulty.

\subsection{Electron impact processes}

Electron impact cross sections for helium are known with high accuracy. Indeed, highly detailed data are available for excitation to many electronic states. Since the present model does not attempt to model the helium excited state manifold in detail, these have been aggregated into a single excitation cross section, which is assumed to populate the lowest helium metastable level. The cross sections employed are those compiled by Biagi, and recently described by Alves et al. [2]. These data are highly consistent with all known transport data, the uncertainty is small, and their contribution to the uncertainty in prediction is minor.

Cross sections for atomic oxygen are predominantly from the review of Laher and Gilmore [72]. These have not been tested against any transport data, and their consistency is therefore uncertain.

For molecular oxygen, we have chosen to use the well-tried set of cross sections compiled by Lawton and Phelps [75], with the exception that we replaced the total ionization cross section of Lawton and Phelps [75] with the partial ionization cross sections of Straub et al. [135]. This substitution has a neglible effect on the total ionization rate. The data of Lawton and Phelps [75] are old, but they are known to be consistent with the available transport data. There is a substantial amount of more recent information $[23,56,58,137,136,74]$, especially relating to dissociation processes, but in our view these need to be critically evaluated, compiled into a fresh set of cross sections, and demonstrated to be consistent with transport data before the data of Lawton and Phelps [75] should be considered superceded. However, retaining the Lawton and Phelps [75] cross sections entails that we interpret the inelastic excitation channels. These include processes with thresholds at $4.5 \mathrm{eV}, 6 \mathrm{eV}$, and $9.97 \mathrm{eV}$, which collectively are an important energy loss channel. One of the experimental reference points is excitation to the $\mathrm{O}_{2}\left(b^{1} \Sigma_{g}^{+}\right)$state [75]. Consistency with this data is achieved by assuming that the $4.5 \mathrm{eV}$ and $6 \mathrm{eV}$ channels lead to excitation of this level, but this is a problematic assumption because it is not easy to see from the potential energy curves how this state can be reached - one would expect dissociation to ground state atoms. This is an unsolved problem at the present time, and in this work we have preferred consistency with the measured excitation coefficients, and hence disregarded the problem of the potential energy curves. The $9.97 \mathrm{eV}$ process is assumed to lead to dissociation to the $\mathrm{O}+\mathrm{O}\left({ }^{1} D\right)$ limit, which is consistent with other recent works suggesting that this is the only important dissociation channel [136].

Table 2 lists the electron impact processes with oxygen that are included in the model. Perhaps not all of these are readily identifiable. Reaction 24 is elastic 
scattering, reaction 25 is rotational excitation, and reactions 26 to 31 are vibrational excitation channels. The cross section set partitions vibrational excitation into several channels involving different numbers of vibrational quanta, and resonant and nonresonant excitation processes [75]. When no better data is available, we assume the same cross sections apply to electronically excited states, with an adjustment to the threshold energy when electronic transitions are involved.

A complete set of cross sections for electron impact processes involving ozone does not exist. We have used such data as are available. These are cross sections for dissociative attachment [111], and for electronic excitation [44]. Excited states of ozone appear either weakly bound or dissociative. We have assumed that low threshold processes lead to dissociation to products including vibrationally excited oxygen molecules, while higher threshold processes lead to dissociation into electronically excited states [6]. This is unlikely to be a definitive assignment. Ionization cross section measurements have been made [86], but these include no data for energies less than $40 \mathrm{eV}$. We have chosen not to attempt an extrapolation into the energy range of interest in the present work, and we have instead used the theoretical results of Joshipura et al. [61].

The Arhenius expressions for electron impact processes that are listed in table 2 have been computed from the cross sections as part of the present study, assuming a Maxwell-Boltzmann distribution of electron speeds. This assumption is simple, convenient and suffices for the present work, but non-Maxwellian distributions are common in experiments, and some more sophisticated machinery should usually be used to compute an accurate electron energy distribution function [46].

\subsection{Neutral Chemistry}

Neutral chemical processes involving oxygen species are of atmospheric importance, and many of these processes have critically evaluated rate constants based on data of good quality, see for example Steinfeld et al. [133], Atkinson et al. [7], Sander et al. [119]. More than $90 \%$ of reactions between oxygen species have category A rate constants. Processes involving helium have been less studied, however, and the sources are often older [60] or obtained by complex fitting procedures [108, 109]. Moreover, a smaller proportion of these rate constants $(\sim 50 \%)$ are in category A. This is often because rates for reactions involving excited helium and oxygen species are not known, and are supposed to be the same as the corresponding process when only one participant is excited. Since such reactions usually occur at a nearly gas kinetic rate, gross error seems unlikely.

A common situation in experimental studies of chemical kinetics is that the gross reaction rate between two species is known with much greater precision than the partial rates for different product channels. Indeed, quite commonly there is no information about the product channels. In cases such as this, the policy of the present work is to assume that all energetically allowed product channels are equally likely. This might 
not be true, but including all channels in this way will allow future sensitivity analysis to scrutinize the importance of each channel, which would not be the case if some were arbitrarily closed. An instance of this kind is recombination of atomic oxygen radicals

$$
\mathrm{O}+\mathrm{O}+\mathrm{M} \rightarrow \mathrm{O}_{2}+\mathrm{M}
$$

which is exothermic by some $5 \mathrm{eV}$. Any electronically excited state of the oxygen molecule can therefore be a product of this reaction. Indeed, the aeronomic community assumes that all electronic states are populated with equal probability [54]. In the present model, which only includes three of the six electronically excited states of the oxygen molecule, we adopt this assumption, but also assume that the unrepresented upper levels are relaxed by unspecified processes into the states that are explicitly in the model. The product distribution assumed in the model reflects these assumptions.

Ozone is one the three neutral radical species that are likely to be important in the effluent or afterglow of the discharge. This molecule is formed by the three body process

$$
\mathrm{O}_{2}+\mathrm{O}+\mathrm{M} \rightarrow \mathrm{O}_{3}+\mathrm{M}
$$

Evidence has accumulated in recent years that the ozone molecules formed in this reaction are often in excited states [133]. In principle, this could include both electronic and ro-vibrational excitation, but the drift of recent work suggests that vibrational excitation is the most important channel $[83,84]$. These excited molecules are far more reactive than those in the ground state, in particular with oxygen atoms. The practical effect of this is to retard the formation of ozone. Elaborate models featuring many vibrational levels have been constructed [83], but it is perhaps doubtful whether the quality of the basic kinetic data justifies such an approach, and in the present work we have favoured the simpler approach of Marinov et al. [84], which features a single effective vibrationally excited ozone state. In dilute mixture of oxygen in helium, in any event, rather efficient vibrational relaxation by helium reduces the importance of these effects.

Ozone in its vibrational ground state also reacts with atomic oxygen

$$
\mathrm{O}+\mathrm{O}_{3} \rightarrow 2 \mathrm{O}_{2}
$$

and in recent work it is commonly assumed that the products include electronically excited states with appreciable branching fractions [71, 95]. However, the primary sources give no support for this supposition [141, 10, 7, 119], suggesting instead that the predominant products are molecules in vibrationally excited states.

The process

$$
\mathrm{O}_{2}\left(a^{1} \Delta_{g}\right)+\mathrm{O}_{2}\left(a^{1} \Delta_{g}\right)+\mathrm{O}_{2} \rightarrow 2 \mathrm{O}_{3}
$$

features in many recent models. However, investigation (discussed in Appendix A) reveals no credible primary source, and we have chosen not to include this reaction in the present model. The motivation for continued interest in this reaction, in spite of the 
sparse evidence, appears to be inconsistency between calculated and measured $\mathrm{O}_{2}\left(a^{1} \Delta_{g}\right)$ densities [123]. An alternative process, also tending to reduce the $\mathrm{O}_{2}\left(a^{1} \Delta_{g}\right)$ density, is

$$
\mathrm{O}+\mathrm{O}_{2}\left(a^{1} \Delta_{g}\right)+\mathrm{O}_{2} \rightarrow 2 \mathrm{O}_{2}+\mathrm{O}
$$

This process was introduced by Braginskiy et al. [20] to reduce a disagreement between experiment and a complex chemistry model, with a suggested rate constant of $1-3 \times 10^{-44} \mathrm{~m}^{6} \mathrm{~s}^{-1}$. One would usually regard this as a weak argument for accepting a process, but further investigations of a more fundamental character by Azyazov et al. [9] have given credence to this idea. In photolysis experiments, Azyazov et al. [9] found a rate for reaction 6 of $1 \times 10^{-43} \mathrm{~m}^{6} \mathrm{~s}^{-1}$, which for various reasons they found implausibly large. However, they suggest that

$$
\mathrm{O}_{3}(\nu)+\mathrm{O}_{2}\left(a^{1} \Delta_{g}\right) \rightarrow \mathrm{O}+2 \mathrm{O}_{2}
$$

which has a rate constant some forty times larger than the same reaction with ozone in the vibrational ground state, is responsible for some of the observed quenching. The experimental observations are fully explained only with the speculation that ozone molecules in higher vibrational states are present and even more reactive [9]. In this complex situation we have retained the rate constant of Braginskiy et al. [20] for reaction 6 , introduced a corresponding process with helium as the third body assuming that the efficacy of helium in this role is similar to other processes [60], and introduced reaction 7 . Clearly, there is some obscurity here that future work may illuminate.

\subsection{Charged species}

Important sources for ion-neutral reactions are the compilations by Baurer and Bortner [12] and Ikezoe [55]. The first of these has a complex publication history with much piecemeal replacement of material, and attention to detail is consequently important when citing this work, or verifying a reference to it. Both of these works survey the literature of the 1960s and 1970s, and to a lesser extent the 1980s, most of which has not been superceded. For exothermic ion-molecule processes for which no rate constant has been measured, we assume the Langevin rate constant applies, given by [73, 31]:

$$
k_{L}=\sqrt{\frac{\pi \alpha e^{2}}{\epsilon_{0} \mu}},
$$

where $\alpha$ is the polarizability of the neutral collision partner in units of cubic meters, and $\mu$ is the reduced mass of the colliding particles. Polarizabilities of ground state species are obtained from Miller [90], and for helium metastables from Crosby and Zorn [24]. We assume the latter value also applies to molecular metastables. The polarizability of atomic and molecular excited states of oxygen appears neligibly different from that of the corresponding ground states [64, 96, 107]. Equation (8) yields values for known rate constants that are generally in reasonable agreement with experiments, and these values are frequently much larger than the corresponding reactions involving neutral species, which cannot therefore be used as a basis for estimation. Although little has been added recently to the database for positive ion processes, there is considerable new 
work on negative ion chemistry. In particular, there is a complicated history of revision in the rate constants for the detachment reaction of the $\mathrm{O}_{2}\left(a^{1} \Delta_{g}\right)$ state with negative ions $[35,138,14]$. The most recent work $[88,89]$ suggests that in addition to detachment channels, there also exists a charge exchange process

$$
\mathrm{O}^{-}+\mathrm{O}_{2}\left(a^{1} \Delta_{g}\right) \rightarrow \mathrm{O}+\mathrm{O}_{2}^{-}
$$

These recent results are adopted in the present model. There is no data for the corresponding processes involving the $\mathrm{O}_{3}^{-}$and $\mathrm{O}_{4}^{-}$ions, which are therefore assumed to proceed at similar rates, consistent with observed interactions with other ions [34]. However, the $\mathrm{O}_{2}\left(a^{1} \Delta_{g}\right)$ state has insufficient energy to detach the $\mathrm{O}_{3}^{-}$ion, and we assume that this reaction has a negligible rate.

Two large groups of reactions are described by essentially theoretical approaches. One of these groups is mutual neutralization, such as

$$
\mathrm{O}^{-}+\mathrm{O}_{2}^{+} \rightarrow \mathrm{O}+\mathrm{O}_{2}
$$

The processes in this class that are included in the present model generally do not have measured rate constants, and we have used the semi-empirical formula of Miller et al. [91] in these cases. This expression has been tested against experiments for a large number of processes, and the uncertainties assigned in the present work are derived from these experiments. A second group of processes for which we are mostly reliant on theoretical results are three body recombination reactions such as

$$
\mathrm{O}^{-}+\mathrm{O}_{2}^{+}+\mathrm{He} \rightarrow \mathrm{O}+\mathrm{O}_{2}+\mathrm{He}
$$

for which we use an expression apparently first given by Biondi [16], and seemingly not superceded [36]. Again, uncertainties for these processes are estimated by considering those cases for which tests against experiments have taken place, which are sparse. There is evidence that the theory gives results of the right order of magnitude, but a stronger conclusion appears difficult to draw. Clearly, distinguishing experimentally between two- and three-body recombination is not straightforward, and such a neat classification is possibly naive in any case [140].

Approximately a quarter of the reactions included in the model are category B processes in one or other of classes described above. We assume that the uncertainties in each of the rate constants for these processes are statistically independent quantities, in spite of the mutual dependence through the governing formulae. This assumption is made because the available experiment tests of these formulae do not seem to show systematic errors. If the errors in these rate constants however were found to be correlated and not independent, the effect would be to increase the uncertainty in the model predictions that we discuss below.

\section{Computational procedure}

Perhaps the most topical use of the $\mathrm{He} / \mathrm{O}_{2}$ chemistry described above is the large family of atmospheric pressure plasma devices developed in recent years, often but not always 
with biomedical applications in mind. These devices differ in detail, but the general concept is the same. The discharge is formed in a channel with a smallest dimension of around $1 \mathrm{~mm}$. This means that when the plasma is excited by, for example, applying a radio-frequency potential, an essentially uniform glow discharge is formed. For neutral species at least, the dominant transport mechanism is associated with the convective flow of the gas mixture through the channel. Consequently, this kind of device is known as a "jet" source. As feedstock gas passes through the channel, the neutral and charged species composition evolves in a quasi one-dimensional manner. When the gas leaves the channel, excitation of the plasma ceases. Charged and transient radical species then decay rapidly, and after a short time there remains only a variety of longer-lived excited species. In general, these species are predominantly responsible for any biological effect that the effluent from the channel exhibits. The present work is not concerned with detailed modelling of any particular plasma jet, but since we must assume some specific conditions, we have chosen to approximate the so-called micro atmospheric pressure plasma jet ( $\mu \mathrm{APPJ})$ [121], which is in many ways a typical example. This device is usually configured with a channel that is $1 \times 1 \mathrm{~mm}^{2}$ and some $30 \mathrm{~mm}$ long. The residence time of the gas in the channel is about $3 \mathrm{~ms}$ at typical gas flow rates. Power is coupled into the plasma by applying a radio-frequency voltage source between a pair of plane electrodes forming two sides of the channel. The other sides of the channel are formed from dielectric slabs, which confine both the plasma and the flowing gas. In the present work, we represent this system in a simple way by assuming that the plasma together with the chemistry can be approximated by a zero-dimensional "global" model, in which balance equations are solved for the electron temperature and plasma species densities [92]. A constant power is applied for $3 \mathrm{~ms}$. This power corresponds to supplying $1 \mathrm{~W}$ to a system with the dimensions mentioned above. We then follow the evolution of the plasma for a further $3 \mathrm{~ms}$, to model the chemical development of the effluent. This is of course a rough model, omitting many practically important effects, but the plasma and chemical parameters that are produced are representative of those found experimentally and in more elaborate models $[65,66]$.

We characterise the uncertainty in each rate constant in the chemistry model of table 2 using the log-normal distribution [59]:

$$
f(x ; \mu, \sigma)=\frac{1}{x \sigma \sqrt{2 \pi}} \exp \left(-\frac{(\ln x-\mu)^{2}}{2 \sigma^{2}}\right),
$$

where the parameters $\mu$ and $\sigma$ are related to the mean $\bar{x}$ and variance $\operatorname{Var}(x)$ of the distribution by

$$
\begin{aligned}
& \mu=\ln \left(\frac{\bar{x}^{2}}{\sqrt{\operatorname{Var}(x)+\bar{x}^{2}}}\right) \\
& \sigma=\sqrt{\ln \left(1+\frac{\operatorname{Var}(x)}{\bar{x}^{2}}\right)} .
\end{aligned}
$$

Examples of this distribution are shown in figure 1. For each rate constant, we assume that the uncertainty is concentrated into the parameter $A$ of equation (1), and 
we therefore assign a mean value and a variance to each such parameter, using the principles that were discussed above in section 3. Specifically, we choose $\bar{x}=A$ and $\operatorname{Var}(x)=(\Delta A)^{2}$. The virtue of the log-normal distribution in this context is that it is only defined for $x \geq 0$, so it is a suitable choice for random variables that must be positive, which is of course the case for rate constants. Equation (12) is a convenient choice, but it is not beyond criticism. For instance, there is a physical upper limit for rate constants (the gas kinetic value) that may not be properly represented by equation (12). For this reason (and others discussed below), we characterize our results below in terms of upper and lower quartile values, which will be relatively insensitive to any unphysical values for rate constants that might occasionally appear.

We then proceeded to generate a population of solutions for each set of physical conditions of interest, by generating a random value for each rate constant from the prescribed distributions, and solving the corresponding set of rate equations as described in the previous paragraph. At any give time coordinate, this means that each variable of the model is characterized by some distribution of values. These distributions are highly skewed, because all the variables are necessarily positive. Consequently, the standard deviation is not a specially helpful metric. For this and other reasons mentioned above, we chose to characterize the distributions by upper and lower quartile values, hereafter denoted by $N_{U}$ and $N_{L}$. This gives a range of values, within which half of the samples are found. We typically calculated several hundred solutions for each set of physical parameters.

\section{Results}

For reasons just mentioned, we will generally represent the results in terms of the range between the upper and lower quartile values obtained from the Monte Carlo calculations. However, it is instructive to examine samples of the discrete solutions, and these are shown in figures 2 and 3. Figure 2 shows a selection of the solutions for the electron temperature $T_{e}$. In view of the strong dependence of the rate constants on the electron temperature, it is not surprising to find that there are not large differences between these curves. Nevertheless, the range of values that are exhibited vary by some $30 \%$ during the first $10^{-5} \mathrm{~s}$, and by rather less during the quasi-equilibrium interval between $10^{-5} \mathrm{~s}$ and $10^{-3} \mathrm{~s}$. Following the end of the discharges at $10^{-3} \mathrm{~s}$, the electron temperature collapses rapidly towards the ambient gas temperature, which time period is not shown in this figure. Figure 3 shows a corresponding sample of solutions for the density of the helium metastable lumped state, He*. The density of this state collapses rapidly at the end of the discharge, and this period is also not shown. In this case, there are variations in the density at any given time, and qualitative differences between the curves. For example, maxima can occur at almost any time, and there is corresponding disagreement concerning the sign of the derivative. All of these curves are consistent with the rate constants reported in table 2. Clearly, if one had access to experimental measurements for comparison with these data, the knowledge that so many outcomes are consistent 
with the rate data should change one's view of what might count as agreement between the model and the experiment. Conversely, not knowing that such diverse results are possible could result in misleading conclusions.

In the remainder of this section, we will focus on excited or radical species formed from oxygen molecules, since, in general, these species are of greatest interest in applications. In these calculations, the molecular oxygen density is $0.4 \%$ of the feedstock gas. Before examining the predictive uncertainty in these species densities, we will briefly look at the behaviour of these species for central values of the rate constants. There are six species to consider, and these fall into two groups. The atomic excited states $\mathrm{O}\left({ }^{1} D\right)$ and $\mathrm{O}\left({ }^{1} S\right)$, and the molecular $\mathrm{O}_{2}\left(b^{1} \Sigma_{u}^{+}\right)$states are formed by a balance of fast processes (with a characteristic time less than the discharge period), so that these species decay rapidly in the afterglow, as show in figure 5. Clearly, there are large differences within this classification - the atomic states decay much faster than the molecular state, and the density of the molecular state is much larger. These observations will be relevant to later discussion. We can also remark that most of the species that will will not discuss in detail, including all of the charged species, decay on similarly rapid time scales. A selection of charged species densities is shown in figure 4.

Figure 6 shows the corresponding densities for three states with relatively slow kinetics. Evidently, both during and after the period when the power is on, the densities of these species evolve on a time scale that is long compared to the time during which the plasma is excited. Consequently, relatively high densities remain for some time after the discharge has ended. Of course, this is why one or other of these species is usually considered the dominant feature in most applications. Since these are the only species with any appreciable density in the afterglow, the chemistry then consists predominantly of reactions between these states, sometimes mediated by other states that appear transiently. (For instance, this is why the $\mathrm{O}_{2}\left(b^{1} \Sigma_{u}^{+}\right)$state persists in the afterglow after the atomic states have vanished.)

The next three figures $(7-9)$ show the densities of $\mathrm{O}, \mathrm{O}_{2}\left(a^{1} \Delta_{g}\right)$ and $\mathrm{O}_{3}$ as they evolve in time under the baseline conditions, using the upper and lower quartile representation discussed above, such that half of the samples fall between these limits. As we have noted above, this compact view of the data may conceal both the variety of permitted solutions, and the presence of the kind of extreme trajectories shown in figure 3. The range of variation shown in figures 7 and 8 is appreciable but not surprising, given the typical size of the error bars on the rate constants. Of greater interest is the data shown in figure 9 for the density of $\mathrm{O}_{3}$, where a much larger range of variation is seen. This is made clearer in figure 10, where the ratio of the upper and lower quartile densities is shown. Evidently, this ratio at times exceeds fourteen.

A question that immediately follows is how much these results change as the conditions are varied. The next three figures show the densities of the same three species at the end of the discharge period, i.e. at $t=3 \mathrm{~ms}$. For $\mathrm{O}$ and $\mathrm{O}_{2}\left(a^{1} \Delta_{g}\right)$, the range of variation does not change greatly over the range of parameters investigated, but for $\mathrm{O}_{3}$, there is a strong dependence, with a maximum at an oxygen fraction of 
about $0.5 \%$, as shown in figure 14 . The next section will discuss why this happens.

One can also ask about the behaviour of other species that we have not discussed in detail. If one were to attempt a general statement, one could say that in most cases, the ratio of the upper and lower quartile densities varies between about two and five. Certain species that are strongly coupled to the $\mathrm{O}_{3}$ density, such as $\mathrm{O}_{3}^{+}$and $\mathrm{O}_{2}\left(b^{1} \Sigma_{u}^{+}\right)$, show predictably larger variations. One can also find very much larger ratios $(>100)$ for some species in the late afterglow, but this is neither very surprising nor very interesting, since it arises from the sensitivity of exponential processes to the rate of decay. Interested readers may refer to electronic supplements to this paper, which contain results for all of the species included in the model.

\section{Discussion}

The results presented in the previous section suggest two immediate conclusions. First, that the uncertainty introduced into plasma chemistry models from uncertainty in rate constants is likely to be significant in any context in which such a model might be useful. This uncertainty is nearly always a factor of two, and is sometimes considerably larger. Combined with the observation that uncertainty of this character can qualitatively change the temporal behaviour of plasma species densities, this suggests that, for instance, a good deal of caution should be exercised when drawing conclusions from comparisons between models and experiments. Apparently large disagreements might not in fact be significant, if the uncertainty in both experiments and models has been properly quantified. Second, we note that the uncertainty in species densities varies surprisingly with time and as a function of the gas composition, as is clear in particular from figures 10 and 14 . This means that proposing a rule of thumb for estimating uncertainties will be hazardous. It also makes it of interest to consider how such large uncertainty can occur.

As a first approximation, the ozone density is controlled by two reactions:

$$
\begin{aligned}
& \mathrm{O}+\mathrm{O}_{2}+\mathrm{M} \rightarrow \mathrm{O}_{3}+\mathrm{M} \\
& \mathrm{O}_{3}+\mathrm{O}_{2}\left(b^{1} \Sigma_{u}^{+}\right) \rightarrow 2 \mathrm{O}_{2}+\mathrm{O} .
\end{aligned}
$$

The second reaction is also important in determining the $\mathrm{O}_{2}\left(b^{1} \Sigma_{u}^{+}\right)$density, if the ozone density is sufficiently large. Consequently

$$
\frac{d\left[\mathrm{O}_{3}\right]}{d t} \approx k_{268}[\mathrm{O}]\left[\mathrm{O}_{2}\right][M]-k_{138}\left[\mathrm{O}_{3}\right]\left[\mathrm{O}_{2}\left(b^{1} \Sigma_{u}^{+}\right)\right]
$$

where the subscripts on the rate constants refer to reaction indices in table 2. There are thus three regimes:

(i) When $\left[\mathrm{O}_{2}\right]$ is small, three body association to ozone is slow and the density of $\mathrm{O}_{2}\left(b^{1} \Sigma_{u}^{+}\right)$is large. Consequently, the ozone density remains small until the end of the discharge pulse, when the $\mathrm{O}_{2}\left(b^{1} \Sigma_{u}^{+}\right)$density collapses, and ozone density grows. 
(ii) When $\left[\mathrm{O}_{2}\right]$ is large, three body association to ozone is fast, quenching of $\mathrm{O}_{2}\left(b^{1} \Sigma_{u}^{+}\right)$ by ozone is fast, and the density of $\mathrm{O}_{2}\left(b^{1} \Sigma\right)$ remains small. Consequently, the second term in equation (17) is small compared to the first.

(iii) In an intermediate regime, both terms in equation (17) are important, and the densities of ozone and $\mathrm{O}_{2}\left(b^{1} \Sigma\right)$ are strongly coupled.

In effect, in the first case, quenching of ozone by $\mathrm{O}_{2}\left(b^{1} \Sigma_{u}^{+}\right)$bleaches the ozone density, and in the second case, the quenching of $\mathrm{O}_{2}\left(b^{1} \Sigma_{u}^{+}\right)$by ozone bleaches the $\mathrm{O}_{2}\left(b^{1} \Sigma_{u}^{+}\right)$ density. In both these cases, the density of the dominant species is hardly affected by the density of the suppressed species. In the intermediate regime, where the densities of these two species are strongly coupled, we find the extraordinary increase in the uncertainty in these species densities. In this case, it is easy to see why this occurs. Evaluating equation (17) in the third case involves substracting two random variables with similar means and standard deviations. However, the result is characterized by the difference of the means and the sum of the variances (using the approximation of normal deviates). Hence the ratio of the mean to the standard deviation can be enormously increased, and this pathology is the cause of the large increase in uncertainty in certain parts of the parameter space. In the context of the present model, this behaviour is untypical, because for most species, the dominant reactions involve a single transient species reacting with a feedstock gas. However, as figures 5 and 6 show, both ozone and $\mathrm{O}_{2}\left(b^{1} \Sigma_{u}^{+}\right)$can reach relatively high densities, and a binary reaction between these species can strongly influence the density of both. Consequently, at higher power densities than those considered here, or with more complex chemistries, one might see pathologies of this kind affecting more species. A more detailed investigation of these phenomena would be of interest, but is outside the scope of the present paper. In other chemistry models, one might also discover other kinds of pathologies, also leading to exceptionally large uncertainties. One might worry, for instance, about species at the end of long chains of polymerising reactions.

Another obvious subject for further investigation is the relationship between the uncertainty in particular reaction rates and the uncertainty in species densities, i.e. one would like to be able to apportion the uncertainty in species densities to uncertainty in particular rate constants. This knowledge would, for example, enable one to identify the rate constants that are most in need of improvement. The simple Monte Carlo procedure employed in this work yields no information on this subject. A tool for finding the dominant reaction pathways is a partial but not a complete solution to this problem $[76,85]$. However, many methods do exist that can be used to extract such data $[93,53,116]$, and applying them is a natural direction for future work.

Clearly, a major source of difficulty both in researching rate constants and analysing sensitivity is the sheer number of processes involved. The model discussed above is traditional in the sense that it seeks to be as comprehensive as possible, and consequently includes every process for which a plausible rate constant can be proposed. However, many of these processes are of at most minor importance under the conditions we have 
investigated, which prompts the reflection that a model with better defined aims could be much simpler. For instance, we could have decided that our aim was to predict the densities of the primary active species $\mathrm{O}, \mathrm{O}_{2}\left(a^{1} \Delta_{u}\right)$ and $\mathrm{O}_{3}$, and then included only those species and reactions that appreciably influence the density of these active species. If we further decide to limit our interest to dilute mixtures of oxygen in helium, then the number of processes can be still further reduced. Preliminary investigations in this direction, which will not be discussed in detail here, suggest that perhaps two thirds of the reactions in the model are superfluous under these restrictions. A disproportionate number of the reactions that are discarded in this procedure have weakly based rate constants in categories $\mathrm{B}$ and $\mathrm{C}$, so the reduced model, apart from being simpler, also contains rate data of higher average quality (this does not, of course, improve the quality of prediction, since the discarded data were not important anyway, but it does make clear that the model is better grounded than first appears). In this context, we can note that there are related fields, such as combustion science, where the practice of developing relatively simple models with relatively narrowly defined predictive scope is well-established. This approach is often combined with a relatively thorough and sophisticated approach to both uncertainty quantification and validation against experiments, which leads to models that can be employed predictively with some confidence $[143,118,125,70,94]$. This is almost the opposite of the situation in low-temperature plasma physics.

Of course, a systematic characterisation of parametric uncertainty of the kind presented above greatly increases the number of cases to be investigated, and there is a corresponding increase in the amount of computation required. This is tolerable in the case of the zero dimensional model employed in the present work, but this might not be so for a multi-dimensional model that is already near the limit of computational feasibility. In such circumstances, some compromise is inescapable. For instance, one can assume that global model calculations under similar conditions adequately characterize the uncertainty, or use global model calculations to identify a reduced list of parameters to be investigated in the full scale simulation.

As a final note in this section, we draw attention to the appendices. These discuss in some detail a number of particular examples of faulty rate constant data employed in recent models. Our purpose here is not to be harshly critical of particular authors or papers, but rather to draw attention to practices that are pervasive in the field (but of course not universal). However, we cannot assert that such practices occur without substantiating the case by mentioning specific examples. Of course, it is of interest to ask whether the use of inappropriate rate data seriously influences model predictions, particular in view of the substantial uncertainty that is in any case present. In at least some of the examples discussed, the effect is at least comparable with the typical level of uncertainty described above, but perhaps not with the more extreme cases mentioned. So it seems likely that a substantial amount of published work is at least materially affected by less than optimal choices of rate data. Of course, that the present work is itself affected by some lapse or another in the selection of rate data is only too likely. 
For this reason, we encourage careful scrutiny from readers, and welcome corrections of whatever errors are found. Even if such mistakes are found, however, they will be unlikely to undermine the leading conclusions of this study.

\section{Concluding Remarks}

As we have noted above, there has been much concern expressed in recent years about the integrity of scientific computation. Appreciation has grown that scientific computation cannot usually deliver exact results, for a variety of reasons. What we can do, however, is quantify the uncertainty that we cannot eliminate, and ensure that any conclusions we have drawn are robust in the face of this uncertainty. In other words, the results of scientific computations, if they are to be taken seriously, should be accompanied by error bars. The purpose of the present paper is to investigate how large an error bar should be associated with plasma chemistry calculations. The results presented above show that a general rule of thumb is difficult to propose, even if we assume that the particular model we have investigated is typical. However, we might assert that if consequential conclusions would be seriously undermined by a change of a factor of ten in some species density, then more detailed investigations should be undertaken. As we have also seen, recent practice in presenting plasma chemistry models both obscures the primary sources of rate data, which presents obstacles to systematic uncertainty quantification, and presents many opportunities for faulty data to persist. Electronic archives, however, greatly reduce the difficulty of addressing this issue.

As we also suggested above, systematic uncertainty quantification should lead to a general enhancement in the quality of plasma chemistry modelling, by focussing on the origins of uncertainty, and hence directing attention towards the rate data where improvement is most needed. This may assist experimentalists (and perhaps funding agencies) to choose the most promising areas for further work. The efforts of modellers may also be usefully prioritised using a knowledge of parametric uncertainty. For instance, refining the physical model may not be helpful if the changes produced by such refinements are dominated by chemical uncertainty. But such judgements, of course, always depend on maintaining a clear view of what is to be predicted, and why.

\section{Acknowledgments}

This work was supported by Science Foundation Ireland under grant number 08/SRC/I1411, and by COST Action MP1101 "Biomedical Applications of Atmospheric Pressure Plasmas." The author is indebted to Vasco Guerra and to Séan Kelly, who kindly drew attention to important sources that might otherwise have been overlooked. 


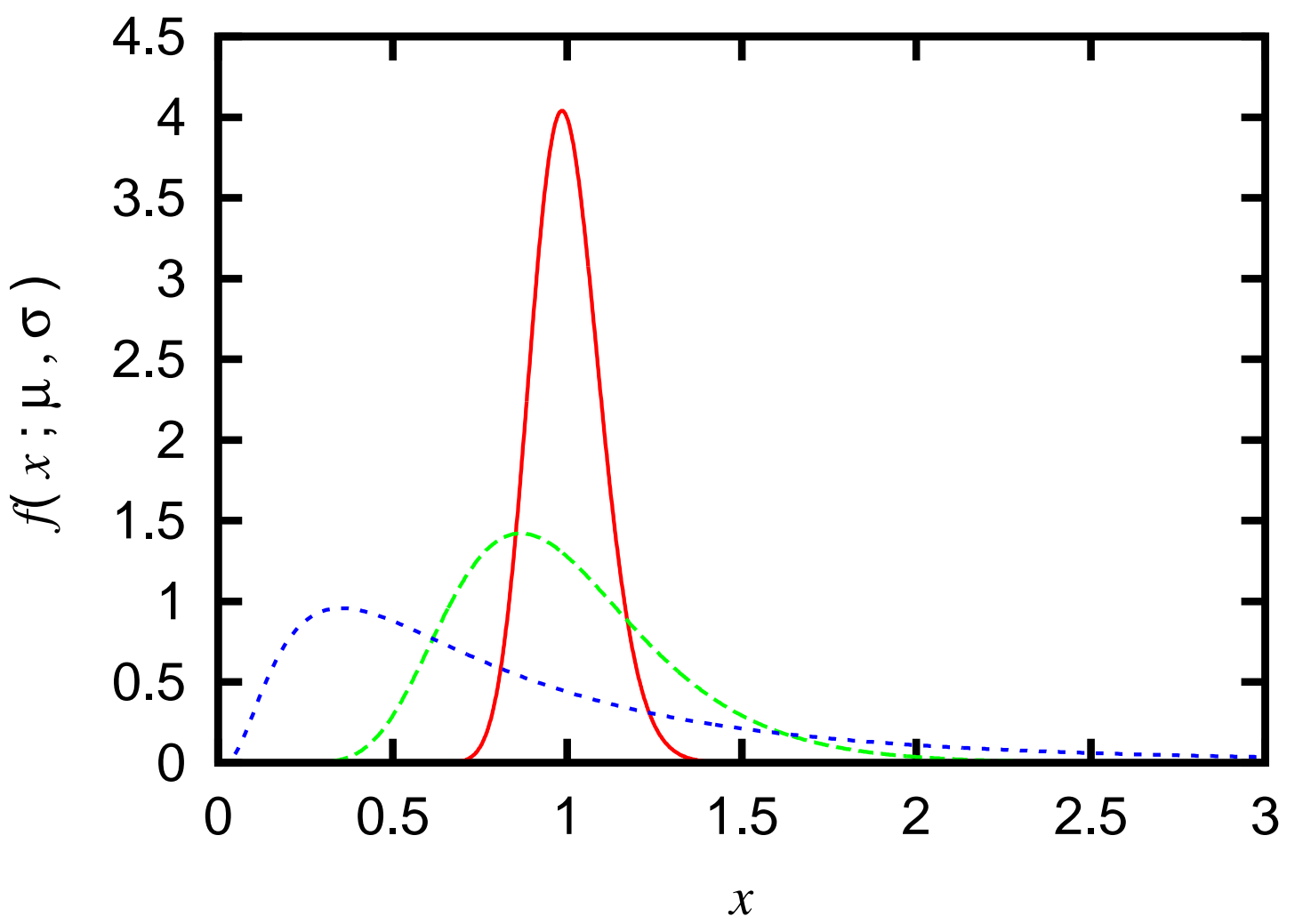

Figure 1. Examples of lognormal probability distributions given by equation (12), with the same mean, but different variances.

Table 1: Species included in the helium-oxygen system

\begin{tabular}{l}
\hline $\mathrm{He}$ \\
$\mathrm{He}^{*}$ \\
$\mathrm{He}^{+}$ \\
$\mathrm{He}_{2}^{*}$ \\
$\mathrm{He}_{2}^{+}$ \\
$\mathrm{O}$ \\
$\mathrm{O}\left({ }^{1} D\right)$ \\
$\mathrm{O}\left({ }^{1} S\right)$ \\
$\mathrm{O}^{+}$ \\
$\mathrm{O}^{-}$ \\
$\mathrm{O}_{2}$ \\
$\mathrm{O}_{2}\left(a^{1} \Delta_{u}\right)$ \\
$\mathrm{O}_{2}\left(a^{1} \Delta_{u}, \nu\right)$ \\
$\mathrm{O}_{2}\left(b^{1} \Sigma_{u}^{+}\right)$ \\
$\mathrm{O}_{2}\left(b^{1} \Sigma_{u}^{+}, \nu\right)$ \\
$\mathrm{O}_{2}(\nu)$ \\
$\mathrm{O}_{2}^{+}$ \\
$\mathrm{O}_{2}^{-}$ \\
$\mathrm{O}_{3}$
\end{tabular}


Uncertainty and Error in Complex Plasma Chemistry Models

$\mathrm{O}_{3}(\nu)$

$\mathrm{O}_{3}^{+}$

$\mathrm{O}_{3}^{-}$

$\mathrm{O}_{4}^{+}$

$\mathrm{O}_{4}^{-}$

e 


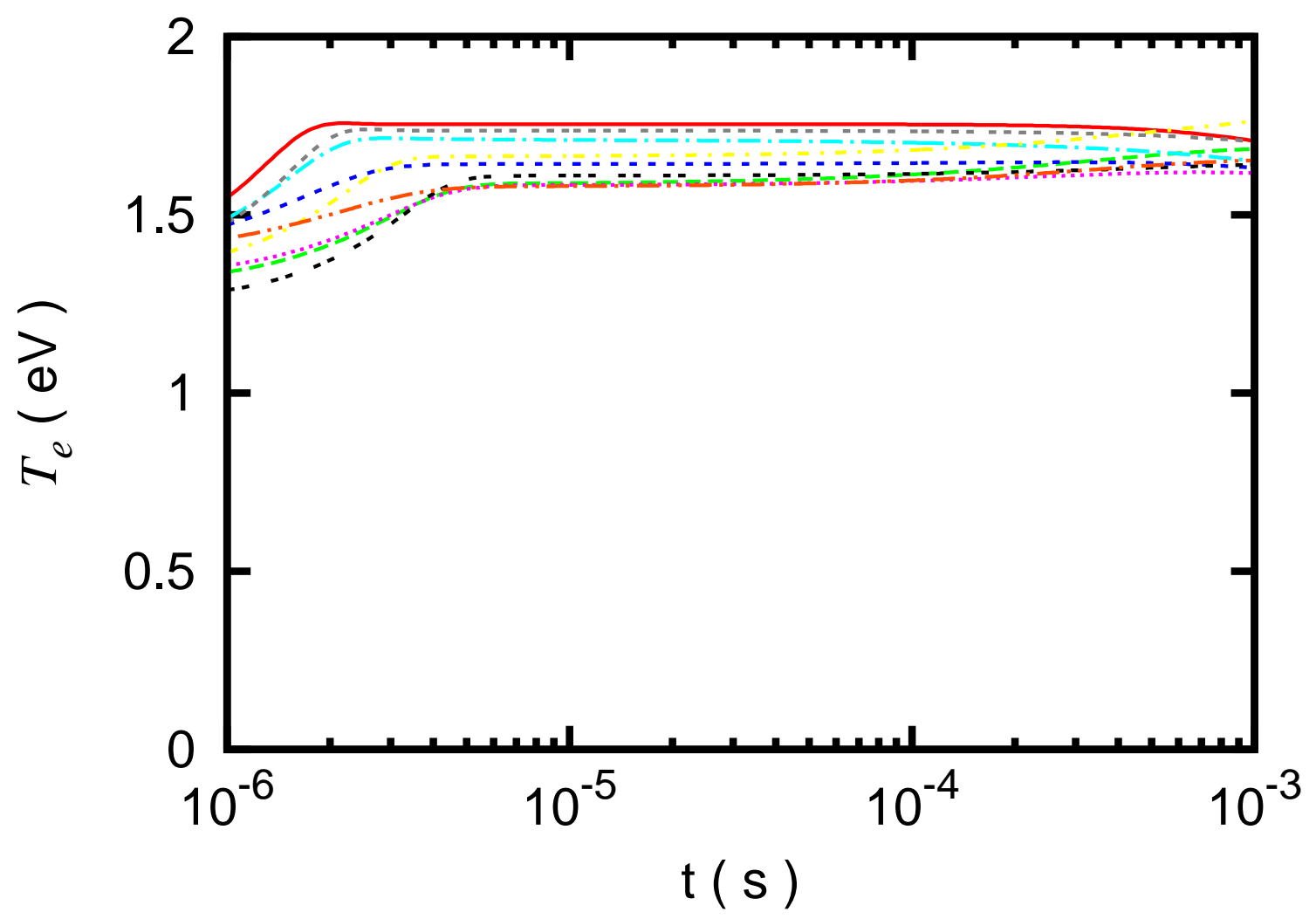

Figure 2. Sample solutions of the electron temperature for several random choices of rate coefficients. Each of these curves is a possible realisation of the chemistry model for the same physical conditions, and all are consistent with the uncertainties associated with the rate constants. These data, and those in figures 6,5 and 4 are for an oxygen fraction of $0.1 \%$. 


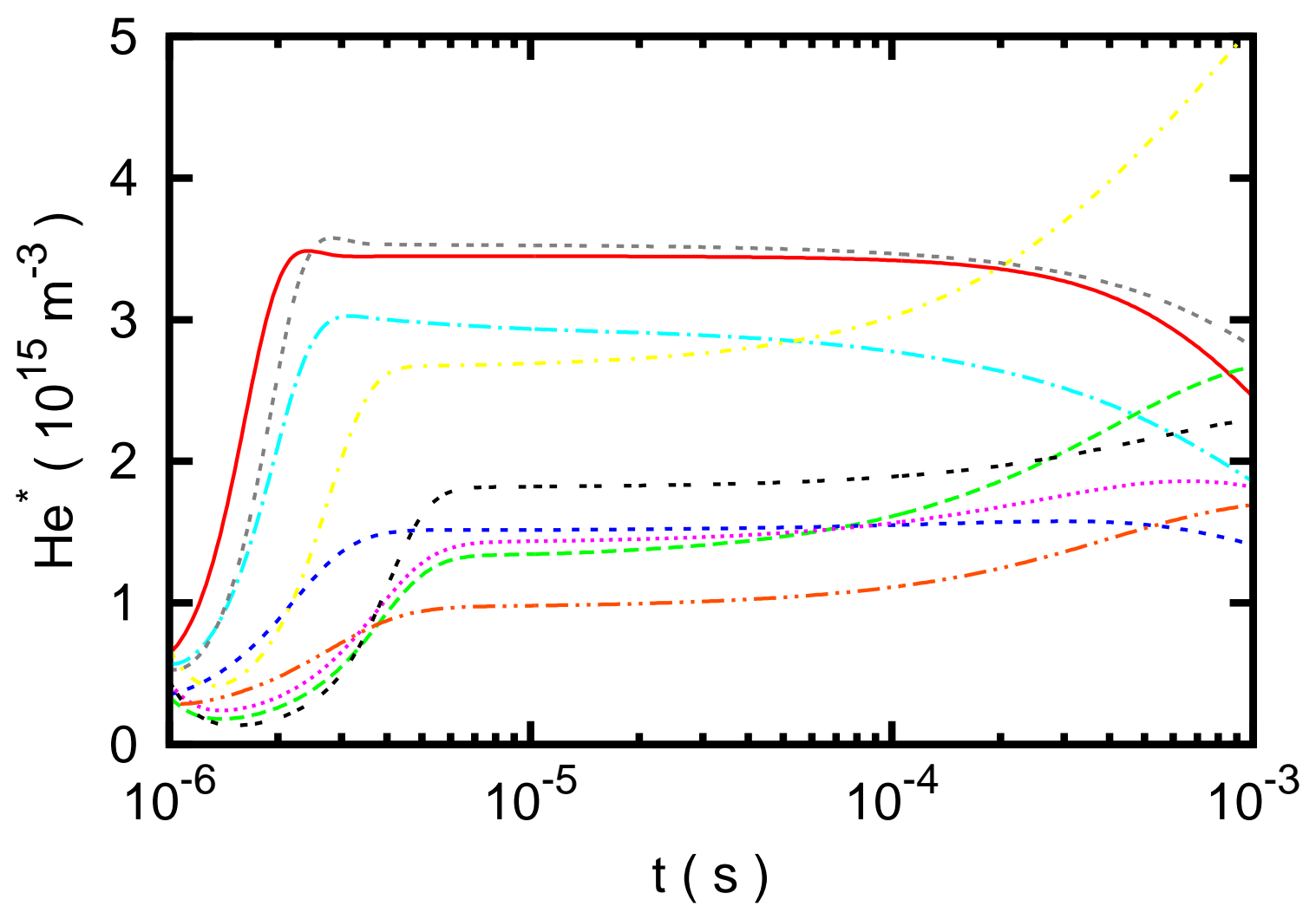

Figure 3. Sample solutions of the helium metastable density for several choices of random rate coefficients. As in figure (2), each of these curves is a possible realisation of the chemistry model for the same physical conditions, and all are consistent with the uncertainties associated with the rate constants. Note only are there large quantitative differences between trajectories, but there are major qualitative variations as well. 


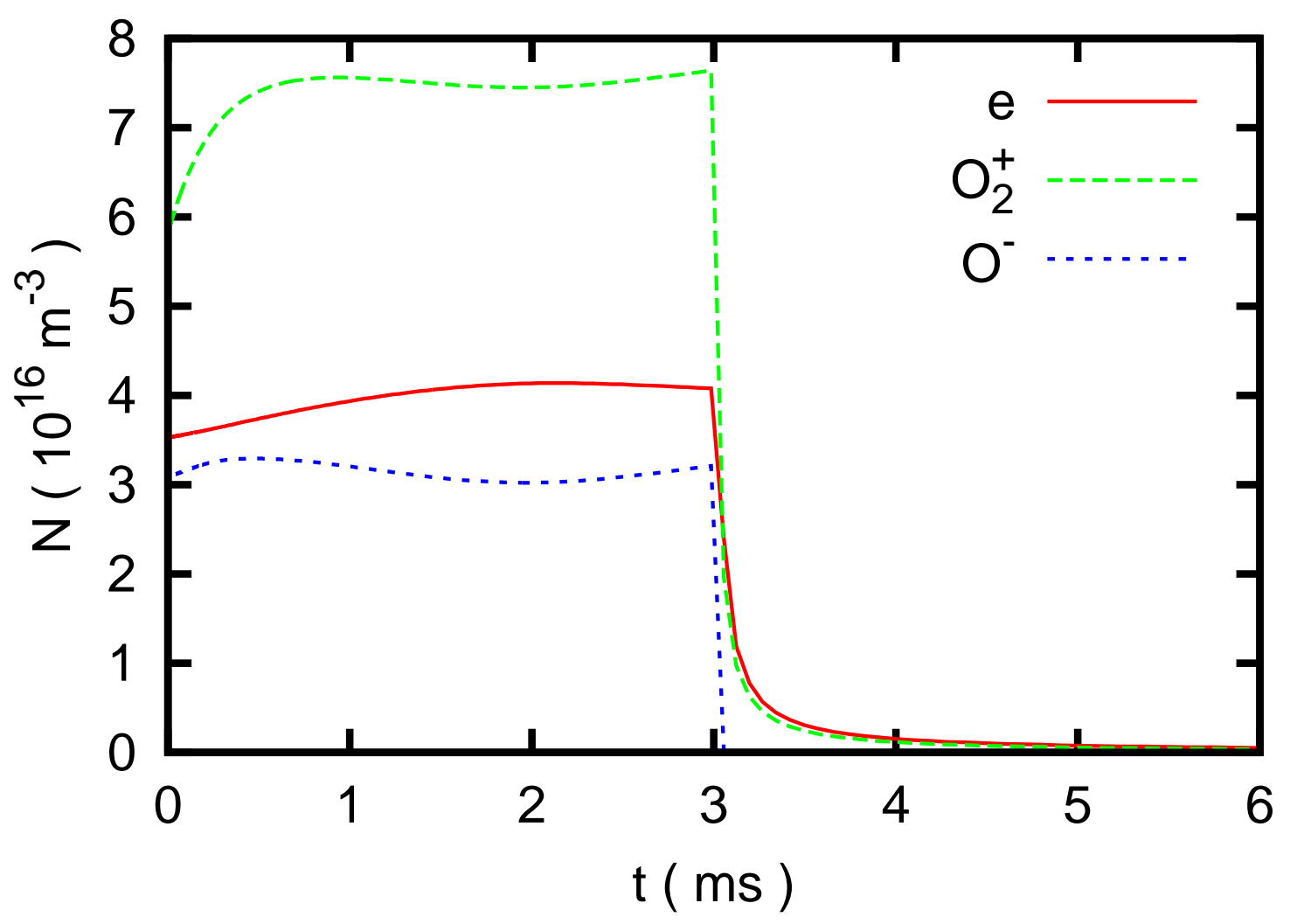

Figure 4. Densities of selected charged species, showing slow evolution during the discharge pulse (up to $3 \mathrm{~ms}$ ), and rapid decay in the afterglow. 


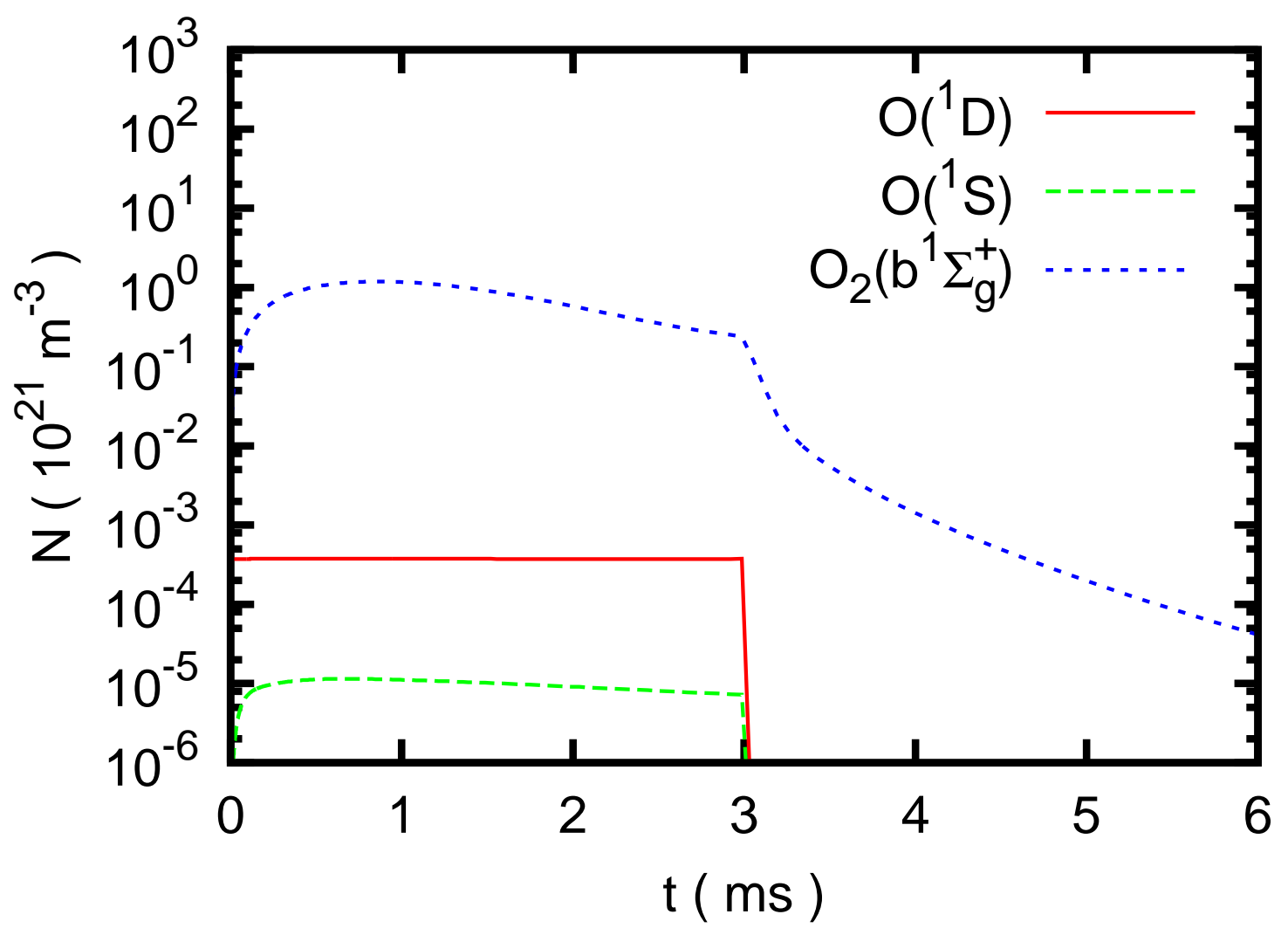

Figure 5. Predictions of the densities of three oxygen excited states that are transient, in the sense that the equilibrium or quasi-equilibrium densities are determined by relatively fast processes, so that these species decay rapidly when the discharge is extinguished at $t=3 \mathrm{~ms}$ 


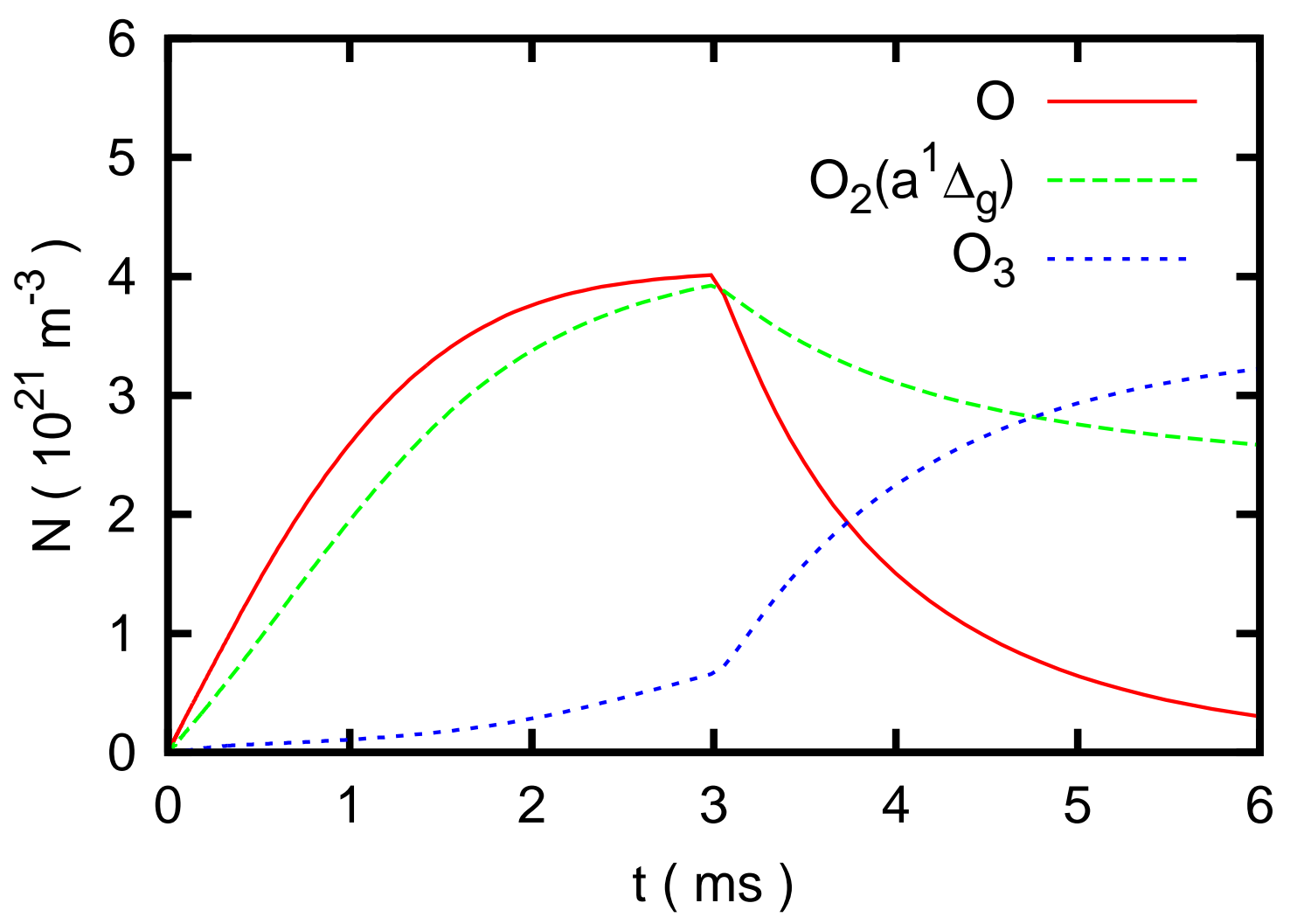

Figure 6. Densities of three oxygen excited states that evolve on slower time scales, so that their densities fall relatively slowly or even increase after the end of the discharge at $t=3 \mathrm{~ms}$. These three species are usually regarded as being responsible for the biological effects produced by the effluent of a $\mathrm{He} / \mathrm{O}_{2}$ discharge. 


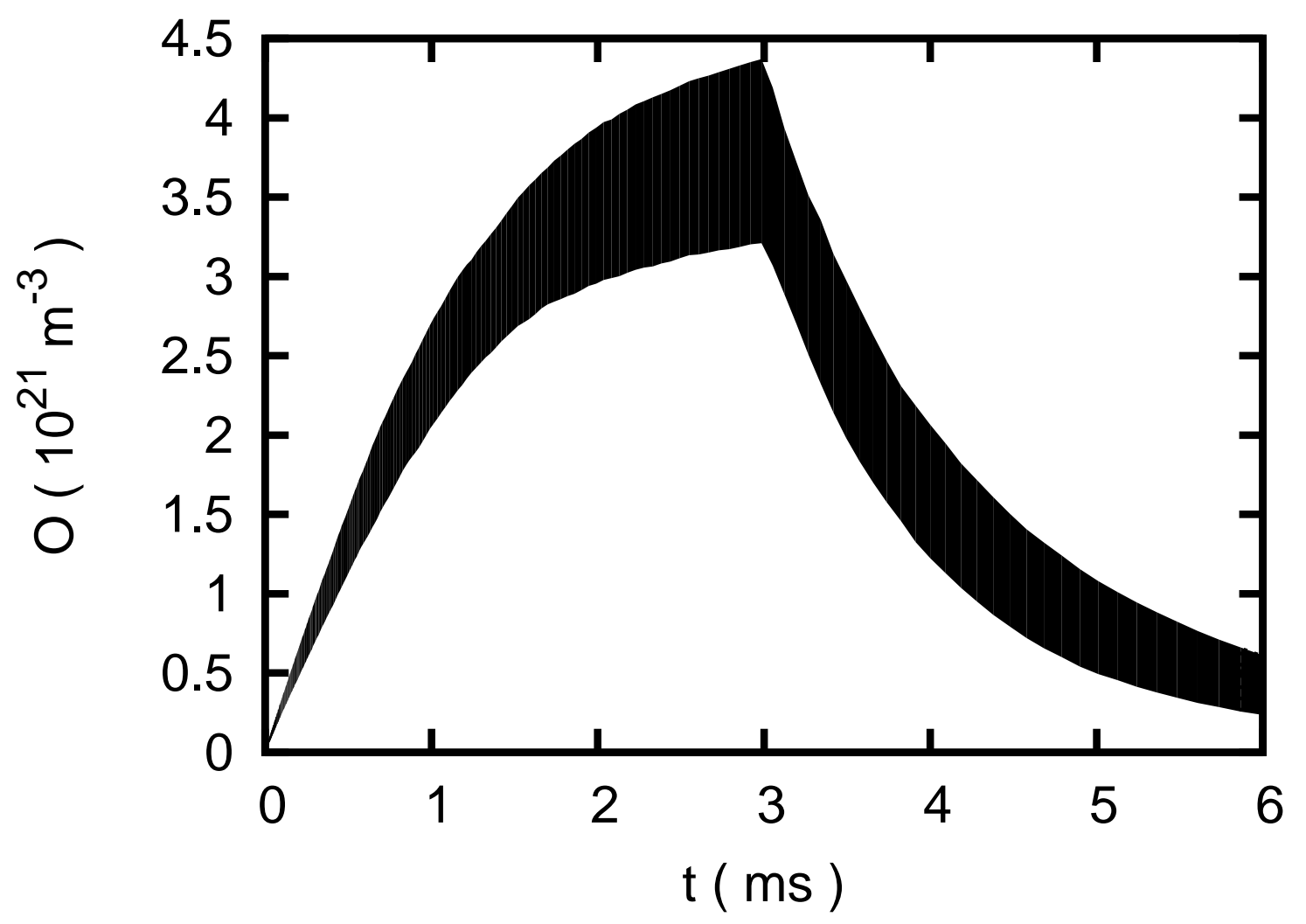

Figure 7. Atomic oxygen density showing the upper and lower quartile limits of a large set of random realisations of the model for the same physical conditions. In this presentation, half of the realized trajectories lie in the shaded region at any given time. Of course, this implies that half of the trajectories are outside the shaded region. These data are for an oxygen fraction of $0.4 \%$ of the feedstock gas. 


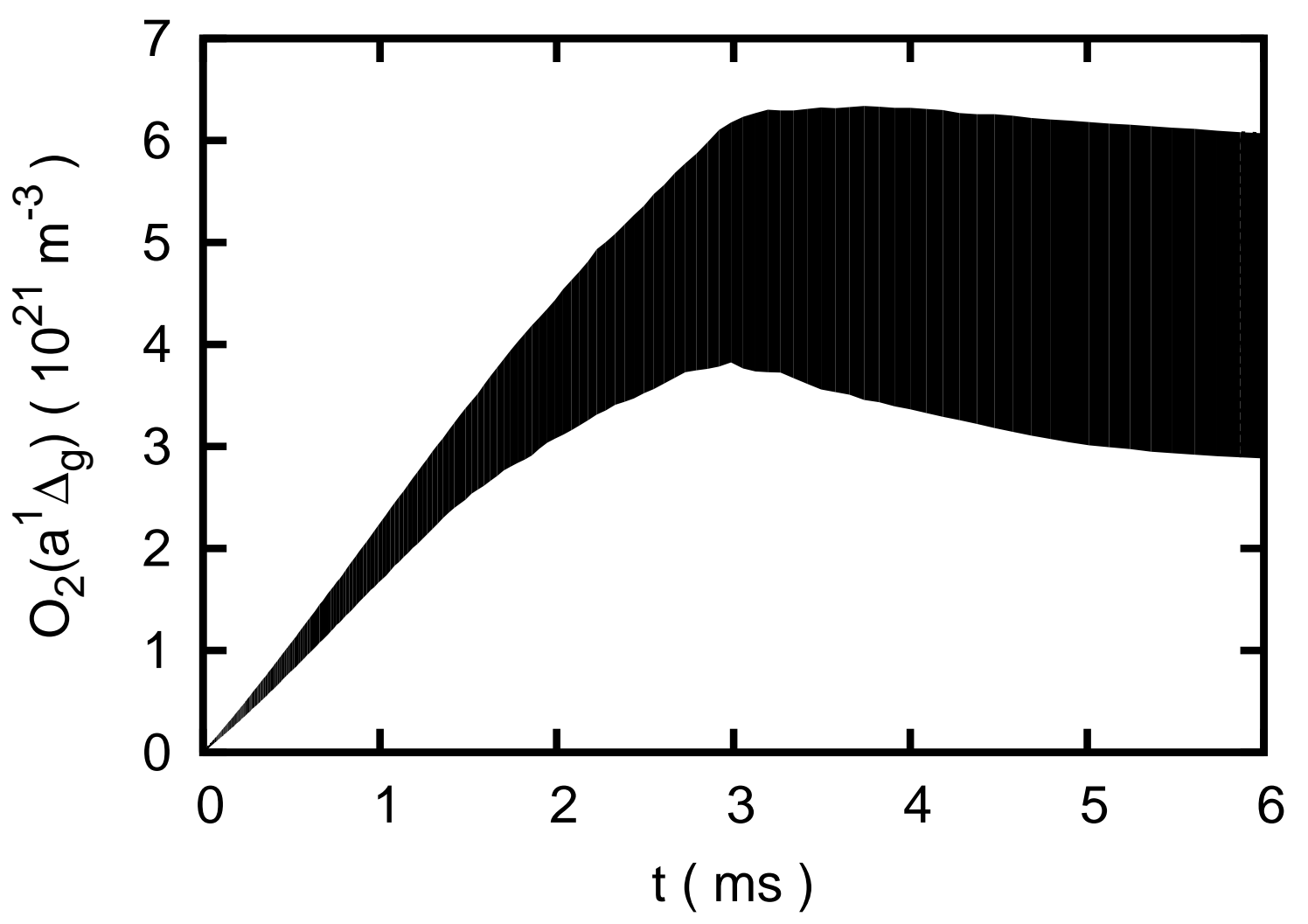

Figure 8. $\mathrm{O}_{2}\left(a^{1} \Delta_{g}\right)$ excited state density showing the upper and lower quartile limits, as in figure 7 . 


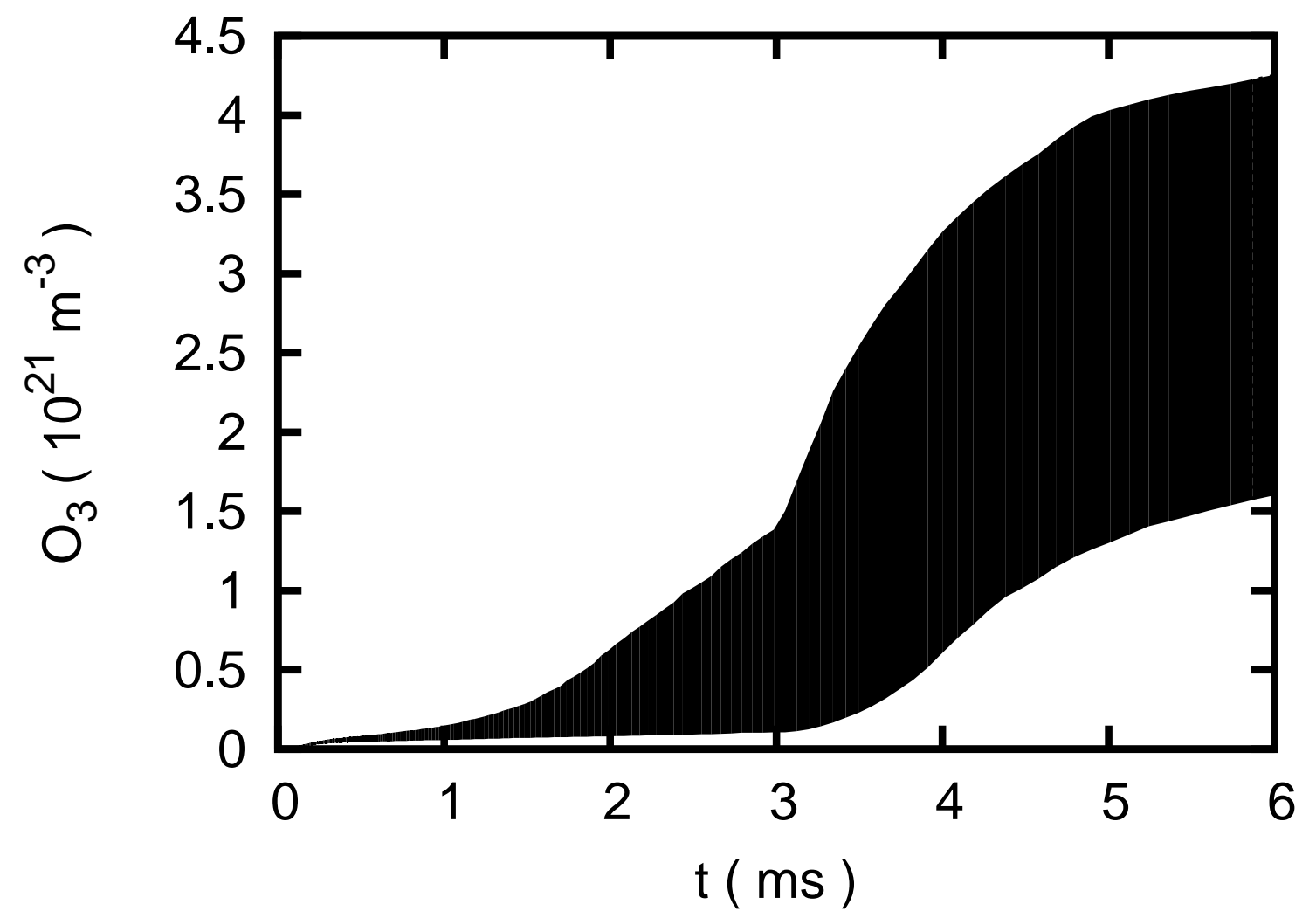

Figure 9. Ozone density showing the upper and lower quartile limits, as in figure 7 . 


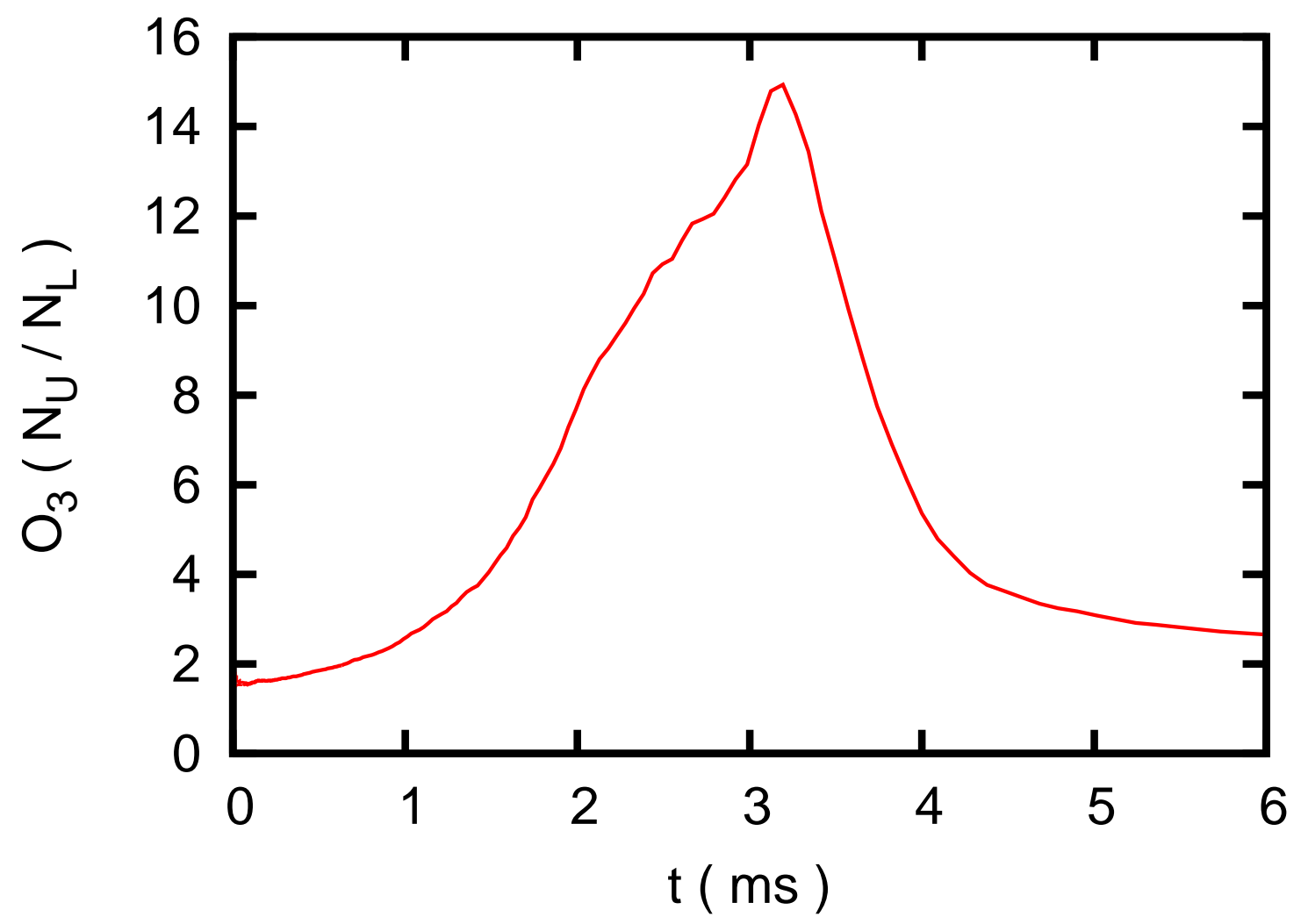

Figure 10. Ozone density showing ratio of the upper and lower quartile limits. This is the same data as in figure 9 . 


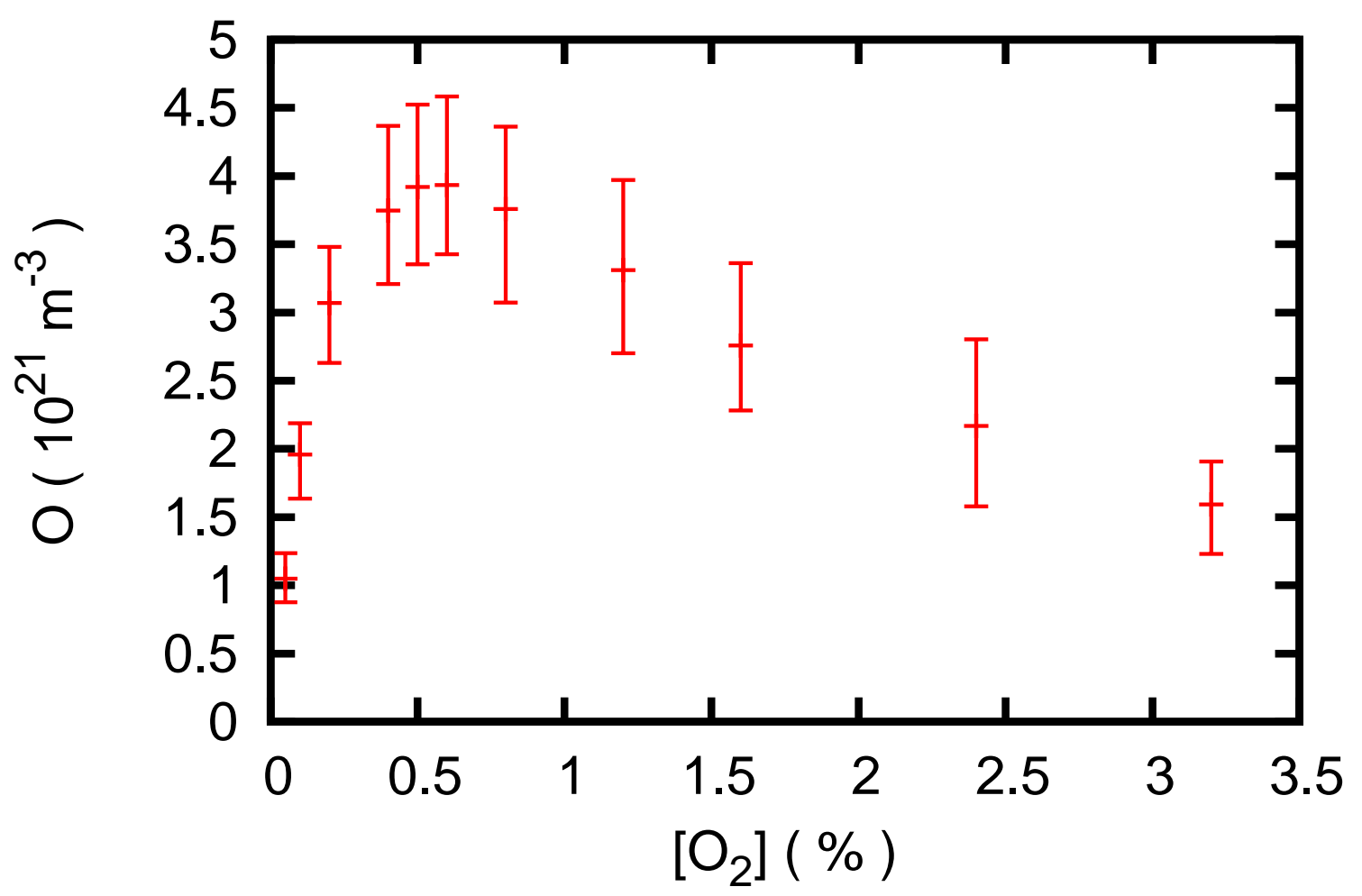

Figure 11. Atomic oxygen density at the end of the discharge pulse, as a function of the fraction of molecular oxygen in the feedstock gas. 


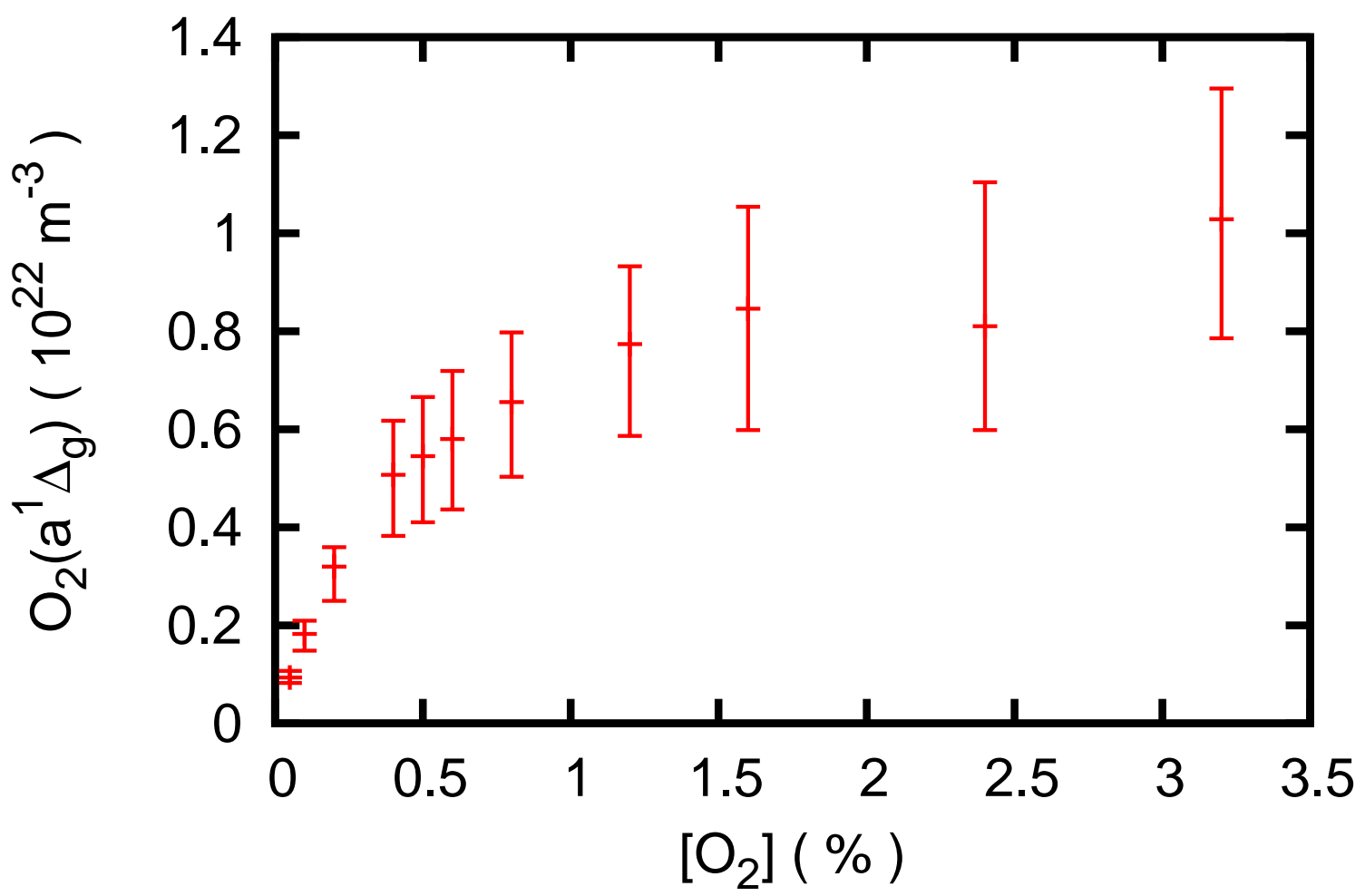

Figure 12. $\mathrm{O}_{2}\left(a^{1} \Delta_{g}\right)$ density at the end of the discharge pulse, as a function of the fraction of molecular oxygen in the feedstock gas. 


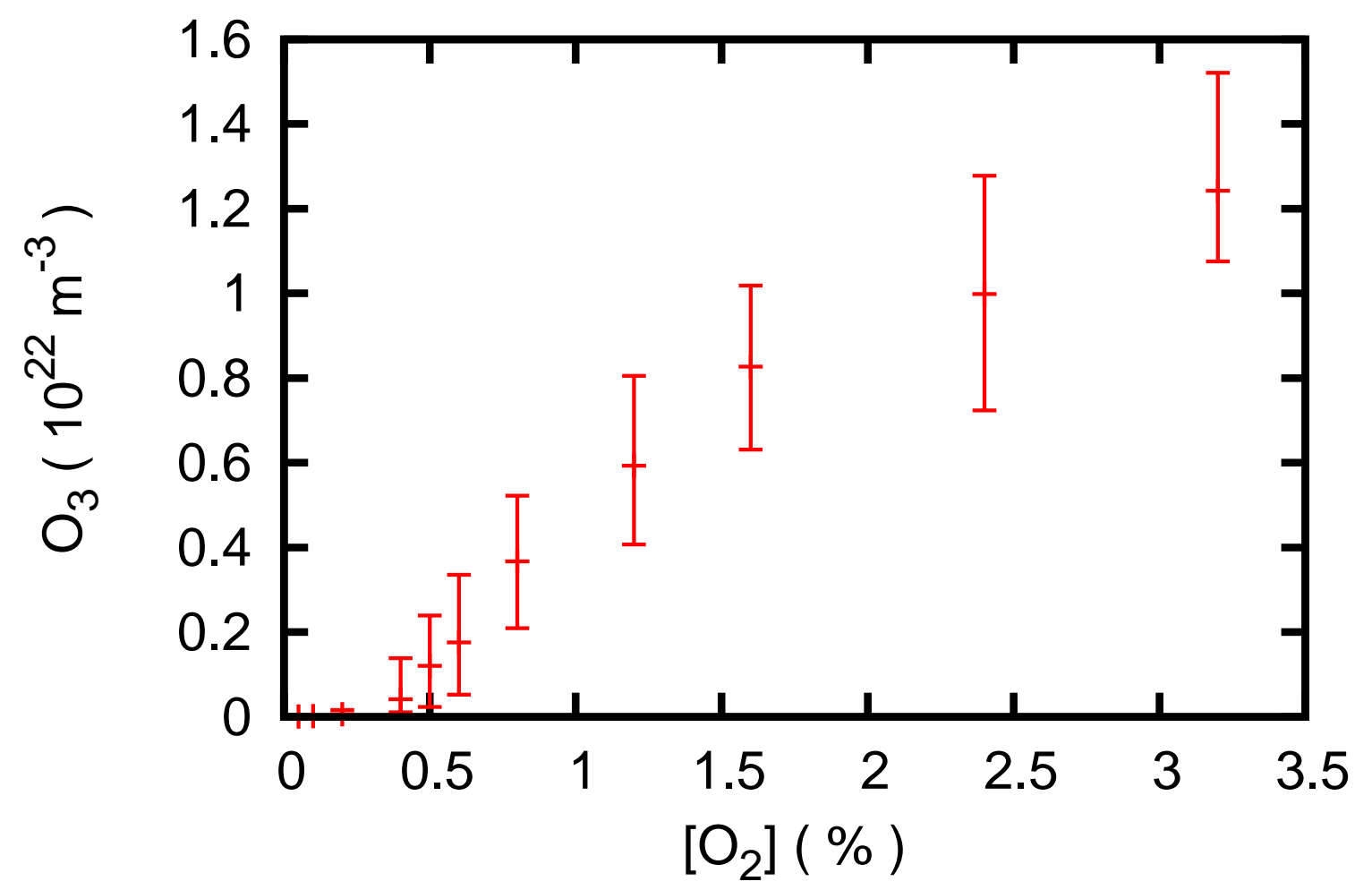

Figure 13. $\mathrm{O}_{3}$ density at the end of the discharge pulse, as a function of the fraction of molecular oxygen in the feedstock gas. 


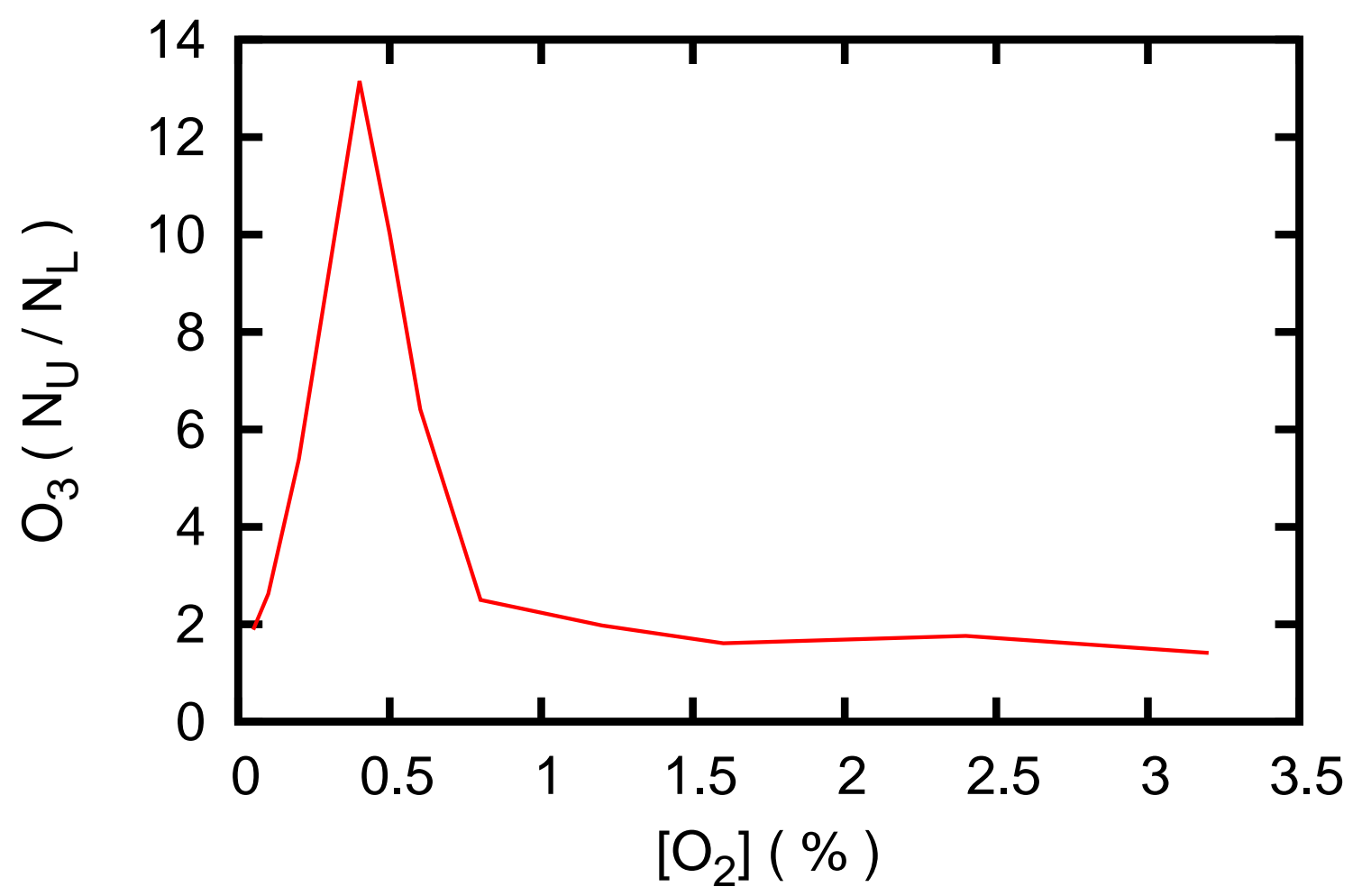

Figure 14. $\mathrm{O}_{3}$ variation at the end of the discharge pulse, as a function of the fraction of molecular oxygen in the feedstock gas. (The same data as in figure 13.) 
Table 2: Reactions and rate constants for the helium-oxygen system. The rubric for this table is as follows: Column 1 contains a reference number for each reaction; column 2 specifies the reaction; column 3 gives the threshold energy of the reaction, expressed in $\mathrm{eV}$; column 4 gives an expression for the rate constant in MKS units, with the electron temperature expressed in $\mathrm{eV}$ and the neutral temperature in $\mathrm{K}$; column 5 is the dimensionless uncertainty discussed in the text; column 6 is the source category (discussed in the text); and column 7 contains references.

\begin{tabular}{|c|c|c|c|c|c|c|}
\hline \multicolumn{7}{|c|}{ Helium-electron chemistry } \\
\hline 1 & $2 e+\mathrm{He}^{+} \rightarrow \mathrm{He}^{*}+e$ & 0.0 & $2.7 \times 10^{-32}\left(\frac{300}{T_{g}}\right)^{4.5}$ & 0.5 & $\mathrm{~A}$ & {$[36]$} \\
\hline 2 & $2 e+\mathrm{He}_{2}^{+} \rightarrow 2 \mathrm{He}+e$ & 0.0 & $4.0 \times 10^{-32}\left(\frac{300}{T_{g}}\right)^{4.0}$ & 0.25 & $\mathrm{~A}$ & {$[36]$} \\
\hline 3 & $e+\mathrm{He}+\mathrm{He}^{+} \rightarrow \mathrm{He}^{*}+\mathrm{He}$ & 0.0 & $2.5 \times 10^{-39} T_{e}^{-2.5}$ & 1.0 & $\mathrm{~B}$ & {$[36]$} \\
\hline 4 & $e+\mathrm{He}+\mathrm{He}_{2}^{+} \rightarrow 3 \mathrm{He}$ & 0.0 & $2.5 \times 10^{-39} T_{e}^{-2.5}$ & 1.0 & $\mathrm{~B}$ & {$[36]$} \\
\hline 5 & $e+\mathrm{He} \rightarrow e+\mathrm{He}$ & 0.0 & $7.77 \times 10^{-14} T_{e}^{0.02} \exp \left(-\frac{0.5}{T_{e}}\right)$ & 0.05 & $\mathrm{~A}$ & {$[2,15]$} \\
\hline 6 & $e+\mathrm{He} \rightarrow 2 e+\mathrm{He}^{+}$ & 24.6 & $4.45 \times 10^{-15} T_{e}^{0.42} \exp \left(-\frac{26.9}{T_{e}}\right)$ & 0.05 & $\mathrm{~A}$ & {$[2,15]$} \\
\hline 7 & $e+\mathrm{He} \rightarrow \mathrm{He}^{*}+e$ & 19.8 & $3.3 \times 10^{-15} T_{e}^{0.33} \exp \left(-\frac{21.6}{T_{e}}\right)^{\prime}$ & 0.05 & $\mathrm{~A}$ & {$[2,15]$} \\
\hline 8 & $e+\mathrm{He}^{*} \rightarrow 2 e+\mathrm{He}^{+}$ & 4.78 & $2.51 \times 10^{-13} T_{e}^{-0.07} \exp \left(-\frac{5.98}{T_{e}}\right)$ & 0.5 & $\mathrm{~A}$ & {$[29]$} \\
\hline 9 & $e+\mathrm{He}^{+} \rightarrow \mathrm{He}^{*}$ & 0.0 & $4.26 \times 10^{-19} T_{e}^{-0.63}$ & 2.0 & $\mathrm{~B}$ & {$[134]$} \\
\hline 10 & $e+\mathrm{He}_{2}^{*} \rightarrow \mathrm{He}_{2}^{+}+2 e$ & 3.9 & $3.78 \times 10^{-13} T_{e}^{-0.19} \exp \left(-\frac{5.6}{T_{e}}\right)$ & 0.5 & $\mathrm{~A}$ & {$[37]$} \\
\hline 11 & $e+\mathrm{He}_{2}^{+} \rightarrow \mathrm{He}+\mathrm{He}^{*}$ & 0.0 & $9.6 \times 10^{-17} T_{e}^{-0.5}$ & 1.0 & $\mathrm{~A}$ & {$[38]$} \\
\hline \multicolumn{7}{|c|}{ Oxygen-electron chemistry } \\
\hline 12 & $e+\mathrm{O} \rightarrow 2 e+\mathrm{O}^{+}$ & 13.6 & $4.93 \times 10^{-15} T_{e}^{0.723} \exp \left(-\frac{13.2}{T_{e}}\right)$ & 0.1 & $\mathrm{~A}$ & {$[72]$} \\
\hline 13 & $e+\mathrm{O} \rightarrow e+\mathrm{O}\left({ }^{1} D\right)$ & 1.96 & $8.45 \times 10^{-15} T_{e}^{-0.306} \exp \left(-\frac{3.13}{T_{e}}\right)$ & 0.3 & $\mathrm{~A}$ & {$[72]$} \\
\hline 14 & $e+\mathrm{O} \rightarrow e+\mathrm{O}\left({ }^{1} S\right)$ & 4.18 & $1.04 \times 10^{-15} T_{e}^{-0.134} \exp \left(-\frac{4.91}{T_{e}}\right)$ & 0.3 & $\mathrm{~A}$ & {$[72]$} \\
\hline
\end{tabular}




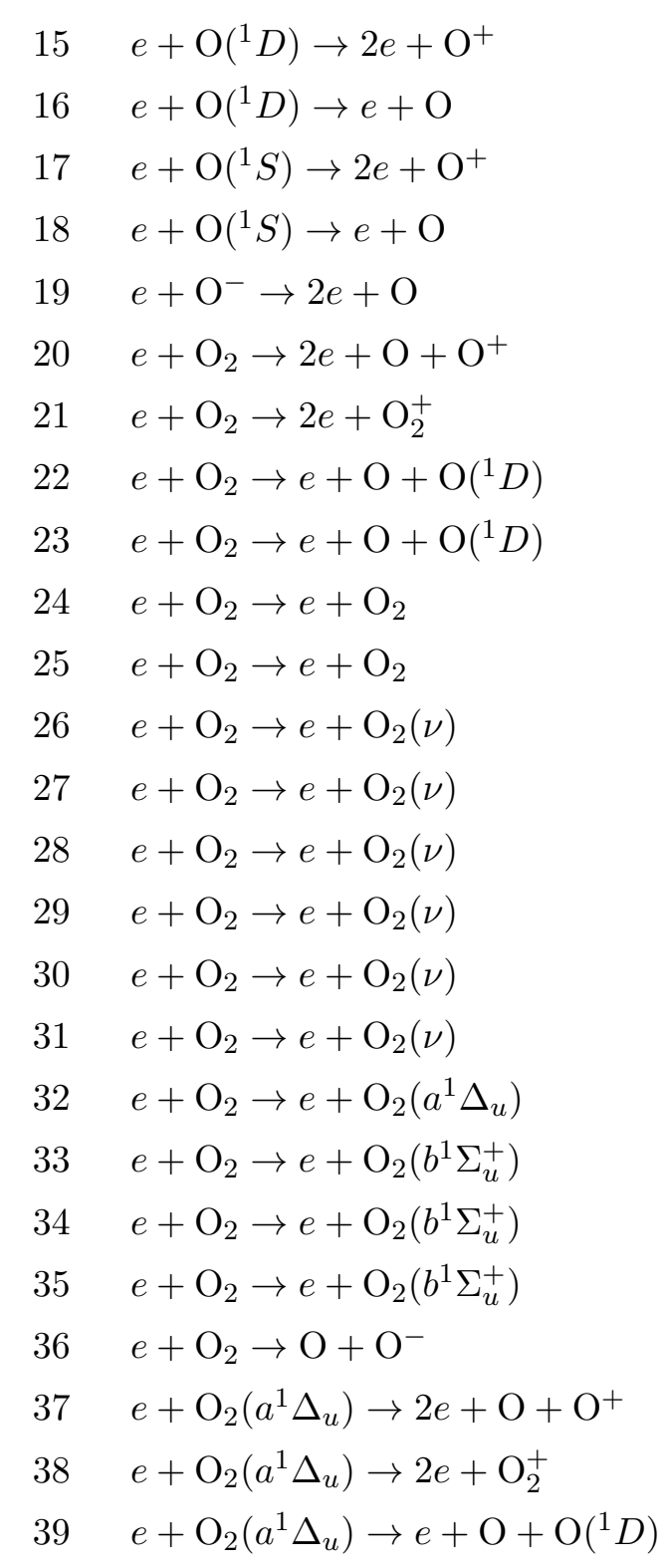

$\begin{array}{lllll}11.65 & 4.93 \times 10^{-15} T_{e}^{0.723} \exp \left(-\frac{11.64}{T_{e}}\right) & 0.2 & \mathrm{C} & \\ -1.96 & 8.45 \times 10^{-15} T_{e}^{0.306} \exp \left(-\frac{1.17}{T_{e}}\right) & 0.3 & \mathrm{~A} & {[72]} \\ 9.43 & 4.93 \times 10^{-15} T_{e}^{0.723} \exp \left(-\frac{9.42}{T_{e}}\right) & 0.2 & \mathrm{C} & \\ -4.18 & 1.04 \times 10^{-15} T_{e}^{-0.134} \exp \left(-\frac{0.73}{T_{e}}\right) & 0.3 & \mathrm{~A} & {[72]} \\ 3.44 & 9.33 \times 10^{-14} T_{e}^{0.178} \exp \left(-\frac{3.13}{T_{e}}\right) & 0.2 & \mathrm{~A} & {[27]} \\ 18.73 & 8.6 \times 10^{-16} T_{e}^{1.11} \exp \left(-\frac{19.84}{T_{e}}\right) & 0.05 & \mathrm{~A} & {[135,86]} \\ 12.06 & 2.32 \times 10^{-15} T_{e}^{0.99} \exp \left(-\frac{12.51}{T_{e}}\right) & 0.05 & \mathrm{~A} & {[135,86]} \\ 8.5 & 3.12 \times 10^{-14} T_{e}^{0.017} \exp \left(-\frac{8.05}{T_{e}}\right) & 0.3 & \mathrm{~A} & {[75,106]} \\ 9.97 & 1.56 \times 10^{-17} T_{e}^{1.5} \exp \left(-\frac{4.68}{T_{e}}\right) & 0.3 & \mathrm{~A} & {[75,106]} \\ 0.0 & 4.15 \times 10^{-14} T_{e}^{0.599} \exp \left(-\frac{0.016}{T_{e}}\right) & 0.1 & \mathrm{~A} & {[75,106]} \\ 0.02 & 3.88 \times 10^{-17} T_{e}^{-1.22} \exp \left(-\frac{0.55}{T_{e}}\right) & 0.3 & \mathrm{~A} & {[75,106]} \\ 0.19 & 4.32 \times 10^{-16} T_{e}^{-1.57} \exp \left(-\frac{0.586}{T_{e}}\right) & 0.1 & \mathrm{~A} & {[75,106]} \\ 0.19 & 2.76 \times 10^{-14} T_{e}^{-1.03} \exp \left(-\frac{6.96}{T_{e}}\right) & 0.1 & \mathrm{~A} & {[75,106]} \\ 0.57 & 5.4 \times 10^{-15} T_{e}^{-0.916} \exp \left(-\frac{6.6}{T_{e}}\right) & 0.1 & \mathrm{~A} & {[75,106]} \\ 0.38 & 1.64 \times 10^{-16} T_{e}^{-1.41} \exp \left(-\frac{0.723}{T_{e}}\right) & 0.1 & \mathrm{~A} & {[75,106]} \\ 0.38 & 1.2 \times 10^{-14} T_{e}^{-1.015} \exp \left(-\frac{6.9}{T_{e}}\right) & 0.1 & \mathrm{~A} & {[75,106]} \\ 0.75 & 5.27 \times 10^{-15} T_{e}^{-1.13} \exp \left(-\frac{7.57}{T_{e}}\right) & 0.1 & \mathrm{~A} & {[75,106]} \\ 0.977 & 2.1 \times 10^{-15} T_{e}^{-0.232} \exp \left(-\frac{2.87}{T_{e}}\right) & 0.3 & \mathrm{~A} & {[75,106]} \\ 1.627 & 3.97 \times 10^{-16} T_{e}^{-0.089} \exp \left(-\frac{2.67}{T_{e}}\right) & 0.3 & \mathrm{~A} & {[75,106]} \\ 4.5 & 1.28 \times 10^{-14} T_{e}^{-1.16} \exp \left(-\frac{7.0}{T_{e}}\right) & 0.3 & \mathrm{~A} & {[75,106]} \\ 6.0 & 1.98 \times 10^{-14} T_{e}^{-0.779} \exp \left(-\frac{7.36}{T_{e}}\right) & 0.3 & \mathrm{~A} & {[75,106]} \\ 0.0 & 1.32 \times 10^{-15} T_{e}^{-1.4} \exp \left(-\frac{6.63}{T_{e}}\right) & 0.3 & \mathrm{~A} & {[75,106]} \\ 18.73 & 8.6 \times 10^{-16} T_{e}^{1.11} \exp \left(-\frac{18.86}{T_{e}}\right) & 0.1 & \mathrm{C} & \\ 12.06 & 2.32 \times 10^{-15} T_{e}^{0.99} \exp \left(-\frac{11.53}{T_{e}}\right) & 0.1 & \mathrm{C} & \\ 8.5 & 3.12 \times 10^{-14} T_{e}^{0.017} \exp \left(-\frac{7.07}{T_{e}}\right) & 0.6 & \mathrm{C} & \\ & & & & \end{array}$




$\begin{array}{ll}40 & e+\mathrm{O}_{2}\left(a^{1} \Delta_{u}\right) \rightarrow e+\mathrm{O}+\mathrm{O}\left({ }^{1} D\right) \\ 41 & e+\mathrm{O}_{2}\left(a^{1} \Delta_{u}\right) \rightarrow e+\mathrm{O}_{2} \\ 42 & e+\mathrm{O}_{2}\left(a^{1} \Delta_{u}\right) \rightarrow e+\mathrm{O}_{2}\left(a^{1} \Delta_{u}\right) \\ 43 & e+\mathrm{O}_{2}\left(a^{1} \Delta_{u}\right) \rightarrow e+\mathrm{O}_{2}\left(a^{1} \Delta_{u}\right) \\ 44 & e+\mathrm{O}_{2}\left(a^{1} \Delta_{u}\right) \rightarrow e+\mathrm{O}_{2}\left(a^{1} \Delta_{u}, \nu\right) \\ 45 & e+\mathrm{O}_{2}\left(a^{1} \Delta_{u}\right) \rightarrow e+\mathrm{O}_{2}\left(a^{1} \Delta_{u}, \nu\right) \\ 46 & e+\mathrm{O}_{2}\left(a^{1} \Delta_{u}\right) \rightarrow e+\mathrm{O}_{2}\left(a^{1} \Delta_{u}, \nu\right) \\ 47 & e+\mathrm{O}_{2}\left(a^{1} \Delta_{u}\right) \rightarrow e+\mathrm{O}_{2}\left(a^{1} \Delta_{u}, \nu\right) \\ 48 & e+\mathrm{O}_{2}\left(a^{1} \Delta_{u}\right) \rightarrow e+\mathrm{O}_{2}\left(a^{1} \Delta_{u}, \nu\right) \\ 49 & e+\mathrm{O}_{2}\left(a^{1} \Delta_{u}\right) \rightarrow e+\mathrm{O}_{2}\left(a^{1} \Delta_{u}, \nu\right) \\ 50 & e+\mathrm{O}_{2}\left(a^{1} \Delta_{u}\right) \rightarrow \mathrm{O}_{2}\left(b^{1} \Sigma_{u}^{+}\right)+e \\ 51 & e+\mathrm{O}_{2}\left(a^{1} \Delta_{u}\right) \rightarrow e+\mathrm{O}_{2}\left(b^{1} \Sigma_{u}^{+}\right) \\ 52 & e+\mathrm{O}_{2}\left(a^{1} \Delta_{u}\right) \rightarrow e+\mathrm{O}_{2}\left(b^{1} \Sigma_{u}^{+}\right) \\ 53 & e+\mathrm{O}_{2}\left(a^{1} \Delta_{u}\right) \rightarrow \mathrm{O}+\mathrm{O}^{-} \\ 54 & e+\mathrm{O}_{2}\left(a^{1} \Delta_{u}\right) \rightarrow \mathrm{O}\left({ }^{1} D\right)+\mathrm{O}^{-} \\ 55 & e+\mathrm{O}_{2}\left(b^{1} \Sigma_{u}^{+}\right) \rightarrow 2 e+\mathrm{O}^{+} \mathrm{O}^{+} \\ 56 & e+\mathrm{O}_{2}\left(b^{1} \Sigma_{u}^{+}\right) \rightarrow 2 e+\mathrm{O}_{2}^{+} \\ 57 & \left.e+\mathrm{O}_{2}\left(b^{1} \Sigma_{u}^{+}\right) \rightarrow e+\mathrm{O}+\mathrm{O}^{1} D\right) \\ 58 & \left.e+\mathrm{O}_{2}\left(b^{1} \Sigma_{u}^{+}\right) \rightarrow e+\mathrm{O}+\mathrm{O}^{1} D\right) \\ 59 & e+\mathrm{O}_{2}\left(b^{1} \Sigma_{u}^{+}\right) \rightarrow e+\mathrm{O}_{2} \\ 60 & e+\mathrm{O}_{2}\left(b^{1} \Sigma_{u}^{+}\right) \rightarrow e+\mathrm{O}_{2}\left(a^{1} \Delta_{u}\right) \\ 61 & e+\mathrm{O}_{2}\left(b^{1} \Sigma_{u}^{+}\right) \rightarrow e+\mathrm{O}_{2}\left(b^{1} \Sigma_{u}^{+}\right) \\ 62 & e+\mathrm{O}_{2}\left(b^{1} \Sigma_{u}^{+}\right) \rightarrow e+\mathrm{O}_{2}\left(b^{1} \Sigma_{u}^{+}\right) \\ 63 & e+\mathrm{O}_{2}\left(b^{1} \Sigma_{u}^{+}\right) \rightarrow e+\mathrm{O}_{2}\left(b^{1} \Sigma_{u}^{+}, \nu\right) \\ 64 & e+\mathrm{O}_{2}\left(b^{1} \Sigma_{u}^{+}\right) \rightarrow e+\mathrm{O}_{2}\left(b^{1} \Sigma_{u}^{+}, \nu\right)\end{array}$

$\begin{array}{lllll}9.97 & 1.56 \times 10^{-17} T_{e}^{1.5} \exp \left(-\frac{3.7}{T_{e}}\right) & 0.6 & \mathrm{C} & \\ 0.977 & 2.1 \times 10^{-15} T_{e}^{-0.232} \exp \left(-\frac{1.89}{T_{e}}\right) & 0.3 & \mathrm{~A} & {[75]} \\ 0.0 & 4.15 \times 10^{-14} T_{e}^{0.599} \exp \left(-\frac{0.016}{T_{e}}\right) & 0.2 & \mathrm{~A} & {[75,106,137]} \\ 0.02 & 3.88 \times 10^{-17} T_{e}^{-1.22} \exp \left(-\frac{0.55}{T_{e}}\right) & 0.6 & \mathrm{C} & \\ 0.19 & 4.32 \times 10^{-16} T_{e}^{-1.57} \exp \left(-\frac{0.586}{T_{e}}\right) & 0.2 & \mathrm{C} & \\ 0.19 & 2.76 \times 10^{-14} T_{e}^{-1.03} \exp \left(-\frac{6.96}{T_{e}}\right) & 0.2 & \mathrm{C} & \\ 0.38 & 1.64 \times 10^{-16} T_{e}^{-1.41} \exp \left(-\frac{0.723}{T_{e}}\right) & 0.2 & \mathrm{C} & \\ 0.38 & 1.2 \times 10^{-15} T_{e}^{-1.015} \exp \left(-\frac{6.9}{T_{e}}\right) & 0.2 & \mathrm{C} & \\ 0.57 & 5.4 \times 10^{-15} T_{e}^{-0.916} \exp \left(-\frac{6.6}{T_{e}}\right) & 0.2 & \mathrm{C} & \\ 0.75 & 5.27 \times 10^{-15} T_{e}^{-1.13} \exp \left(-\frac{7.57}{T_{e}}\right) & 0.2 & \mathrm{C} & \\ 0.657 & 5.25 \times 10^{-15} T_{e}^{-0.44} \exp \left(-\frac{1.49}{T_{e}}\right) & 0.3 & \mathrm{~A} & {[137]} \\ 4.5 & 1.28 \times 10^{-14} T_{e}^{-1.16} \exp \left(-\frac{6.02}{T_{e}}\right) & 0.6 & \mathrm{C} & \\ 6.0 & 1.98 \times 10^{-14} T_{e}^{-0.779} \exp \left(-\frac{6.38}{T_{e}}\right) & 0.6 & \mathrm{C} & \\ 3.0 & 4.14 \times 10^{-15} T_{e}^{-1.34} \exp \left(-\frac{5.15}{T_{e}}\right) & 0.3 & \mathrm{~A} & {[57]} \\ 3.0 & 9.2 \times 10^{-16} T_{e}^{-1.26} \exp \left(-\frac{6.55}{T_{e}}\right) & 0.3 & \mathrm{~A} & {[57]} \\ 18.73 & 8.6 \times 10^{-16} T_{e}^{1.11} \exp \left(-\frac{18.21}{T_{e}}\right) & 0.1 & \mathrm{C} & \\ 12.06 & 2.32 \times 10^{-15} T_{e}^{0.99} \exp \left(-\frac{10.88}{T_{e}}\right) & 0.1 & \mathrm{C} & \\ 8.5 & 3.12 \times 10^{-14} T_{e}^{0.017} \exp \left(-\frac{6.42}{T_{e}}\right) & 0.6 & \mathrm{C} & \\ 9.97 & 1.56 \times 10^{-17} T_{e}^{1.5} \exp \left(-\frac{3.05}{T_{e}}\right) & 0.6 & \mathrm{C} & \\ 1.627 & 3.97 \times 10^{-16} T_{e}^{-0.089} \exp \left(-\frac{1.04}{T_{e}}\right) & 0.3 & \mathrm{~A} & {[75,106]} \\ -0.657 & 5.25 \times 10^{-15} T_{e}^{-0.44} \exp \left(-\frac{0.833}{T_{e}}\right) & 0.3 & \mathrm{~A} & {[137]} \\ 0.0 & 4.15 \times 10^{-14} T_{e}^{0.599} \exp \left(-\frac{0.016}{T_{e}}\right) & 0.2 & \mathrm{~A} & {[75,106,137]} \\ 0.02 & 3.88 \times 10^{-17} T_{e}^{-1.22} \exp \left(-\frac{0.55}{T_{e}}\right) & 0.6 & \mathrm{C} & \\ 0.19 & 4.32 \times 10^{-16} T_{e}^{-1.57} \exp \left(-\frac{0.586}{T_{e}}\right) & 0.2 & \mathrm{C} & \\ 0.19 & 2.76 \times 10^{-14} T_{e}^{-1.03} \exp \left(-\frac{6.96}{T_{e}}\right) & 0.2 & \mathrm{C} & \\ & & & & \\ & & & & \end{array}$




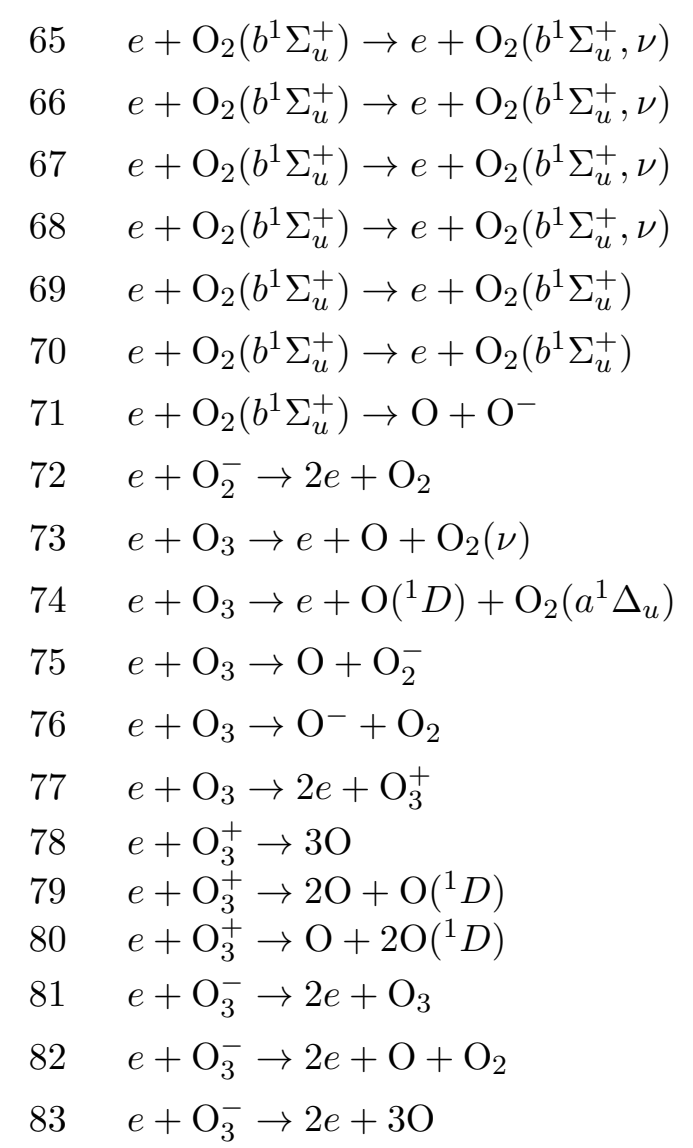

$\begin{array}{lllll}0.38 & 1.64 \times 10^{-16} T_{e}^{-1.41} \exp \left(-\frac{0.723}{T_{e}}\right) & 0.2 & \mathrm{C} & \\ 0.38 & 1.2 \times 10^{-15} T_{e}^{-1.015} \exp \left(-\frac{6.9}{T_{e}}\right) & 0.2 & \mathrm{C} & \\ 0.57 & 5.4 \times 10^{-15} T_{e}^{-0.916} \exp \left(-\frac{6.6}{T_{e}}\right) & 0.2 & \mathrm{C} & \\ 0.75 & 5.27 \times 10^{-15} T_{e}^{-1.13} \exp \left(-\frac{7.57}{T_{e}}\right) & 0.2 & \mathrm{C} & \\ 4.5 & 1.28 \times 10^{-14} T_{e}^{-1.16} \exp \left(-\frac{5.37}{T_{e}}\right) & 0.6 & \mathrm{C} & \\ 6.0 & 1.98 \times 10^{-14} T_{e}^{-0.779} \exp \left(-\frac{5.73}{T_{e}}\right) & 0.6 & \mathrm{C} & \\ 0.0 & 7.11 \times 10^{-16} T_{e}^{-1.04} \exp \left(-\frac{0.23}{T_{e}}\right) & 0.5 & \mathrm{~A} & {[49]} \\ 4.68 & 1.57 \times 10^{-14} T_{e}^{1.01} \exp \left(-\frac{1.77}{T_{e}}\right) & 2.0 & \mathrm{~A} & {[28]} \\ 2.6 & 1.7 \times 10^{-14} T_{e}^{-0.57} \exp \left(-\frac{2.48}{T_{e}}\right) & 0.5 & \mathrm{~A} & {[44]} \\ 5.72 & 3.22 \times 10^{-13} T_{e}^{-1.18} \exp \left(-\frac{9.17}{T_{e}}\right) & 0.5 & \mathrm{~A} & {[44]} \\ 0.0 & 1.02 \times 10^{-15} T_{e}^{-1.3} \exp \left(-\frac{1.03}{T_{e}}\right) & 0.3 & \mathrm{~A} & {[111]} \\ 0.0 & 3.45 \times 10^{-15} T_{e}^{-0.96} \exp \left(-\frac{1.0}{T_{e}}\right) & 0.3 & \mathrm{~A} & {[111]} \\ 12.43 & 5.96 \times 10^{-15} T_{e}^{0.978} \exp \left(-\frac{12.55}{T_{e}}\right) & 0.3 & \mathrm{~A} & {[61,86]} \\ -6.27 & 2.07 \times 10^{-13} T_{e}^{-0.55} & 0.15 & \mathrm{~A} & {[144]} \\ -4.3 & 6.69 \times 10^{-13} T_{e}^{-0.55} & 0.15 & \mathrm{~A} & {[144]} \\ -2.33 & 1.55 \times 10^{-13} T_{e}^{-0.55} & 0.15 & \mathrm{~A} & {[144]} \\ 2.1 & 2.12 \times 10^{-14} T_{e}^{0.51} \exp \left(-\frac{5.87}{T_{e}}\right) & 2.0 & \mathrm{~A} & {[122]} \\ 3.2 & 7.12 \times 10^{-14} T_{e}^{-0.132} \exp \left(-\frac{5.94}{T_{e}}\right) & 2.0 & \mathrm{~A} & {[122]} \\ 8.4 & 1.42 \times 10^{-14} T_{e}^{-0.52} \exp \left(-\frac{9.3}{T_{e}}\right) & 2.0 & \mathrm{~A} & {[122]}\end{array}$

Neutral chemistry of helium

\begin{tabular}{|c|c|c|c|c|c|c|}
\hline 84 & $2 \mathrm{He}+\mathrm{He}^{*} \rightarrow \mathrm{He}_{2}^{*}+\mathrm{He}$ & 0.0 & $1.5 \times 10^{-46}$ & 0.5 & $\mathrm{~A}$ & {$[26]$} \\
\hline 85 & $2 \mathrm{He}+\mathrm{He}^{+} \rightarrow \mathrm{He}_{2}^{+}+\mathrm{He}$ & 0.0 & $1.3 \times 10^{-43}\left(\frac{300}{T_{a}}\right)^{0.6}$ & 0.1 & $\mathrm{~A}$ & {$[19]$} \\
\hline 86 & $2 \mathrm{He}^{*} \rightarrow e+\mathrm{He}+\mathrm{He}^{+}$ & -16.6 & $4.5 \times 10^{-16}$ & 0.5 & A & {$[26,105]$} \\
\hline 87 & $2 \mathrm{He}^{*} \rightarrow e+\mathrm{He}_{2}^{+}$ & -19.0 & $1.05 \times 10^{-15}$ & 0.5 & $\mathrm{~A}$ & {$[26,105]$} \\
\hline 88 & $\mathrm{He}^{*}+\mathrm{He}_{2}^{*} \rightarrow e+\mathrm{He}^{+}+2 \mathrm{He}$ & -15.0 & $5.0 \times 10^{-16}$ & 1.0 & A & {$[26,105]$} \\
\hline 89 & $\mathrm{He}^{*}+\mathrm{He}_{2}^{*} \rightarrow e+\mathrm{He}+\mathrm{He}_{2}^{+}$ & -15.0 & $2.0 \times 10^{-15}$ & 1.0 & A & {$[26,105]$} \\
\hline
\end{tabular}




\begin{tabular}{|c|c|c|c|c|c|c|}
\hline $\begin{array}{l}90 \\
91\end{array}$ & $\begin{array}{l}2 \mathrm{He}_{2}^{*} \rightarrow e+\mathrm{He}^{+}+3 \mathrm{He} \\
2 \mathrm{He}_{2}^{*} \rightarrow e+2 \mathrm{He}+\mathrm{He}_{2}^{+}\end{array}$ & $\begin{array}{l}-15.0 \\
-15.0\end{array}$ & $\begin{array}{l}3.0 \times 10^{-16} \\
1.2 \times 10^{-15}\end{array}$ & $\begin{array}{l}1.0 \\
1.0\end{array}$ & $\begin{array}{l}\mathrm{A} \\
\mathrm{A}\end{array}$ & $\begin{array}{l}{[26,105]} \\
{[26,105]}\end{array}$ \\
\hline \multicolumn{7}{|c|}{ Neutral chemistry of oxygen } \\
\hline 92 & $3 \mathrm{O} \rightarrow \mathrm{O}+\mathrm{O}_{2}$ & 0.0 & $3.8 \times 10^{-44}\left(\frac{300}{T_{q}}\right) \exp \left(-\frac{170}{T_{q}}\right)$ & 1.0 & $\mathrm{~A}$ & {$[60]$} \\
\hline 93 & $3 \mathrm{O} \rightarrow \mathrm{O}+\mathrm{O}_{2}\left(b^{1} \Sigma_{u}^{+}\right)$ & 0.0 & $1.4 \times 10^{-42} \exp \left(-\frac{650}{T_{q}}\right)$ & 2.0 & $\mathrm{~A}$ & {$[12$, p. $24-42]$} \\
\hline 94 & $2 \mathrm{O}+\mathrm{O}_{2} \rightarrow \mathrm{O}+\mathrm{O}_{3}$ & 0.0 & $4.2 \times 10^{-47} \exp \left(\frac{1056}{T_{g}}\right)$ & 1.5 & $\mathrm{~A}$ & {$[113,60]$} \\
\hline 95 & $2 \mathrm{O}+\mathrm{O}_{2} \rightarrow \mathrm{O}+\mathrm{O}_{3}(\nu)$ & 0.0 & $9.8 \times 10^{-47} \exp \left(\frac{1056}{T_{g}}\right)$ & 1.5 & $\mathrm{~A}$ & {$[113,60]$} \\
\hline 96 & $2 \mathrm{O}+\mathrm{O}_{2} \rightarrow \mathrm{O}_{2}\left(a^{1} \Delta_{u}\right)+\mathrm{O}_{2}$ & 0.0 & $6.5 \times 10^{-45}\left(\frac{300}{T_{g}}\right) \exp \left(-\frac{170}{T_{g}}\right)$ & 1.0 & $\mathrm{~A}$ & {$[129,60]$} \\
\hline 97 & $2 \mathrm{O}+\mathrm{O}_{2} \rightarrow \mathrm{O}_{2}\left(b^{1} \Sigma_{u}^{+}\right)+\mathrm{O}_{2}$ & 0.0 & $6.5 \times 10^{-45}\left(\frac{300}{T_{q}}\right) \exp \left(-\frac{170}{T_{q}}\right)$ & 1.0 & $\mathrm{~A}$ & {$[129,60]$} \\
\hline 98 & $\mathrm{O}+\mathrm{O}\left({ }^{1} D\right) \rightarrow 2 \mathrm{O}$ & 0.0 & $2.0 \times 10^{-18}$ & 0.6 & $\mathrm{~A}$ & {$[130]$} \\
\hline 99 & $\mathrm{O}+\mathrm{O}\left({ }^{1} S\right) \rightarrow 2 \mathrm{O}$ & 0.0 & $2.5 \times 10^{-17} \exp \left(-\frac{300}{T_{g}}\right)$ & 1.0 & $\mathrm{~A}$ & {$[120]$} \\
\hline 100 & $\mathrm{O}+\mathrm{O}\left({ }^{1} S\right) \rightarrow \mathrm{O}+\mathrm{O}\left({ }^{1} D\right)$ & 0.0 & $2.5 \times 10^{-17} \exp \left(-\frac{300}{T_{g}}\right)$ & 1.0 & $\mathrm{~A}$ & {$[120]$} \\
\hline 101 & $\mathrm{O}+2 \mathrm{O}_{2} \rightarrow \mathrm{O}_{2}+\mathrm{O}_{3}$ & 0.0 & $1.8 \times 10^{-46}\left(\frac{300}{T_{g}}\right)^{2.6}$ & 0.1 & $\mathrm{~A}$ & {$[119$, p. $2-3][7$, p. 1473$][113]$} \\
\hline 102 & $\mathrm{O}+2 \mathrm{O}_{2} \rightarrow \mathrm{O}_{2}+\mathrm{O}_{3}(\nu)$ & 0.0 & $4.2 \times 10^{-46}\left(\frac{300}{T_{g}}\right)^{2.6}$ & 0.1 & $\mathrm{~A}$ & {$[119$, p. $2-3][7$, p. 1473$]$} \\
\hline 103 & $\mathrm{O}+\mathrm{O}_{2}+\mathrm{O}_{2}\left(a^{1} \Delta_{u}\right) \rightarrow \mathrm{O}+2 \mathrm{O}_{2}$ & 0.0 & $1.1 \times 10^{-44}$ & 5.0 & $\mathrm{~A}$ & {$[9,20]$} \\
\hline 104 & $\mathrm{O}+\mathrm{O}_{2}+\mathrm{O}_{3} \rightarrow 2 \mathrm{O}_{3}$ & 0.0 & $1.4 \times 10^{-47} \exp \left(-\frac{1050}{T_{g}}\right)$ & 0.3 & $\mathrm{~A}$ & {$[60]$} \\
\hline 105 & $\mathrm{O}+\mathrm{O}_{2}+\mathrm{O}_{3} \rightarrow \mathrm{O}_{3}+\mathrm{O}_{3}(\nu)$ & 0.0 & $3.27 \times 10^{-47} \exp \left(-\frac{1050}{T_{g}}\right)$ & 0.3 & $\mathrm{~A}$ & {$[60]$} \\
\hline 106 & $\mathrm{O}+\mathrm{O}_{2}\left(a^{1} \Delta_{u}\right) \rightarrow \mathrm{O}+\mathrm{O}_{2}$ & -2.14 & $1.0 \times 10^{-22}$ & 1.0 & $\mathrm{~A}$ & {$[119]$} \\
\hline 107 & $\mathrm{O}+\mathrm{O}_{2}\left(b^{1} \Sigma_{u}^{+}\right) \rightarrow \mathrm{O}+\mathrm{O}_{2}\left(a^{1} \Delta_{u}\right)$ & -0.65 & $8.0 \times 10^{-20}$ & 1.0 & $\mathrm{~A}$ & {$[119$, p. $1-44][7$, p. 1486$]$} \\
\hline 108 & $\mathrm{O}+\mathrm{O}_{3} \rightarrow 2 \mathrm{O}+\mathrm{O}_{2}$ & 0.0 & $1.2 \times 10^{-15} \exp \left(-\frac{11400}{T_{g}}\right)$ & 0.3 & $\mathrm{~A}$ & {$[60]$} \\
\hline 109 & $\mathrm{O}+\mathrm{O}_{3} \rightarrow 2 \mathrm{O}_{2}(\nu)$ & 0.0 & $8.0 \times 10^{-18} \exp \left(-\frac{2060}{T_{g}}\right)$ & 0.2 & $\mathrm{~A}$ & {$[119$, p. $1-35][7$, p. 1475$][10][141]$} \\
\hline 110 & $\mathrm{O}+\mathrm{O}_{3}(\nu) \rightarrow 2 \mathrm{O}_{2}$ & 0.0 & $4.5 \times 10^{-18}$ & 0.5 & $\mathrm{~A}$ & {$[133]$} \\
\hline 111 & $\mathrm{O}+\mathrm{O}_{3}(\nu) \rightarrow \mathrm{O}_{3}+\mathrm{O}$ & 0.0 & $1.05 \times 10^{-17}$ & 0.5 & $\mathrm{~A}$ & {$[133]$} \\
\hline 112 & $\mathrm{O}\left({ }^{1} D\right)+\mathrm{O}_{2} \rightarrow \mathrm{O}+\mathrm{O}_{2}\left(b^{1} \Sigma_{u}^{+}\right)$ & 0.0 & $2.64 \times 10^{-17} \exp \left(\frac{55}{T_{g}}\right)$ & 0.1 & $\mathrm{~A}$ & {$[119$, p. $1-35]$} \\
\hline 113 & $\mathrm{O}\left({ }^{1} D\right)+\mathrm{O}_{2} \rightarrow \mathrm{O}+\mathrm{O}_{2}\left(a^{1} \Delta_{u}\right)$ & 0.0 & $6.6 \times 10^{-18} \exp \left(\frac{55}{T_{g}}\right)$ & 0.1 & $\mathrm{~A}$ & {$[119$, p. $1-35]$} \\
\hline 114 & $\mathrm{O}\left({ }^{1} D\right)+\mathrm{O}_{3} \rightarrow 2 \mathrm{O}+\mathrm{O}_{2}$ & 0.0 & $1.2 \times 10^{-16}$ & 0.2 & $\mathrm{~A}$ & {$[119,7,133]$} \\
\hline
\end{tabular}




\begin{tabular}{|c|c|c|c|c|c|c|}
\hline 115 & $\mathrm{O}\left({ }^{1} D\right)+\mathrm{O}_{3} \rightarrow 2 \mathrm{O}_{2}$ & 0.0 & $1.2 \times 10^{-16}$ & 0.2 & $\mathrm{~A}$ & {$[119,7,133]$} \\
\hline 116 & $\mathrm{O}\left({ }^{1} S\right)+\mathrm{O}_{2} \rightarrow \mathrm{O}+\mathrm{O}_{2}$ & 0.0 & $3.0 \times 10^{-18} \exp \left(-\frac{850}{T_{q}}\right)$ & 1.0 & $\mathrm{~A}$ & {$[12$, p. $24-52][126]$} \\
\hline 117 & $\mathrm{O}\left({ }^{1} S\right)+\mathrm{O}_{2} \rightarrow \mathrm{O}\left({ }^{1} D\right)+\mathrm{O}_{2}$ & 0.0 & $1.3 \times 10^{-18} \exp \left(-\frac{850}{T_{a}}\right)$ & 1.0 & $\mathrm{~A}$ & {$[12$, p. $24-52][126]$} \\
\hline 118 & $\mathrm{O}\left({ }^{1} S\right)+\mathrm{O}_{2}\left(a^{1} \Delta_{u}\right) \rightarrow 3 \mathrm{O}$ & 0.0 & $3.2 \times 10^{-17}$ & 0.3 & A & {$[127,128,67]$} \\
\hline 119 & $\mathrm{O}\left({ }^{1} S\right)+\mathrm{O}_{2}\left(a^{1} \Delta_{u}\right) \rightarrow \mathrm{O}+\mathrm{O}_{2}\left(b^{1} \Sigma_{u}^{+}\right)$ & 0.0 & $1.3 \times 10^{-16}$ & 0.3 & $\mathrm{~A}$ & {$[127,128,67]$} \\
\hline 120 & $\mathrm{O}\left({ }^{1} S\right)+\mathrm{O}_{2}\left(a^{1} \Delta_{u}\right) \rightarrow \mathrm{O}\left({ }^{1} D\right)+\mathrm{O}_{2}{ }^{\omega}$ & 0.0 & $3.6 \times 10^{-17}$ & 0.3 & $\mathrm{~A}$ & {$[127,128]$} \\
\hline 121 & $\mathrm{O}\left({ }^{1} S\right)+\mathrm{O}_{3} \rightarrow \mathrm{O}+\mathrm{O}\left({ }^{1} D\right)+\mathrm{O}_{2}$ & 0.0 & $1.93 \times 10^{-16}$ & 0.6 & $\mathrm{~A}$ & {$[133]$} \\
\hline 122 & $\mathrm{O}\left({ }^{1} S\right)+\mathrm{O}_{3} \rightarrow 2 \mathrm{O}_{2}$ & 0.0 & $1.93 \times 10^{-16}$ & 0.6 & $\mathrm{~A}$ & {$[133]$} \\
\hline 123 & $\mathrm{O}\left({ }^{1} S\right)+\mathrm{O}_{3} \rightarrow 2 \mathrm{O}+\mathrm{O}_{2}$ & 0.0 & $1.93 \times 10^{-16}$ & 0.6 & $\mathrm{~A}$ & {$[133]$} \\
\hline 124 & $2 \mathrm{O}_{2} \rightarrow 2 \mathrm{O}+\mathrm{O}_{2}$ & 0.0 & $6.6 \times 10^{-15}\left(\frac{300}{T_{0}}\right)^{1.5} \exp \left(-\frac{59000}{T}\right)$ & 0.5 & A & {$[12$, p. $24-44]$} \\
\hline 125 & $\mathrm{O}_{2}+\mathrm{O}_{2}(\nu) \rightarrow 2 \mathrm{O}_{2}$ & -0.19 & $2.0 \times 10^{-20}$ & 0.5 & $\mathrm{~A}$ & {$[102]$} \\
\hline 126 & $\mathrm{O}_{2}+\mathrm{O}_{2}\left(a^{1} \Delta_{u}\right) \rightarrow 2 \mathrm{O}_{2}$ & 0.0 & $3.6 \times 10^{-24} \exp \left(-\frac{220}{T_{q}}\right)$ & 0.2 & $\mathrm{~A}$ & {$[119$, p. $1-43]$} \\
\hline 127 & $\mathrm{O}_{2}+\mathrm{O}_{2}\left(a^{1} \Delta_{u}, \nu\right) \rightarrow \mathrm{O}_{2}(\nu)+\mathrm{O}_{2}\left(a^{1} \Delta_{u}\right)$ & -0.19 & $5.0 \times 10^{-17}$ & 0.5 & $\mathrm{~A}$ & {$[4]$} \\
\hline 128 & $\mathrm{O}_{2}+\mathrm{O}_{2}\left(b^{1} \Sigma_{u}^{+}\right) \rightarrow \mathrm{O}_{2}+\mathrm{O}_{2}\left(a^{1} \Delta_{u}\right)$ & 0.0 & $3.8 \times 10^{-23}$ & 0.5 & $\mathrm{~A}$ & {$[119$, p. $1-44][63][68]$} \\
\hline 129 & $\mathrm{O}_{2}+\mathrm{O}_{2}\left(b^{1} \Sigma_{u}^{+}, \nu\right) \rightarrow \mathrm{O}_{2}(\nu)+\mathrm{O}_{2}\left(b^{1} \Sigma_{u}^{+}\right)$ & -0.19 & $1.5 \times 10^{-17}$ & 0.1 & $\mathrm{~A}$ & {$[62]$} \\
\hline 130 & $\mathrm{O}_{2}+\mathrm{O}_{3} \rightarrow \mathrm{O}+2 \mathrm{O}_{2}$ & 0.0 & $7.26 \times 10^{-16} \exp \left(-\frac{11435}{T_{g}}\right)$ & 0.3 & $\mathrm{~A}$ & {$[133]$} \\
\hline 131 & $\mathrm{O}_{2}+\mathrm{O}_{3}(\nu) \rightarrow \mathrm{O}_{2}+\mathrm{O}_{3}$ & 0.0 & $4.0 \times 10^{-20}$ & 0.5 & $\mathrm{~A}$ & {$[133]$} \\
\hline 132 & $2 \mathrm{O}_{2}\left(a^{1} \Delta_{u}\right) \rightarrow \mathrm{O}_{2}+\mathrm{O}_{2}\left(b^{1} \Sigma_{u}^{+}\right)$ & 0.0 & $2.7 \times 10^{-23}$ & 0.2 & A & {$[79]$} \\
\hline 133 & $\mathrm{O}_{2}\left(a^{1} \Delta_{u}\right)+\mathrm{O}_{2}\left(b^{1} \Sigma_{u}^{+}\right) \rightarrow \mathrm{O}_{2}+\mathrm{O}_{2}\left(b^{1} \Sigma_{u}^{+}\right)$ & 0.0 & $2.7 \times 10^{-23}$ & 2.0 & $\mathrm{C}$ & \\
\hline 134 & $2 \mathrm{O}_{2}\left(b^{1} \Sigma_{u}^{+}\right) \rightarrow \mathrm{O}_{2}+\mathrm{O}_{2}\left(b^{1} \Sigma_{u}^{+}\right)$ & 0.0 & $2.7 \times 10^{-23}$ & 2.0 & $\mathrm{C}$ & \\
\hline 135 & $\mathrm{O}_{2}\left(a^{1} \Delta_{u}\right)+\mathrm{O}_{3} \rightarrow 2 \mathrm{O}_{2}+\mathrm{O}$ & 0.0 & $5.2 \times 10^{-17} \exp \left(-\frac{2840}{T_{q}}\right)$ & 0.2 & $\mathrm{~A}$ & {$[119$, p. $1-43][133]$} \\
\hline 136 & $\mathrm{O}_{2}\left(a^{1} \Delta_{u}\right)+\mathrm{O}_{3}(\nu) \rightarrow \mathrm{O}_{2}+\mathrm{O}_{3}$ & 0.0 & $5.0 \times 10^{-17}$ & 5.0 & $\mathrm{~A}$ & {$[133]$} \\
\hline 137 & $\mathrm{O}_{2}\left(b^{1} \Sigma_{u}^{+}\right)+\mathrm{O}_{3} \rightarrow \mathrm{O}+2 \mathrm{O}_{2}$ & 0.0 & $2.4 \times 10^{-17} \exp \left(-\frac{135}{T_{g}}\right)$ & 0.2 & $\mathrm{~A}$ & {$[119,7]$} \\
\hline 138 & $\mathrm{O}_{2}\left(b^{1} \Sigma_{u}^{+}\right)+\mathrm{O}_{3} \rightarrow \mathrm{O}_{2}+\mathrm{O}_{3}$ & 0.0 & $5.5 \times 10^{-18} \exp \left(-\frac{135}{T_{g}}\right)$ & 0.2 & $\mathrm{~A}$ & {$[119,7]$} \\
\hline 139 & $\mathrm{O}_{2}\left(b^{1} \Sigma_{u}^{+}\right)+\mathrm{O}_{3} \rightarrow \mathrm{O}_{2}\left(a^{1} \Delta_{u}\right)+\mathrm{O}_{3}$ & 0.0 & $5.5 \times 10^{-18} \exp \left(-\frac{135}{T_{g}}\right)$ & 0.2 & $\mathrm{~A}$ & {$[119,7]$} \\
\hline 140 & $2 \mathrm{O}_{3} \rightarrow \mathrm{O}+\mathrm{O}_{2}+\mathrm{O}_{3}$ & 0.0 & $1.65 \times 10^{-15} \exp \left(-\frac{11435}{T_{g}}\right)$ & 0.3 & $\mathrm{~A}$ & {$[133]$} \\
\hline 141 & $\mathrm{O}_{3}+\mathrm{O}_{3}(\nu) \rightarrow 2 \mathrm{O}_{3}$ & 0.0 & $1.0 \times 10^{-19}$ & 0.5 & $\mathrm{~A}$ & {$[133]$} \\
\hline
\end{tabular}




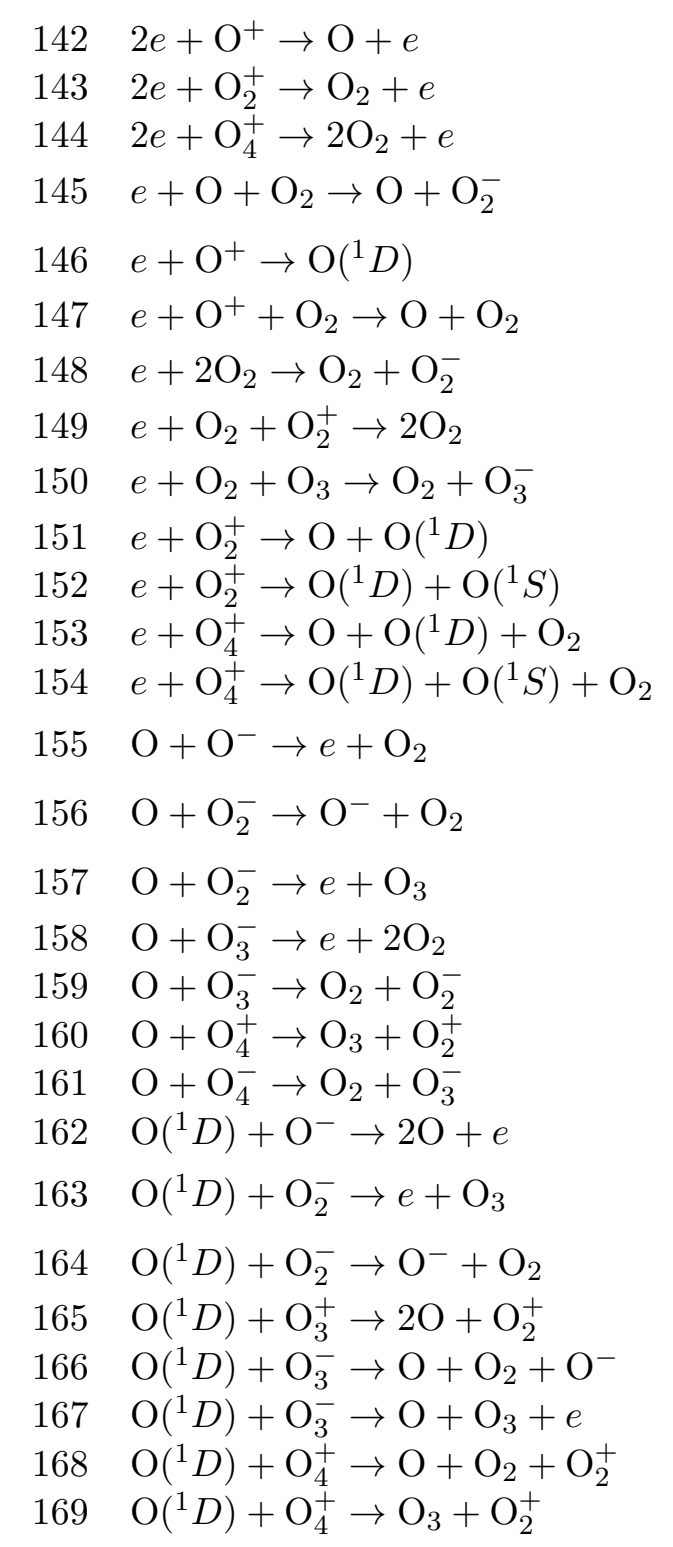

$\begin{array}{ll}0.0 & 2.0 \times 10^{-39} T_{e}^{-4.5} \\ 0.0 & 2.0 \times 10^{-39} T_{e}^{-4.5} \\ 0.0 & 2.0 \times 10^{-39} T_{e}^{-4.5} \\ 0.0 & 1.4 \times 10^{-41}\left(\frac{300}{T_{g}}\right) \exp \left(-\frac{600}{T_{g}}\right) \\ 0.0 & 3.5 \times 10^{-18}\left(\frac{300}{T_{g}}\right)^{0.7} \\ 0.0 & 3.3 \times 10^{-44} T_{e}^{-2.5} \\ 0.0 & 1.4 \times 10^{-41}\left(\frac{300}{T_{g}}\right) \exp \left(-\frac{600}{T_{g}}\right) \\ 0.0 & 3.3 \times 10^{-44} T_{e}^{-2.5} \\ 0.0 & 1.4 \times 10^{-41}\left(\frac{300}{T_{g}}\right) \exp \left(-\frac{600}{T_{g}}\right) \\ 0.0 & 9.1 \times 10^{-15} T_{e}^{-0.7} \\ 0.0 & 6.0 \times 10^{-15} T_{e}^{-0.7} \\ 0.0 & 2.02 \times 10^{-14} T_{e}^{-0.48} \\ 0.0 & 1.35 \times 10^{-14} T_{e}^{-0.48} \\ 0.0 & 2.3 \times 10^{-16}\left(\frac{300}{T_{g}}\right)^{1.3} \\ 0.0 & 8.5 \times 10^{-17}\left(\frac{300}{T_{g}}\right)^{1.8} \\ 0.0 & 8.5 \times 10^{-17}\left(\frac{300}{T_{g}}\right)^{1.8} \\ 0.0 & 1.0 \times 10^{-17} \\ 0.0 & 2.5 \times 10^{-16} \\ 0.0 & 3.0 \times 10^{-16} \\ 0.0 & 4.0 \times 10^{-16} \\ 0.0 & 7.4 \times 10^{-16} \\ 0.0 & 8.5 \times 10^{-17}\left(\frac{300}{T_{g}}\right)^{1.8} \\ 0.0 & 8.5 \times 10^{-17}\left(\frac{300}{T_{g}}\right)^{1.8} \\ 0.0 & 3.0 \times 10^{-16} \\ 0.0 & 3.0 \times 10^{-16} \\ 0.0 & 3.0 \times 10^{-16} \\ 0.0 & 3.0 \times 10^{-16} \\ 0.0 & 3.0 \times 10^{-16} \\ & \end{array}$




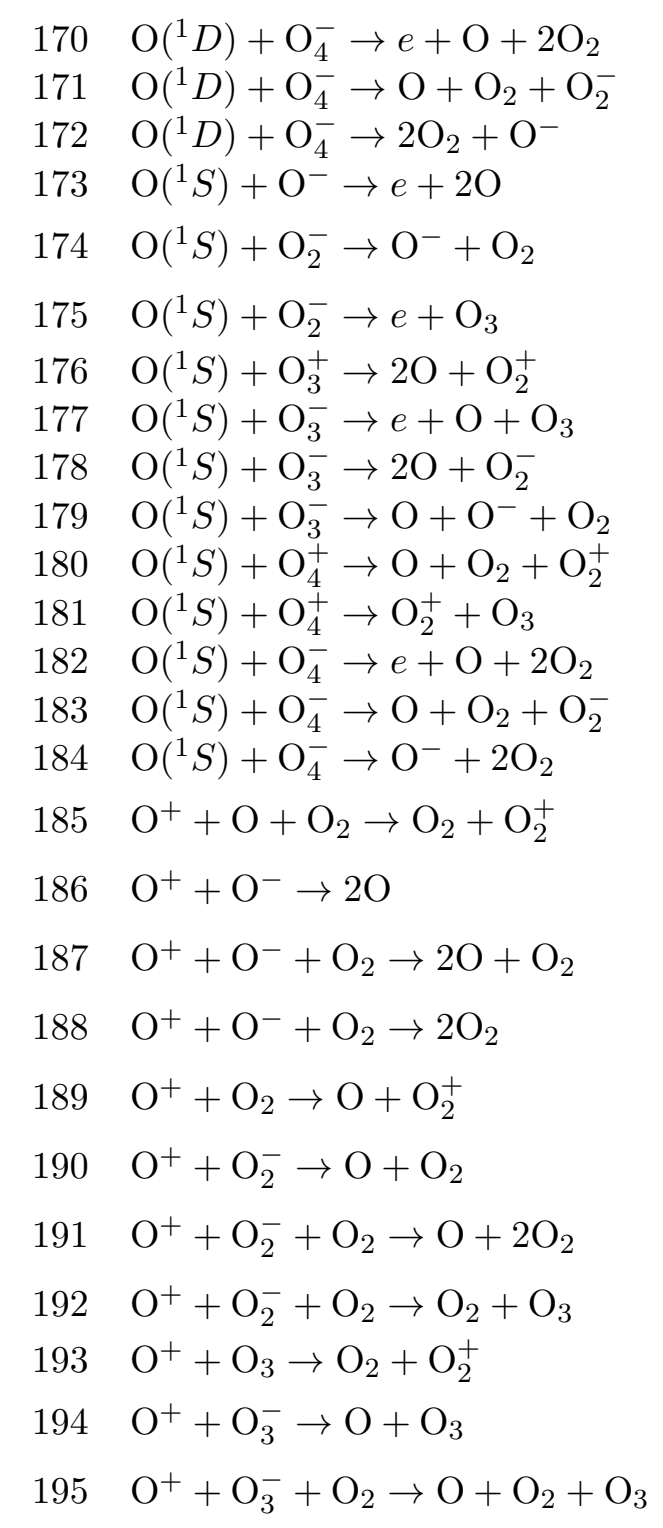

$\begin{array}{ll}0.0 & 2.0 \times 10^{-16} \\ 0.0 & 2.0 \times 10^{-16} \\ 0.0 & 2.0 \times 10^{-16} \\ 0.0 & 7.4 \times 10^{-16} \\ 0.0 & 8.5 \times 10^{-17}\left(\frac{300}{T_{g}}\right)^{1.8} \\ 0.0 & 8.5 \times 10^{-17}\left(\frac{300}{T_{g}}\right)^{1.8} \\ 0.0 & 2.0 \times 10^{-16} \\ 0.0 & 2.0 \times 10^{-16} \\ 0.0 & 2.0 \times 10^{-16} \\ 0.0 & 2.0 \times 10^{-16} \\ 0.0 & 3.0 \times 10^{-16} \\ 0.0 & 3.0 \times 10^{-16} \\ 0.0 & 2.0 \times 10^{-16} \\ 0.0 & 2.0 \times 10^{-16} \\ 0.0 & 2.0 \times 10^{-16} \\ 0.0 & 4.0 \times 10^{-42}\left(\frac{300}{T_{g}}\right)^{2.93} \\ 0.0 & 3.1 \times 10^{-14}\left(\frac{300}{T_{g}}\right)^{1.1} \\ 0.0 & 1.0 \times 10^{-37}\left(\frac{300}{T_{g}}\right)^{2.5} \\ 0.0 & 1.0 \times 10^{-37}\left(\frac{300}{T_{g}}\right)^{2.5} \\ 0.0 & 2.1 \times 10^{-17}\left(\frac{300}{T_{g}}\right)^{0.4} \\ 0.0 & 3.22 \times 10^{-14}\left(\frac{300}{T_{g}}\right)^{1.1} \\ 0.0 & 1.0 \times 10^{-37}\left(\frac{300}{T_{g}}\right)^{2.5} \\ 0.0 & 1.0 \times 10^{-37}\left(\frac{300}{T_{g}}\right)^{2.5} \\ 0.0 & 1.2 \times 10^{-15} \\ 0.0 & 7.33 \times 10^{-14}\left(\frac{300}{T_{g}}\right)^{0.9} \\ 0.0 & 2.0 \times 10^{-37}\left(\frac{300}{T_{g}}\right)^{2.5} \\ & \end{array}$

\begin{tabular}{lll}
1.7 & B & {$[73,90,31]$} \\
1.7 & B & {$[73,90,31]$} \\
1.7 & B & {$[73,90,31]$} \\
1.0 & B & {$[31,96,73]$} \\
2.0 & C & \\
2.0 & C & \\
1.7 & B & {$[73,90,31]$} \\
1.7 & B & {$[73,90,31]$} \\
1.7 & B & {$[73,90,31]$} \\
1.7 & B & {$[73,90,31]$} \\
1.4 & B & {$[73,96,31]$} \\
1.4 & B & {$[73,96,31]$} \\
1.7 & B & {$[73,90,31]$} \\
1.7 & B & {$[31,90,73]$} \\
1.7 & B & {$[31,90,73]$} \\
0.5 & C & \\
0.4 & B & {$[91$, eq. 3$]$} \\
4.2 & B & {$[16]$} \\
4.2 & B & {$[16]$} \\
0.1 & A & {$[3][12$, p. $24-18]$} \\
0.4 & B & {$[91$, eq. 3] } \\
4.2 & B & {$[16]$} \\
4.2 & B & {$[16]$} \\
1.0 & B & {$[31,90,73]$} \\
0.4 & B & {$[91$, eq. 4] } \\
3.0 & B & {$[16]$} \\
\hline & &
\end{tabular}




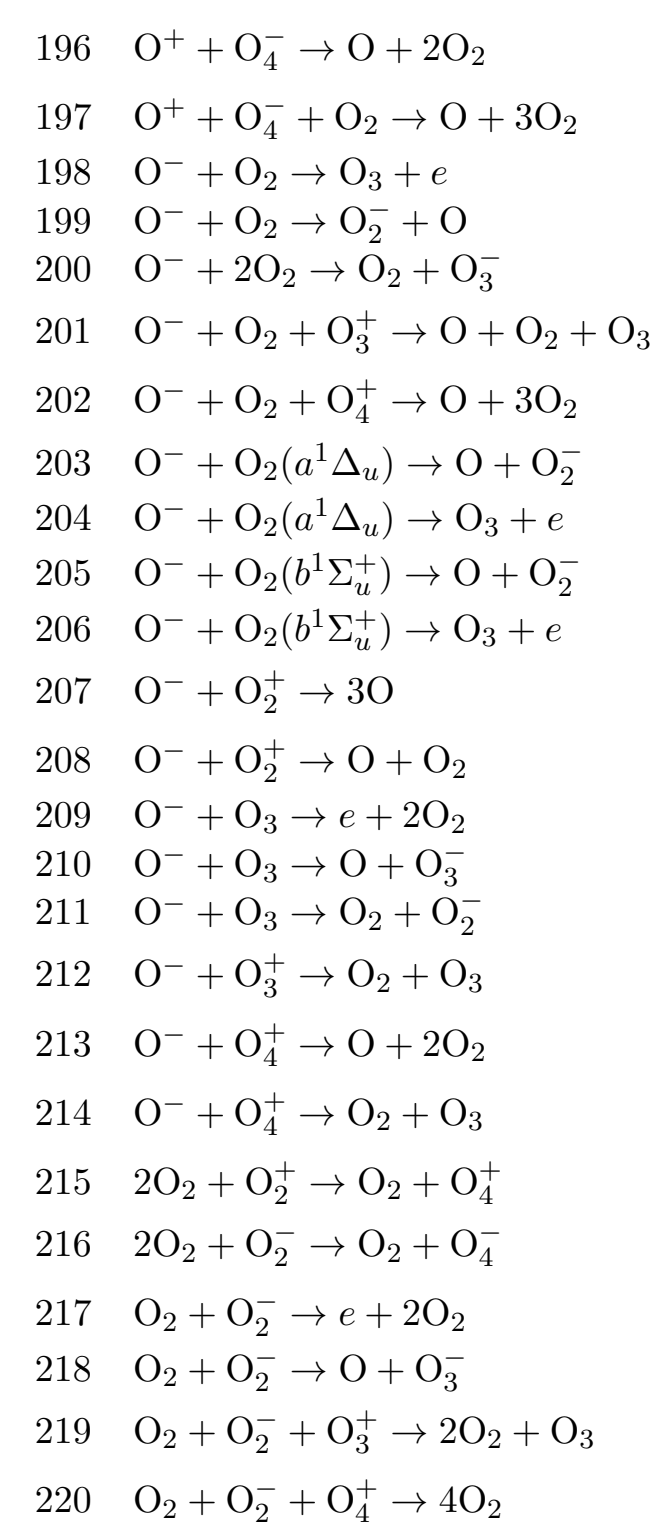

\begin{tabular}{|c|c|c|c|c|}
\hline 0.0 & $7.87 \times 10^{-14}\left(\frac{300}{T_{g}}\right)^{0.9}$ & 0.4 & $\mathrm{~B}$ & {$[91$, eq. 4$]$} \\
\hline 0.0 & $2.0 \times 10^{-37}\left(\frac{300}{T_{g}}\right)^{2.5}$ & 3.0 & $\mathrm{~B}$ & {$[16]$} \\
\hline 0.0 & $1.0 \times 10^{-18}$ & 5.0 & $\mathrm{~A}$ & {$[55$, p. 195$]$} \\
\hline 0.0 & $1.0 \times 10^{-18}$ & 0.5 & $\mathrm{~A}$ & {$[55$, p. 195$]$} \\
\hline 0.0 & $1.1 \times 10^{-42}$ & 0.1 & $\mathrm{~A}$ & {$[12$, p. $24-39]$} \\
\hline 0.0 & $2.0 \times 10^{-37}\left(\frac{300}{T_{g}}\right)^{2.5}$ & 3.0 & $\mathrm{~B}$ & {$[16]$} \\
\hline 0.0 & $2.0 \times 10^{-37}\left(\frac{300}{T_{g}}\right)^{2.5}$ & 3.0 & $\mathrm{~B}$ & {$[16]$} \\
\hline 0.0 & $7.9 \times 10^{-16} \exp \left(-\frac{890}{T_{a}}\right)$ & 0.3 & $\mathrm{~A}$ & {$[89]$} \\
\hline 0.0 & $6.1 \times 10^{-17}$ & 0.3 & $\mathrm{~A}$ & [89] \\
\hline 0.0 & $7.9 \times 10^{-16} \exp \left(-\frac{890}{T_{q}}\right)$ & 0.6 & $\mathrm{C}$ & \\
\hline 0.0 & $6.1 \times 10^{-17}$ & 0.6 & $\mathrm{C}$ & \\
\hline 0.0 & $1.61 \times 10^{-14}\left(\frac{300}{T_{g}}\right)^{1.1}$ & 0.4 & $\mathrm{~B}$ & {$[91$, eq. 3$]$} \\
\hline 0.0 & $1.61 \times 10^{-14}\left(\frac{300}{T_{q}}\right)^{1.1}$ & 0.4 & $\mathrm{~B}$ & {$[91$, eq. 3$]$} \\
\hline 0.0 & $3.0 \times 10^{-16}$ & 0.4 & $\mathrm{~A}$ & {$[78][55$, p. 195$]$} \\
\hline 0.0 & $2.0 \times 10^{-16}$ & 0.4 & $\mathrm{~A}$ & {$[78][55$, p. 195$]$} \\
\hline 0.0 & $1.0 \times 10^{-17}$ & 0.4 & $\mathrm{~A}$ & {$[78][55$, p. 195$]$} \\
\hline 0.0 & $3.07 \times 10^{-14}\left(\frac{300}{T_{g}}\right)^{1.1}$ & 0.3 & $\mathrm{~B}$ & {$[91$, eq. 3$]$} \\
\hline 0.0 & $1.54 \times 10^{-14}\left(\frac{300}{T_{g}}\right)^{0.9}$ & 0.4 & $\mathrm{~B}$ & [91, eq. 3$]$ \\
\hline 0.0 & $1.54 \times 10^{-14}\left(\frac{300}{T_{g}}\right)^{0.9}$ & 0.4 & $\mathrm{~B}$ & {$[91$, eq. 3$]$} \\
\hline 0.0 & $4.0 \times 10^{-42}\left(\frac{300}{T_{q}}\right)^{2.93}$ & 0.1 & $\mathrm{~A}$ & {$[17]$} \\
\hline 0.0 & $3.5 \times 10^{-43}\left(\frac{300}{T_{g}}\right)$ & 0.3 & $\mathrm{~A}$ & {$[12$, p. $24-39]$} \\
\hline 0.0 & $2.7 \times 10^{-16}\left(\frac{T_{g}}{300}\right)^{0.5} \exp \left(-\frac{5590}{T_{g}}\right)$ & 0.1 & $\mathrm{~A}$ & [12, p. $24-15]$ \\
\hline 0.0 & $3.5 \times 10^{-21}$ & 1.0 & $\mathrm{~A}$ & {$[55$, p. 196$]$} \\
\hline 0.0 & $2.0 \times 10^{-37}\left(\frac{300}{T_{g}}\right)^{2.5}$ & 3.0 & $\mathrm{~B}$ & {$[16]$} \\
\hline 0.0 & $2.0 \times 10^{-37}\left(\frac{300}{T_{T}}\right)^{2}$ & 3.0 & B & {$[16]$} \\
\hline
\end{tabular}




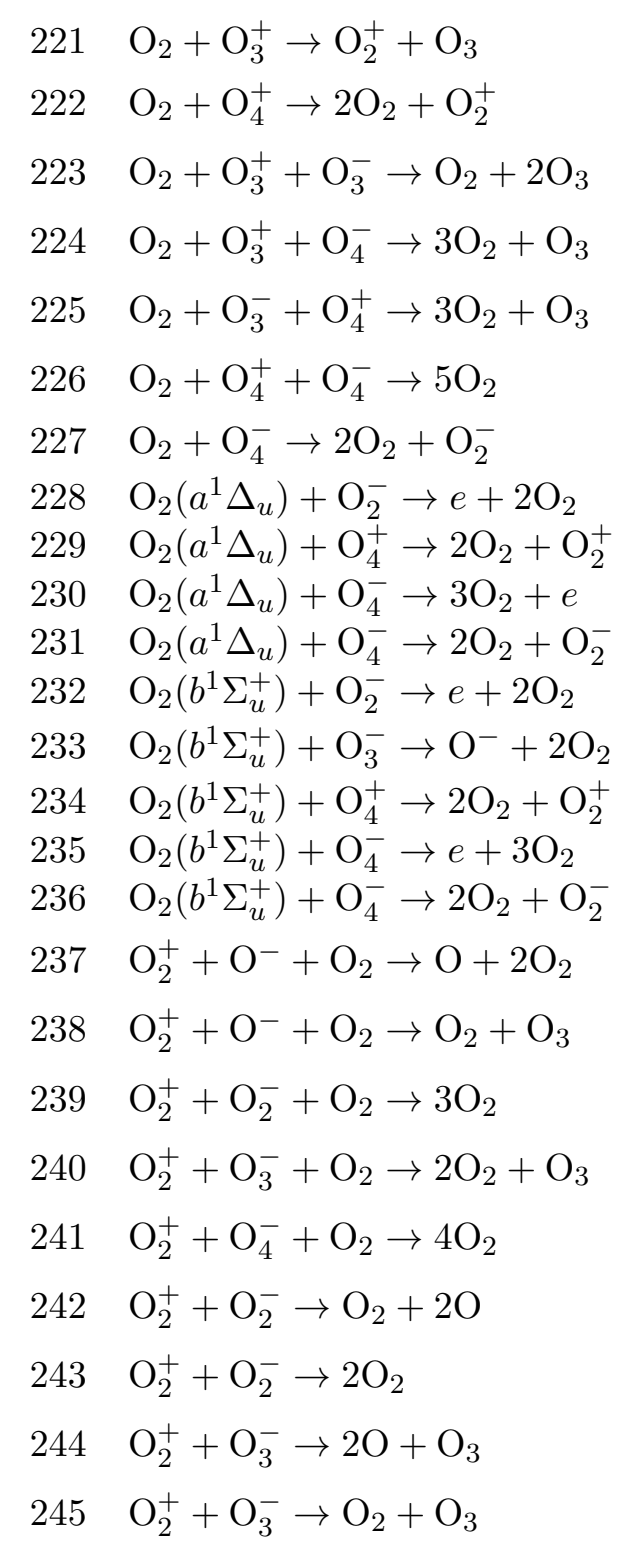

$\begin{array}{ll}0.0 & 6.7 \times 10^{-16} \\ 0.0 & 1.0 \times 10^{-11}\left(\frac{300}{T_{g}}\right)^{4.2} \exp \left(-\frac{5400}{T_{g}}\right) \\ 0.0 & 2.0 \times 10^{-37}\left(\frac{300}{T_{g}}\right)^{2.5} \\ 0.0 & 2.0 \times 10^{-37}\left(\frac{300}{T_{g}}\right)^{2.5} \\ 0.0 & 2.0 \times 10^{-37}\left(\frac{300}{T_{g}}\right)^{2.5} \\ 0.0 & 2.0 \times 10^{-37}\left(\frac{300}{T_{g}}\right)^{2.5} \\ 0.0 & 2.2 \times 10^{-11}\left(\frac{300}{T_{g}}\right) \exp \left(-\frac{6300}{T_{g}}\right) \\ 0.0 & 7.0 \times 10^{-16} \\ 0.0 & 6.0 \times 10^{-16} \\ 0.0 & 3.0 \times 10^{-16} \\ 0.0 & 3.0 \times 10^{-16} \\ 0.0 & 7.0 \times 10^{-16} \\ 0.0 & 6.7 \times 10^{-16} \exp \left(-\frac{1300}{T_{g}}\right) \\ 0.0 & 6.0 \times 10^{-16} \\ 0.0 & 3.0 \times 10^{-16} \\ 0.0 & 3.0 \times 10^{-16} \\ 0.0 & 1.0 \times 10^{-37}\left(\frac{300}{T_{g}}\right)^{2.5} \\ 0.0 & 1.0 \times 10^{-37}\left(\frac{300}{T_{g}}\right)^{2.5} \\ 0.0 & 2.0 \times 10^{-37}\left(\frac{300}{T_{g}}\right)^{2.5} \\ 0.0 & 2.0 \times 10^{-37}\left(\frac{300}{T_{g}}\right)^{2.5} \\ 0.0 & 2.0 \times 10^{-37}\left(\frac{300}{T_{g}}\right)^{2.5} \\ 0.0 & 1.6 \times 10^{-14}\left(\frac{300}{T_{g}}\right)^{1.1} \\ 0.0 & 1.6 \times 10^{-14}\left(\frac{300}{T_{g}}\right)^{1.1} \\ 0.0 & 2.9 \times 10^{-14}\left(\frac{300}{T_{g}}\right)^{0.9} \\ 0.0 & 2.9 \times 10^{-14}\left(\frac{300}{T_{g}}\right)^{0.9} \\ & \\ 0.0 & \\ 0.0 & \\ 0.0 & \end{array}$

\begin{tabular}{|c|c|c|}
\hline 1.0 & $\mathrm{~B}$ & {$[73,90,25,31]$} \\
\hline 1.0 & $\mathrm{~A}$ & {$[12$, p. $24-36][55$, p. 139$]$} \\
\hline 3.0 & $\mathrm{~B}$ & {$[16]$} \\
\hline 3.0 & $\mathrm{~B}$ & {$[16]$} \\
\hline 3.0 & $\mathrm{~B}$ & {$[16]$} \\
\hline 3.0 & $\mathrm{~B}$ & {$[16]$} \\
\hline 0.5 & $\mathrm{~A}$ & {$[12$, p. $24-40]$} \\
\hline 0.3 & $\mathrm{~A}$ & [89] \\
\hline 2.0 & $\mathrm{~B}$ & {$[73,90,31]$} \\
\hline 1.4 & $\mathrm{~B}$ & {$[73,90,31]$} \\
\hline 1.4 & $\mathrm{~B}$ & {$[73,90,31]$} \\
\hline 0.6 & $\mathrm{C}$ & \\
\hline 1.0 & $\mathrm{~B}$ & {$[73,90,31]$} \\
\hline 2.0 & $\mathrm{C}$ & \\
\hline 1.4 & $\mathrm{~B}$ & {$[73,90,31]$} \\
\hline 1.4 & $\mathrm{~B}$ & {$[73,90,31]$} \\
\hline 4.2 & $\mathrm{~B}$ & {$[16]$} \\
\hline 4.2 & $\mathrm{~B}$ & {$[16]$} \\
\hline 3.0 & $\mathrm{~B}$ & {$[16]$} \\
\hline 3.0 & $\mathrm{~B}$ & {$[16]$} \\
\hline 3.0 & $\mathrm{~B}$ & {$[16]$} \\
\hline 0.4 & $\mathrm{~B}$ & {$[91$, eq. 3$]$} \\
\hline 0.4 & $\mathrm{~B}$ & {$[91$, eq. 3$]$} \\
\hline 0.4 & $\mathrm{~B}$ & {$[91$, eq. 4$]$} \\
\hline 0.4 & $\mathrm{~B}$ & {$[91$, eq. 4$]$} \\
\hline
\end{tabular}




\begin{tabular}{|c|c|c|c|c|c|c|}
\hline 246 & $\mathrm{O}_{2}^{+}+\mathrm{O}_{4}^{-} \rightarrow 3 \mathrm{O}_{2}$ & 0.0 & $6.07 \times 10^{-14}\left(\frac{300}{T_{q}}\right)^{0.9}$ & 0.4 & $\mathrm{~B}$ & {$[91$, eq. 4$]$} \\
\hline 247 & $\mathrm{O}_{2}^{-}+\mathrm{O}_{3} \rightarrow \mathrm{O}_{2}+\mathrm{O}_{3}^{-}$ & 0.0 & $6.0 \times 10^{-16}$ & 1.0 & $\mathrm{~A}$ & {$[55$, p. 196$]$} \\
\hline 248 & $\mathrm{O}_{2}^{-}+\mathrm{O}_{3}^{+} \rightarrow \mathrm{O}_{2}+\mathrm{O}_{3}$ & 0.0 & $3.29 \times 10^{-14}\left(\frac{300}{T_{g}}\right)^{1.1}$ & 0.3 & $\mathrm{~B}$ & {$[91$, eq. 3$]$} \\
\hline 249 & $\mathrm{O}_{2}^{-}+\mathrm{O}_{4}^{+} \rightarrow 2 \mathrm{O}+2 \mathrm{O}_{2}$ & 0.0 & $1.6 \times 10^{-14}\left(\frac{300}{T_{g}}\right)^{1.1}$ & 0.4 & $\mathrm{~B}$ & {$[91$, eq. 3$]$} \\
\hline 250 & $\mathrm{O}_{2}^{-}+\mathrm{O}_{4}^{+} \rightarrow 3 \mathrm{O}_{2}$ & 0.0 & $1.6 \times 10^{-14}\left(\frac{300}{T_{g}}\right)^{1.1}$ & 0.4 & $\mathrm{~B}$ & {$[91$, eq. 3$]$} \\
\hline 251 & $\mathrm{O}_{3}+\mathrm{O}_{4}^{-} \rightarrow 2 \mathrm{O}_{2}+\mathrm{O}_{3}^{-}$ & 0.0 & $8.0 \times 10^{-16}$ & 1.0 & $\mathrm{~B}$ & {$[73,90,31]$} \\
\hline 252 & $\mathrm{O}_{3}^{+}+\mathrm{O}_{3}^{-} \rightarrow 2 \mathrm{O}_{3}$ & 0.0 & $5.19 \times 10^{-14}\left(\frac{300}{T_{g}}\right)^{0.9}$ & 0.3 & $\mathrm{~B}$ & {$[91$, eq. 3$]$} \\
\hline 253 & $\mathrm{O}_{3}^{+}+\mathrm{O}_{4}^{-} \rightarrow 2 \mathrm{O}_{2}+\mathrm{O}_{3}$ & 0.0 & $5.37 \times 10^{-14}\left(\frac{300}{T_{g}}\right)^{0.9}$ & 0.3 & $\mathrm{~B}$ & {$[91$, eq. 3$]$} \\
\hline 254 & $\mathrm{O}_{3}^{-}+\mathrm{O}_{3} \rightarrow e+3 \mathrm{O}_{2}$ & 0.0 & $8.5 \times 10^{-16}$ & 1.0 & $\mathrm{~B}$ & {$[73,90,31]$} \\
\hline 255 & $\mathrm{O}_{3}^{-}+\mathrm{O}_{4}^{+} \rightarrow \mathrm{O}+3 \mathrm{O}_{2}$ & 0.0 & $2.43 \times 10^{-14}\left(\frac{300}{T_{g}}\right)^{0.9}$ & 0.4 & $\mathrm{~B}$ & {$[91$, eq. 4$]$} \\
\hline 256 & $\mathrm{O}_{3}^{-}+\mathrm{O}_{4}^{+} \rightarrow 2 \mathrm{O}_{2}+\mathrm{O}_{3}$ & 0.0 & $2.43 \times 10^{-14}\left(\frac{300}{T_{g}}\right)^{0.9}$ & 0.4 & $\mathrm{~B}$ & {$[91$, eq. 4$]$} \\
\hline 257 & $\mathrm{O}_{4}^{+}+\mathrm{O}_{4}^{-} \rightarrow 4 \mathrm{O}_{2}$ & 0.0 & $4.97 \times 10^{-14}\left(\frac{300}{T_{g}}\right)^{0.9}$ & 0.4 & $\mathrm{~B}$ & {$[91$, eq. 4$]$} \\
\hline \multicolumn{7}{|c|}{ Neutral chemistry of helium-oxygen mixtures } \\
\hline 258 & $\mathrm{He}+\mathrm{He}^{*}+\mathrm{O} \rightarrow e+2 \mathrm{He}+\mathrm{O}^{+}$ & 0.0 & $1.6 \times 10^{-43}$ & 2.0 & $\mathrm{C}$ & \\
\hline 259 & $\mathrm{He}+\mathrm{He}^{*}+\mathrm{O}\left({ }^{1} D\right) \rightarrow e+2 \mathrm{He}+\mathrm{O}^{+}$ & 0.0 & $1.6 \times 10^{-43}$ & 2.0 & $\mathrm{C}$ & \\
\hline 260 & $\mathrm{He}+\mathrm{He}^{*}+\mathrm{O}\left({ }^{1} S\right) \rightarrow e+2 \mathrm{He}+\mathrm{O}^{+}$ & 0.0 & $1.6 \times 10^{-43}$ & 2.0 & $\mathrm{C}$ & \\
\hline 261 & $\mathrm{He}+\mathrm{He}^{*}+\mathrm{O}_{2} \rightarrow e+2 \mathrm{He}+\mathrm{O}_{2}^{+}$ & 0.0 & $1.6 \times 10^{-43}$ & 0.5 & $\mathrm{~A}$ & {$[109]$} \\
\hline 262 & $\mathrm{He}+\mathrm{He}^{*}+\mathrm{O}_{2}\left(a^{1} \Delta_{u}\right) \rightarrow e+2 \mathrm{He}+\mathrm{O}_{2}^{+}$ & 0.0 & $1.6 \times 10^{-43}$ & 2.0 & $\mathrm{C}$ & \\
\hline 263 & $\mathrm{He}+\mathrm{He}^{*}+\mathrm{O}_{2}\left(b^{1} \Sigma_{u}^{+}\right) \rightarrow e+2 \mathrm{He}+\mathrm{O}_{2}^{+}$ & 0.0 & $1.6 \times 10^{-43}$ & 2.0 & $\mathrm{C}$ & \\
\hline 264 & $\mathrm{He}+\mathrm{He}^{*}+\mathrm{O}_{3} \rightarrow e+2 \mathrm{He}+\mathrm{O}+\mathrm{O}_{2}^{+}$ & 0.0 & $1.6 \times 10^{-43}$ & 2.0 & $\mathrm{C}$ & \\
\hline 265 & $\mathrm{He}+2 \mathrm{O} \rightarrow \mathrm{He}+\mathrm{O}_{2}\left(a^{1} \Delta_{u}\right)$ & 0.0 & $2.0 \times 10^{-45}\left(\frac{300}{T_{q}}\right) \exp \left(-\frac{170}{T_{q}}\right)$ & 1.0 & $\mathrm{~A}$ & {$[60,129]$} \\
\hline 266 & $\mathrm{He}+2 \mathrm{O} \rightarrow \mathrm{He}+\mathrm{O}_{2}\left(b^{1} \Sigma_{u}^{+}\right)$ & 0.0 & $2.0 \times 10^{-45}\left(\frac{300}{T_{g}}\right) \exp \left(-\frac{170}{T_{g}}\right)$ & 1.0 & $\mathrm{~A}$ & {$[60,129]$} \\
\hline 267 & $\mathrm{He}+\mathrm{O}+\mathrm{O}_{2} \rightarrow \mathrm{He}+\mathrm{O}_{3}$ & 0.0 & $9.0 \times 10^{-47}\left(\frac{300}{T_{g}}\right)^{2.6}$ & 0.5 & $\mathrm{~A}$ & {$[7,133,21]$} \\
\hline 268 & $\mathrm{He}+\mathrm{O}+\mathrm{O}_{2} \rightarrow \mathrm{He}+\mathrm{O}_{3}(\nu)$ & 0.0 & $2.1 \times 10^{-46}\left(\frac{300}{T_{0}}\right)^{2.6}$ & 0.5 & $\mathrm{~A}$ & {$[7,133,21]$} \\
\hline 269 & $\mathrm{He}+\mathrm{O}+\mathrm{O}_{2}\left(a^{1} \Delta_{u}\right) \rightarrow \mathrm{He}+\mathrm{O}_{2}+\mathrm{O}$ & 0.0 & $4.0 \times 10^{-45}$ & 3.0 & $\mathrm{~A}$ & {$[9,20]$} \\
\hline 270 & $\mathrm{He}+\mathrm{O}\left({ }^{1} D\right) \rightarrow \mathrm{He}+\mathrm{O}$ & 0.0 & $1.0 \times 10^{-21}$ & 1.0 & $\mathrm{~A}$ & {$[124,52,51]$} \\
\hline
\end{tabular}




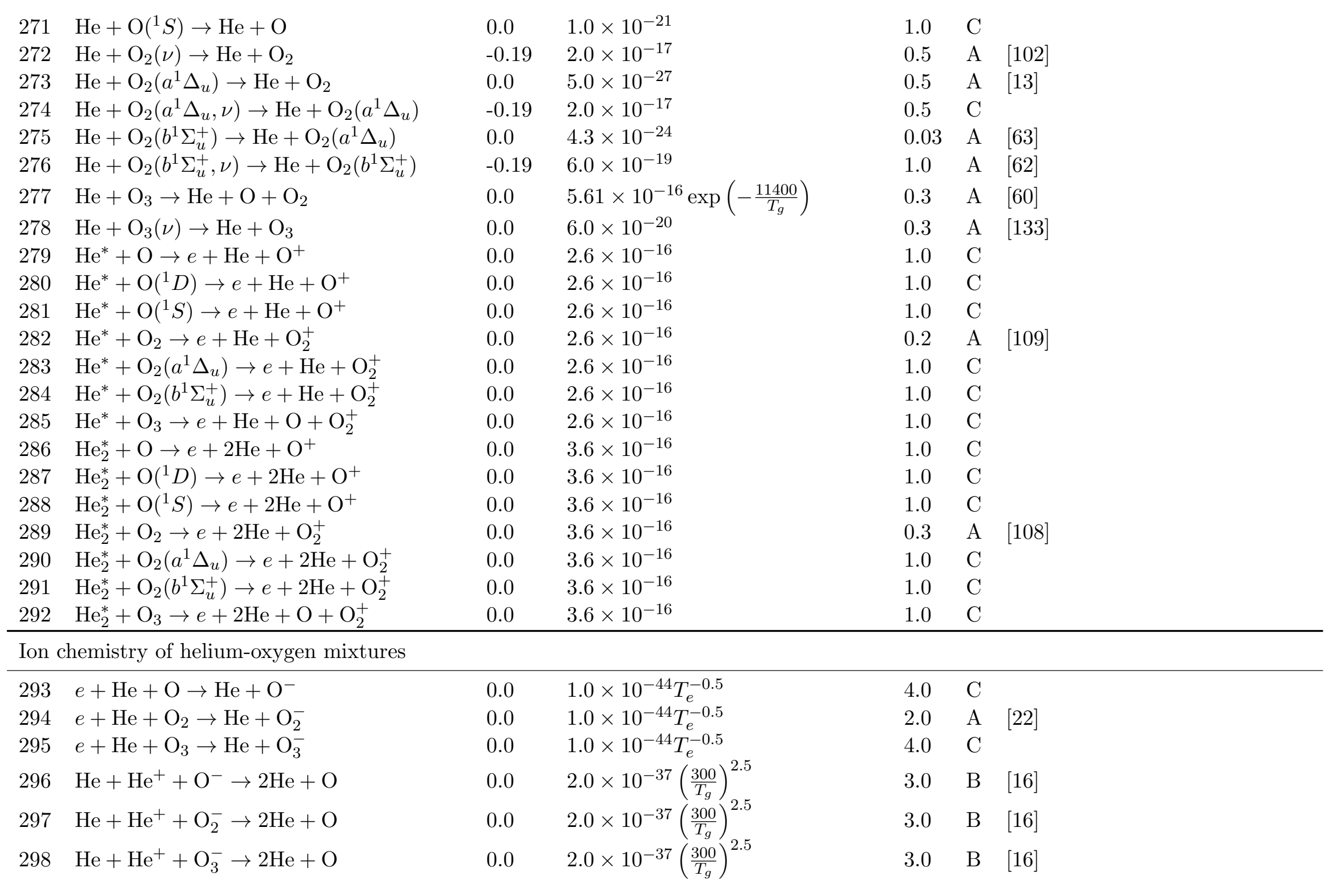




$$
\begin{array}{ll}
299 & \mathrm{He}+\mathrm{He}^{+}+\mathrm{O}_{4}^{-} \rightarrow 2 \mathrm{He}+2 \mathrm{O}_{2} \\
300 & \mathrm{He}+\mathrm{He}_{2}^{+}+\mathrm{O}^{-} \rightarrow 3 \mathrm{He}+\mathrm{O} \\
301 & \mathrm{He}+\mathrm{He}_{2}^{+}+\mathrm{O}_{2} \rightarrow 3 \mathrm{He}+\mathrm{O}_{2}^{+} \\
302 & \mathrm{He}+\mathrm{He}_{2}^{+}+\mathrm{O}_{2}^{-} \rightarrow 3 \mathrm{He}+\mathrm{O}_{2} \\
303 & \mathrm{He}+\mathrm{He}_{2}^{+}+\mathrm{O}_{3}^{-} \rightarrow 3 \mathrm{He}+\mathrm{O}_{3} \\
304 & \mathrm{He}+\mathrm{He}_{2}^{+}+\mathrm{O}_{4}^{-} \rightarrow 3 \mathrm{He}+2 \mathrm{O}_{2} \\
305 & \mathrm{He}+\mathrm{O}^{+} \mathrm{O}^{+} \rightarrow \mathrm{He}+\mathrm{O}_{2}^{+} \\
306 & \mathrm{He}+\mathrm{O}^{+}+\mathrm{O}^{-} \rightarrow \mathrm{He}+2 \mathrm{O} \\
307 & \mathrm{He}+\mathrm{O}^{+}+\mathrm{O}_{2}^{-} \rightarrow \mathrm{He}+\mathrm{O}+\mathrm{O}_{2} \\
308 & \mathrm{He}+\mathrm{O}^{+}+\mathrm{O}_{3}^{-} \rightarrow \mathrm{He}+\mathrm{O}+\mathrm{O}_{3} \\
309 & \mathrm{He}+\mathrm{O}^{+}+\mathrm{O}_{4}^{-} \rightarrow \mathrm{He}+\mathrm{O}+2 \mathrm{O}_{2} \\
310 & \mathrm{He}+\mathrm{O}^{-} \rightarrow e+\mathrm{He}+\mathrm{O} \\
311 & \mathrm{He}+\mathrm{O}^{-}+\mathrm{O}_{2} \rightarrow \mathrm{He}+\mathrm{O}_{3}^{-} \\
312 & \mathrm{He}+\mathrm{O}^{-}+\mathrm{O}_{2}^{+} \rightarrow \mathrm{He}+\mathrm{O}_{+} \mathrm{O}_{2} \\
313 & \mathrm{He}+\mathrm{O}^{-}+\mathrm{O}_{3}^{+} \rightarrow \mathrm{He}+\mathrm{O}+\mathrm{O}_{3} \\
314 & \mathrm{He}+\mathrm{O}^{-}+\mathrm{O}_{4}^{+} \rightarrow \mathrm{He}+\mathrm{O}+2 \mathrm{O}_{2} \\
315 & \mathrm{He}+\mathrm{O}_{2}+\mathrm{O}_{2}^{+} \rightarrow \mathrm{He}+\mathrm{O}_{4}^{+} \\
316 & \mathrm{He}+\mathrm{O}_{2}+\mathrm{O}_{2}^{-} \rightarrow \mathrm{He}+\mathrm{O}_{4}^{-} \\
317 & \mathrm{He}+\mathrm{O}_{2}^{+}+\mathrm{O}_{2}^{-} \rightarrow \mathrm{He}+2 \mathrm{O}_{2} \\
318 & \mathrm{He}+\mathrm{O}_{2}^{+}+\mathrm{O}_{3}^{-} \rightarrow \mathrm{He}+\mathrm{O}_{2}+\mathrm{O}_{3} \\
319 & \mathrm{He}+\mathrm{O}_{2}^{+}+\mathrm{O}_{4}^{-} \rightarrow \mathrm{He}+3 \mathrm{O}_{2} \\
320 & \mathrm{He}+\mathrm{O}_{2}^{-} \rightarrow e+\mathrm{He}+\mathrm{O}_{2} \\
321 & \mathrm{He}+\mathrm{O}_{2}^{-}+\mathrm{O}_{3}^{+} \rightarrow \mathrm{He}+\mathrm{O}_{2}+\mathrm{O}_{3}
\end{array}
$$

$\begin{array}{ll}0.0 & 2.0 \times 10^{-37}\left(\frac{300}{T_{g}}\right)^{2.5} \\ 0.0 & 2.0 \times 10^{-37}\left(\frac{300}{T_{g}}\right)^{2.5} \\ 0.0 & 3.5 \times 10^{-41}{ }^{2.5} \\ 0.0 & 2.0 \times 10^{-37}\left(\frac{300}{T_{g}}\right)^{2.5} \\ 0.0 & 2.0 \times 10^{-37}\left(\frac{300}{T_{g}}\right)^{2.5} \\ 0.0 & 2.0 \times 10^{-37}\left(\frac{300}{T_{g}}\right)^{2.5} \\ 0.0 & 5.5 \times 10^{-43}\left(\frac{300}{T_{g}}\right)^{2.7} \\ 0.0 & 2.0 \times 10^{-37}\left(\frac{300}{T_{g}}\right)^{2.5} \\ 0.0 & 2.0 \times 10^{-37}\left(\frac{300}{T_{g}}\right)^{2.5} \\ 0.0 & 2.0 \times 10^{-37}\left(\frac{300}{T_{g}}\right)^{2.5} \\ 0.0 & 2.0 \times 10^{-37}\left(\frac{300}{T_{g}}\right)^{2.5} \\ 0.0 & 2.5 \times 10^{-24}\left(\frac{T_{g}}{300}\right)^{0.6} \\ 0.0 & 3.7 \times 10^{-43}\left(\frac{300}{T_{g}}\right)^{2.5} \\ 0.0 & 2.0 \times 10^{-37}\left(\frac{300}{T_{g}}\right)^{2.5} \\ 0.0 & 2.0 \times 10^{-37}\left(\frac{300}{T_{g}}\right)^{2.5} \\ 0.0 & 2.0 \times 10^{-37}\left(\frac{300}{T_{g}}\right)^{2.5} \\ 0.0 & 5.5 \times 10^{-43}\left(\frac{300}{T_{g}}\right)^{2.7} \\ 0.0 & 1.2 \times 10^{-43}\left(\frac{300}{T_{g}}\right)^{2.7} \\ 0.0 & 2.0 \times 10^{-37}\left(\frac{300}{T_{g}}\right)^{2.5} \\ 0.0 & 2.0 \times 10^{-37}\left(\frac{300}{T_{g}}\right)^{2.5} \\ 0.0 & 2.0 \times 10^{-37}\left(\frac{300}{T_{g}}\right)^{2.5} \\ 0.0 & 3.9 \times 10^{-16} \mathrm{exp}\left(-\frac{7400}{T_{g}}\right) \\ 0.0 & 2.0 \times 10^{-37}\left(\frac{300}{T_{g}}\right)^{2.5} \\ & \\ 0.0 & \end{array}$

$\begin{array}{lll}3.0 & \text { B } & {[16]} \\ 3.0 & \text { B } & {[16]} \\ 0.3 & \text { A } & {[55, \text { p. 151] }} \\ 3.0 & \text { B } & {[16]} \\ 3.0 & \text { B } & {[16]} \\ 3.0 & \text { B } & {[16]} \\ 0.5 & \text { C } & \\ 3.0 & \text { B } & {[16]} \\ 3.0 & \text { B } & {[16]} \\ 3.0 & \text { B } & {[16]} \\ 3.0 & \text { B } & {[16]} \\ 2.0 & \text { A } & {[82,103]} \\ 1.0 & \text { A } & {[12, \text { p. 24-39][60] }} \\ 3.0 & \text { B } & {[16]} \\ 3.0 & \text { B } & {[16]} \\ 3.0 & \text { B } & {[16]} \\ 0.05 & \text { A } & {[18][55, \text { p. 156] }} \\ 0.5 & \text { A } & {[60][12, \text { p. 24-39] }} \\ 3.0 & \text { B } & {[16]} \\ 3.0 & \text { B } & {[16]} \\ 3.0 & \text { B } & {[16]} \\ 3.0 & \text { A } & {[8]} \\ 3.0 & \text { B } & {[16]} \\ & & \end{array}$




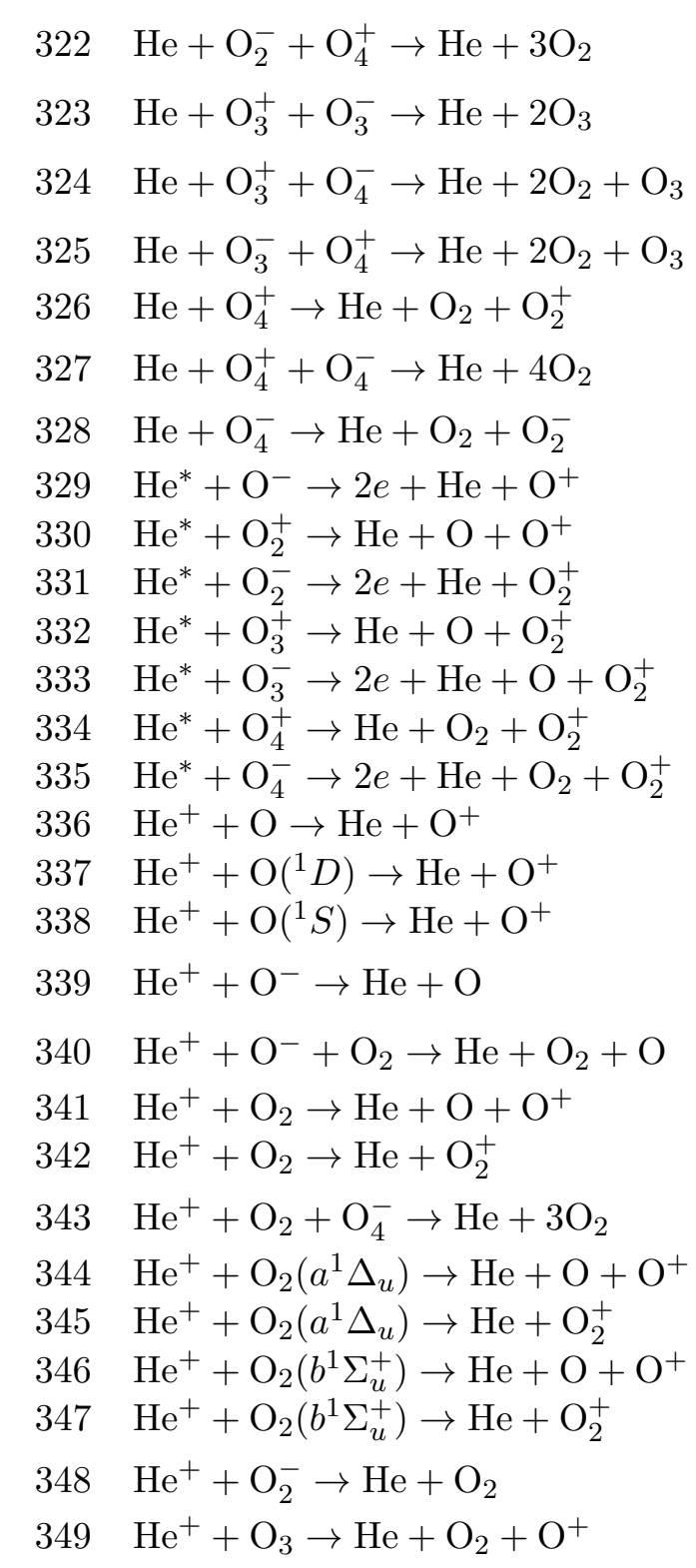

$\begin{array}{lllll}0.0 & 2.0 \times 10^{-37}\left(\frac{300}{T_{g}}\right)^{2.5} & 3.0 & \mathrm{~B} & {[16]} \\ 0.0 & 2.0 \times 10^{-37}\left(\frac{300}{T_{g}}\right)^{2.5} & 3.0 & \mathrm{~B} & {[16]} \\ 0.0 & 2.0 \times 10^{-37}\left(\frac{300}{T_{g}}\right)^{2.5} & 3.0 & \mathrm{~B} & {[16]} \\ 0.0 & 2.0 \times 10^{-37}\left(\frac{300}{T_{g}}\right)^{2.5} & 3.0 & \mathrm{~B} & {[16]} \\ 0.0 & 3.6 \times 10^{-20} & 0.75 & \mathrm{~A} & {[55, \mathrm{p} .139]} \\ 0.0 & 2.0 \times 10^{-37}\left(\frac{300}{T_{g}}\right)^{2.5} & 3.0 & \mathrm{~B} & {[16]} \\ 0.0 & 2.2 \times 10^{-11}\left(\frac{300}{T_{g}}\right) \exp \left(-\frac{6300}{T_{g}}\right) & 2.0 & \mathrm{~A} & {[12, \mathrm{p} .24-40]} \\ 0.0 & 8.7 \times 10^{-15} & 1.0 & \mathrm{~B} & {[31,24,73]} \\ 0.0 & 8.2 \times 10^{-15} & 1.0 & \mathrm{~B} & {[31,24,73]} \\ 0.0 & 8.3 \times 10^{-15} & 1.0 & \mathrm{~B} & {[31,24,73]} \\ 0.0 & 8.1 \times 10^{-15} & 1.0 & \mathrm{~B} & {[31,24,73]} \\ 0.0 & 8.1 \times 10^{-15} & 1.0 & \mathrm{~B} & {[31,24,73]} \\ 0.0 & 8.0 \times 10^{-15} & 1.0 & \mathrm{~B} & {[31,24,73]} \\ 0.0 & 8.0 \times 10^{-15} & 1.0 & \mathrm{~B} & {[31,24,73]} \\ 0.0 & 5.8 \times 10^{-16} & 1.0 & \mathrm{~B} & {[31,90,73]} \\ 0.0 & 5.8 \times 10^{-16} & 1.0 & \mathrm{~B} & {[31,90,73]} \\ 0.0 & 5.8 \times 10^{-16} & 1.0 & \mathrm{~B} & {[31,90,73]} \\ 0.0 & 3.12 \times 10^{-14}\left(\frac{300}{T_{g}}\right)^{1.1} & 0.4 & \mathrm{~B} & {[91, \mathrm{eq} .3]} \\ 0.0 & 2.0 \times 10^{-37}\left(\frac{300}{T_{g}}\right)^{2.5} & 3.0 & \mathrm{~B} & {[16]} \\ 0.0 & 9.7 \times 10^{-16} & 0.1 & \mathrm{~A} & {[3][55, \mathrm{p} .113]} \\ 0.0 & 3.0 \times 10^{-17} & 0.1 & \mathrm{~A} & {[3][55, \mathrm{p} .113]} \\ 0.0 & 2.0 \times 10^{-37}\left(\frac{300}{T_{g}}\right)^{2.5} & 3.0 & \mathrm{~B} & {[16]} \\ 0.0 & 9.7 \times 10^{-16} & 1.0 & \mathrm{~B} & {[31][90][73][3][55, \mathrm{p} .113]} \\ 0.0 & 3.0 \times 10^{-17} & 1.0 & \mathrm{~B} & {[31][90][73][3][55, \mathrm{p} .113]} \\ 0.0 & 9.7 \times 10^{-16} & 1.0 & \mathrm{~B} & {[31][90][73][3][55, \mathrm{p} .113]} \\ 0.0 & 3.0 \times 10^{-17} & 1.0 & \mathrm{~B} & {[31][90][73][3][55, \mathrm{p} .113]} \\ 0.0 & 3.26 \times 10^{-14}\left(\frac{300}{T_{g}}\right)^{1.1} & 0.4 & \mathrm{~B} & {[91, \mathrm{eq} .3]} \\ 0.0 & 2.2 \times 10^{-15} & 1.0 & \mathrm{~B} & {[31,90,73]} \\ & & & & \\ 0 & & & \end{array}$




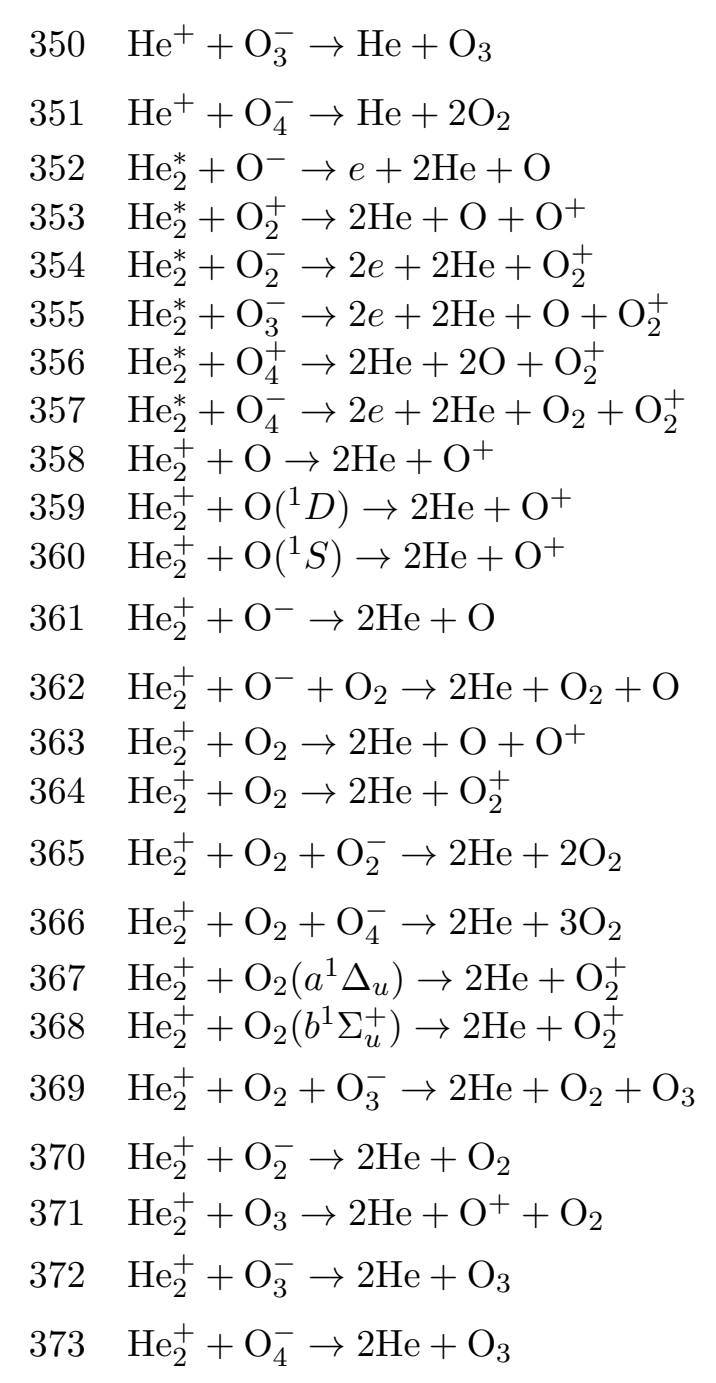

$\begin{array}{ll}0.0 & 1.32 \times 10^{-13}\left(\frac{300}{T_{g}}\right)^{0.9} \\ 0.0 & 1.45 \times 10^{-13}\left(\frac{300}{T_{g}}\right)^{0.9} \\ 0.0 & 6.7 \times 10^{-15} \\ 0.0 & 6.2 \times 10^{-15} \\ 0.0 & 6.1 \times 10^{-15} \\ 0.0 & 6.0 \times 10^{-15} \\ 0.0 & 5.8 \times 10^{-15} \\ 0.0 & 5.8 \times 10^{-15} \\ 0.0 & 9.0 \times 10^{-16} \\ 0.0 & 9.0 \times 10^{-16} \\ 0.0 & 9.0 \times 10^{-16} \\ 0.0 & 3.1 \times 10^{-14}\left(\frac{300}{T_{g}}\right)^{1.1} \\ 0.0 & 2.0 \times 10^{-37}\left(\frac{300}{T_{g}}\right)^{2.5} \\ 0.0 & 1.0 \times 10^{-16} \\ 0.0 & 9.0 \times 10^{-16} \\ 0.0 & 2.0 \times 10^{-37}\left(\frac{300}{T_{g}}\right)^{2.5} \\ 0.0 & 2.0 \times 10^{-37}\left(\frac{300}{T_{g}}\right)^{2.5} \\ 0.0 & 1.2 \times 10^{-15} \\ 0.0 & 1.2 \times 10^{-15} \\ 0.0 & 2.0 \times 10^{-37}\left(\frac{300}{T_{g}}\right)^{2.5} \\ 0.0 & 3.26 \times 10^{-14}\left(\frac{300}{T_{g}}\right)^{1.1} \\ 0.0 & 1.6 \times 10^{-15} \\ 0.0 & 1.34 \times 10^{-13}\left(\frac{300}{T_{g}}\right)^{0.9} \\ 0.0 & 1.45 \times 10^{-13}\left(\frac{300}{T_{g}}\right)^{0.9}\end{array}$

$\begin{array}{lll}0.4 & \text { B } & {[91, \text { eq. } 4]} \\ 0.4 & \text { B } & {[91, \text { eq. } 4]} \\ 1.0 & \text { B } & {[31,24,73]} \\ 1.0 & \text { B } & {[31,24,73]} \\ 1.0 & \text { B } & {[31,24,73]} \\ 1.0 & \text { B } & {[31,24,73]} \\ 1.0 & \text { B } & {[31,24,73]} \\ 1.0 & \text { B } & {[31,24,73]} \\ 1.0 & \text { B } & {[31,90,73]} \\ 1.0 & \text { B } & {[31,90,73]} \\ 1.0 & \text { B } & {[31,90,73]} \\ 0.4 & \text { B } & {[91, \text { eq. 3] }} \\ 3.0 & \text { B } & {[16]} \\ 0.3 & \text { A } & {[55, \text { p. 114] }} \\ 0.3 & \text { A } & {[55, \text { p. } 114]} \\ 3.0 & \text { B } & {[16]} \\ 3.0 & \text { B } & {[16]} \\ 1.0 & \text { B } & {[31,90,73]} \\ 1.0 & \text { B } & {[31,90,73]} \\ 3.0 & \text { B } & {[16]} \\ 0.4 & \text { B } & {[91, \text { eq. 3] }} \\ 1.0 & \text { B } & {[31,90,73]} \\ 0.4 & \text { B } & {[91, \text { eq. } 4]} \\ 0.4 & \text { B } & {[91, \text { eq. 4] }} \\ & & \end{array}$




\section{Appendix A. Problematic Processes}

In the appendices that follow, we discuss details of several processes that emerged as difficult during the compilation of the present chemistry scheme, in the sense that many recent models contain doubtful rate data. The examples that we discuss below are not exhaustive, but have been chosen to illustrate different categories of problems in the transmission of rate constants.

\section{Appendix A.1. Errors perpetuated}

Ionization of molecular metastables is usually included in chemistry models for mixtures that include helium:

$$
\mathrm{He}_{2}^{*}+e \rightarrow \mathrm{He}_{2}^{+}+2 e .
$$

A cross section for this process was computed by Flannery et al. [37], and the result is (not surprisingly) similar to the cross section for ionization of the corresponding atomic state. Consequently, it is remarkable to see rate expressions for these reactions differing by some two orders of magnitude $[112,101,82,95]$. These expressions have been reevaluated from the cross sections in the present work, and found to be of the same magnitude. The origin of this error is not clear (conceivably, a typographical mistake), but this is an instance where a transparently erroneous rate constant has persisted in the literature for more than a decade. The mistake may have failed to be noted in some cases because of the practice of computing the atomic metastable ionization rate by a Boltzmann equation solver, while using a parametric expression for the molecular metastable [82]. This is also, of course, probably not a very important process, except perhaps in pure or nearly pure helium.

\section{Appendix A.2. Illusory sources}

The reaction

$$
\mathrm{O}_{2}\left(a^{1} \Delta_{g}\right)+\mathrm{O}_{2}\left(a^{1} \Delta_{g}\right)+\mathrm{O}_{2} \rightarrow 2 \mathrm{O}_{3}
$$

appears in many recent models, e.g., but not exhaustively, Eliasson et al. [33], HadjZiane et al. [45], Gordiets et al. [42], Soria et al. [131], Liu et al. [82], Mennad et al. [87], Shepelenko et al. [123], Murakami et al. [95], but the primary source for this process is obscure. The process was apparently first mentioned by Fournier et al. [39] in a conference abstract that the present author has not seen. Later discussion [40] implies that the excited state involved was then thought to be $\mathrm{O}_{2}\left(b^{1} \Sigma_{u}^{+}\right)$, but the original proposal was, in any case, qualified by suggestions of alternative mechanisms that might also explain the experimental observations. As far as can now be discovered, none of these ideas reached the refereed literature. However, these works were noted by Eliasson and Kogelschatz [32]. For unclear reasons, they replaced $\mathrm{O}_{2}\left(b^{1} \Sigma_{u}^{+}\right)$with $\mathrm{O}_{2}\left(a^{1} \Delta_{g}\right)$, but the reference to the work of Fournier et al. [39] is explicit. They also called this process "questionable" and in effect advised that it be omitted, by recommending 
a rate constant of zero. Nevertheless, this process is in most recent models that treat ozone kinetics.

In this example, contact with the primary source has been essentially lost, and this loss has obscured the speculative and equivocal character of the evidence that was first advanced. Curiously, this was appreciated by Eliasson and Kogelschatz [32], but their view was generally ignored. Whether this was because their views were unread, even by those who cited them, is impossible to say. In some cases, interest in this reaction may have been motivated by over-predictions of the $\mathrm{O}_{2}\left(a^{1} \Delta_{g}\right)$ by some models [123], relative to some experiments, but even if this were so, one would have thought the absence of primary experimental evidence was worth noting.

\section{Appendix A.3. Complex sources}

The reaction

$$
\begin{aligned}
\mathrm{O}\left({ }^{1} D\right)+\mathrm{O}_{3} & \rightarrow 2 \mathrm{O}+\mathrm{O}_{2} \\
& \rightarrow 2 \mathrm{O}_{2}
\end{aligned}
$$

is well documented. Sander et al. [119] mention ten relevant experimental studies, and there have been three critical evaluations since 1987 [133, 7, 119], all reaching essentially the same recommendation, namely that the gross rate constant is $k=2.4 \times 10^{-16} \mathrm{~m}^{3} \mathrm{~s}^{-1}$, with an uncertainty of $\pm 20 \%$ and equal branching between the channels shown above. Other channels are energetically open, but appear unimportant [133, 7, 119]. Evidently, this is a reaction for which expert evaluation is desirable (because the evidence is complex), but where such evaluation gives an unambiguous recommendation. Good practice in presenting a chemistry model would therefore be to rely on (and cite) one or more of these expert evaluations.

A review of eight models featuring this reaction (all published after Steinfeld et al. [133]) shows that not one follows this obviously desirable practice, and several contain egregious confusions [45, 69, 42, 132, 131, 43, 82, 95]. Most extraordinary is HadjZiane et al. [45], who include five product channels with a gross rate constant of $k=11.2 \times 10^{-16} \mathrm{~m}^{3} \mathrm{~s}^{-1}$, almost five times the recommended value. Less extreme instances of this spurious increase in the gross rate also occur [131, 43, 95], usually through adding product channels without adjusting the gross rate constant. Gordiets et al. [42] adopt the recommended gross rate, but only include the first product channel. The remaining works mentioned above [69, 132, 82] use the recommended rate and product channels, but none directly cites a critical evaluation as authority for doing so.

In this example, difficulties have arisen from a mixture of misunderstanding of rather complex experimental data, and uncritical reliance on earlier authors, who themselves often obscured the sources of their data by opaque citation practices. Experimentation with the present model shows that changing the recommended rate for this process by a factor of five shifts the $\mathrm{O}\left({ }^{1} D\right)$ state density by about a factor of two, and the densities of other states nearby in the chemistry scheme by smaller 
amounts. This is not negligible, even in the context of the uncertainty analysis of the present paper.

\section{Appendix A.4. Reaction mechanisms misunderstood}

Negative ions that are stable at around room temperature may be detached in reactions with excited states, e.g.

$$
\mathrm{O}^{-}+\mathrm{O}_{2}\left(a^{1} \Delta_{g}\right) \rightarrow e+\mathrm{O}+\mathrm{O}_{2}
$$

The rate of this reaction has been much discussed, but the balance of recent opinion is that the rate is close to the gas kinetic, or Langevin, value [88, 89]. One may naturally assume that this rate may be extended to related reactions involving different ions, e.g.

$$
\mathrm{O}_{3}^{-}+\mathrm{O}_{2}\left(a^{1} \Delta_{g}\right) \rightarrow e+\mathrm{O}_{3}+\mathrm{O}_{2}
$$

and this reaction features in at least one recent model [95], with an approximately gas kinetic rate. However, consideration of the energetics of this process shows that it is appreciably endothermic (because the electron affinity of the $\mathrm{O}_{3}^{-}$ion is larger than the internal energy of the $\mathrm{O}_{2}\left(a^{1} \Delta_{g}\right)$ state) so is unlikely to proceed rapidly near room temperature. In this instance, the effect of introducing this erroneous reaction can be seen in the model predictions with some confidence: In the calculations of Liu et al. [82] and in the present work, $\mathrm{O}_{3}^{-}$tends to be the dominant negative ion. However in Murakami et al. [95], $\mathrm{O}_{2}^{-}$is the dominant ion, and probably this is because of the spurious reaction (A.6). In this case, the error is rather elementary, but a wider hazard is illustrated by this case. As we have shown above, over half of the rate constants in the present model are not directly based on experiments, but are obtained either from formulae, or by an assumption of similarity with a related reaction. Failure to appreciate subtle (or not so subtle) features of the reaction kinetics exposes us to the risk of inadvertently introducing grossly incorrect rate constants in these cases.

\section{References}

[1] E. Alge, N. G. Adams, and D. Smith. Measurements of the dissociative recombination coefficients of $\mathrm{O}_{2}^{+}, \mathrm{NO}^{+}$and $\mathrm{NH}_{4}^{+}$in the temperature range 200600K. J. Phys. B: At. Mol. Phys., 16(8):1433, April 1983. ISSN 0022-3700.

[2] L L Alves, K Bartschat, S F Biagi, M C Bordage, L C Pitchford, C M Ferreira, G J M Hagelaar, W L Morgan, S Pancheshnyi, A V Phelps, V Puech, and O Zatsarinny. Comparisons of sets of electron-neutral scattering cross sections and swarm parameters in noble gases: II. Helium and neon. J. Phys. D: Appl. Phys., 46(33):334002, August 2013. ISSN 0022-3727, 1361-6463.

[3] Vincent G Anicich. Evaluated bimolecular ion-molecule gas phase kinetics of positive-ions for use in modeling planetary atmospheres, cometary comae, and interstellar clouds. J. Phys. Chem. Ref. Data, 22(6):1469-1569, 1993. 
[4] Ivan O. Antonov, Valery N. Azyazov, and Nikolay I. Ufimtsev. Experimental and theoretical study of distribution of $\mathrm{O}_{2}$ molecules over vibrational levels in $\mathrm{O}_{2}\left(a^{1} \Delta_{g}\right)$-I mixture. J. Chem. Phys., 119(20):10638-10646, November 2003. ISSN 0021-9606, 1089-7690.

[5] Shaun G. Ard, Joshua J. Melko, Bin Jiang, Yongle Li, Nicholas S. Shuman, Hua Guo, and Albert A. Viggiano. Temperature dependences for the reactions of $\mathrm{O}_{2}^{-}$ and $\mathrm{O}^{-}$with $\mathrm{N}$ and $\mathrm{O}$ atoms in a selected-ion flow tube instrument. J. Chem. Phys., 139(14):144302, 2013. ISSN 00219606.

[6] I. Arnold and F. J. Comes. Photolysis of ozone in the ultraviolet region. reactions of $\mathrm{O}\left({ }^{1} \mathrm{D}\right), \mathrm{O}_{2}\left({ }^{1} \Delta_{g}\right)$ and $\mathrm{O}_{2}^{/=}$. Chem. Phys., 47(1):125-130, March 1980. ISSN 0301-0104.

[7] R. Atkinson, D. L. Baulch, R. A. Cox, J. N. Crowley, R. F. Hampson, R. G. Hynes, M. E. Jenkin, M. J. Rossi, and J. Troe. Evaluated kinetic and photochemical data for atmospheric chemistry: Volume I - gas phase reactions of $\mathrm{O}_{x}, \mathrm{HO}_{x}, \mathrm{NO}_{x}$ and $\mathrm{SO}_{x}$ species. Atmos. Chem. Phys., 4(6):1461-1738, September 2004. ISSN 16807324.

[8] S. D. T. Axford and A. N. Hayhurst. Mass spectrometric sampling of negative ions from flames of hydrogen and oxygen: The kinetics of electron attachment and detachment in hot mixtures of $\mathrm{H}_{2} \mathrm{O}, \mathrm{O}_{2}, \mathrm{OH}$ and $\mathrm{HO}_{2}$. Proc. R. Soc. Lond. A, 452(1948):1007-1033, May 1996. ISSN 1364-5021, 1471-2946.

[9] Valeriy N. Azyazov, Paul Mikheyev, David Postell, and Michael C. Heaven. $\mathrm{O}_{2}\left(a^{1} \Delta\right)$ quenching in the $\mathrm{O} / \mathrm{O}_{2} / \mathrm{O}_{3}$ system. Chem. Phys. Lett., 482(1-3):56-61, November 2009. ISSN 00092614.

[10] D L Baulch, R A Cox, R F Hampson, Jr, J A Kerr, J Troe, and R T Watson. Evaluated kinetic and photochemical data for atmospheric chemistry: Supplement II. CODATA task group on gas phase chemical kinetics. J. Phys. Chem. Ref. Data, 13(4):1259-1378, 1984.

[11] T. Baurer and M. H. Bortner. Defense Nuclear Agency Reaction Rate Handbook. Second Edition. Revision Number 9. Technical Report DNA-1948H-Rev-9, Kamen Tempo, 1983.

[12] Theodore Baurer and Marlyn H Bortner. Defense Nuclear Agency Reaction Rate Handbook. Second Edition. Revision Number 7. Technical Report DNA-1948HRev-7, General Electric Company, 1978.

[13] K.H. Becker, W. Groth, and U. Schurath. The quenching of metastable $\mathrm{O}_{2}\left({ }^{1} \Delta_{g}\right)$ and $\mathrm{O}_{2}\left({ }^{1} \Sigma_{g}^{+}\right)$molecules. Chem. Phys. Lett., 8(3):259-262, February 1971. ISSN 0009-2614.

[14] S. G. Belostotsky, D. J. Economou, D. V. Lopaev, and T. V. Rakhimova. Negative ion destruction by $\mathrm{O}\left({ }^{3} P\right)$ atoms and $\mathrm{O}_{2}\left(a^{1} \Delta_{g}\right)$ molecules in an oxygen plasma. Plasma Sources Sci. Technol., 14(3):532, August 2005. ISSN 0963-0252. 
[15] Stephen Francis Biagi. Cross section compilation, version 7.1. http://www.lxcat.net, 2004. http://www.lxcat.net.

[16] Manfred A. Biondi. Atmospheric electron-ion and ion-ion recombination processes. Can. J. Chem., 47(10):1711-1719, 1969.

[17] H. Böhringer and F. Arnold. Temperature dependence of three-body association reactions from 45 to $400 \mathrm{~K}$. the reactions $\mathrm{N}_{2}^{+}+2 \mathrm{~N}_{2} \rightarrow \mathrm{N}_{4}^{+}+\mathrm{N}_{2}$ and $\mathrm{O}_{2}^{+}+2 \mathrm{O}_{2} \rightarrow \mathrm{O}_{4}^{+}$ $+\mathrm{O}_{2}$. J. Chem. Phys., 77(11):5534-5541, December 1982. ISSN 0021-9606, 10897690 .

[18] H. Böhringer, F. Arnold, D. Smith, and N. G. Adams. A study of the temperature dependences of the $\mathrm{N}_{2}^{+}+\mathrm{N}_{2} \rightarrow \mathrm{N}_{4}^{+}$and $\mathrm{O}_{2}^{+}+\mathrm{O}_{2} \rightarrow \mathrm{O}_{4}^{+}$association reactions using the selected-ion flow-tube and drift-tube techniques. Int. J. Mass Spectrom. Ion Phys., 52(1):25-41, August 1983. ISSN 0020-7381.

[19] H. Böhringer, W. Glebe, and F. Arnold. Temperature dependence of the mobility and association rate coefficient of $\mathrm{He}^{+}$ions in He from 30-350K. J. Phys. B: At. Mol. Phys., 16(14):2619, 1983.

[20] O V Braginskiy, A N Vasilieva, K S Klopovskiy, A S Kovalev, D V Lopaev, O V Proshina, T V Rakhimova, and A T Rakhimov. Singlet oxygen generation in $\mathrm{O}_{2}$ flow excited by RF discharge: I. homogeneous discharge mode: $\alpha$-mode. J. Phys. D: Appl. Phys., 38(19):3609-3625, October 2005. ISSN 0022-3727, 1361-6463.

[21] E. Castellano and H. J. Schumacher. Die kinetik des photochemischen zerfalles von ozon in rot-gelbem licht. Z. Phys. Chem., 34(1-4):198-212, September 1962. ISSN 0942-9352.

[22] L. M. Chanin, A. V. Phelps, and M. A. Biondi. Measurements of the attachment of low-energy electrons to oxygen molecules. Phys. Rev., 128(1):219-230, October 1962.

[23] P. C. Cosby. Electron-impact dissociation of oxygen. J. Chem. Phys., 98(12): 9560-9569, June 1993. ISSN 0021-9606, 1089-7690.

[24] David A. Crosby and Jens C. Zorn. Dipole polarizability of $2^{3} S_{1}$ and $2^{1} S_{0}$ metastable helium measured by the electric deflection time-of-flight method. Phys. Rev. A, 16(2):488-491, August 1977.

[25] Giulia de Petris. Atmospherically relevant ion chemistry of ozone and its cation. Mass Spectrom. Rev., 22(4):251-271, August 2003. ISSN 0277-7037.

[26] R. Deloche, P. Monchicourt, M. Cheret, and F. Lambert. High-pressure helium afterglow at room temperature. Phys. Rev. A, 13(3):1140, 1976.

[27] H Deutsch, P Scheier, K Becker, and T.D Märk. Calculated cross-sections for the electron-impact detachment from negative ions using the Deutsch-Märk (DM) formalism. Chem. Phys. Lett., 382(1-2):26-31, November 2003. ISSN 00092614.

[28] H. Deutsch, K. Becker, M. Probst, W. Zhu, and T.D. Märk. Calculated absolute cross-sections for the electron-induced detachment of the $\mathrm{B}_{2}^{-}, \mathrm{O}_{2}^{-}, \mathrm{BO}^{-}$, and $\mathrm{CN}^{-}$ 
anions using the Deutsch-Märk (DM) formalism. Int. J. Mass Spec., 277(1-3): 151-154, November 2008. ISSN 13873806.

[29] A. J. Dixon, M. F. A. Harrison, and A. C. H. Smith. A measurement of the electron impact ionization cross section of helium atoms in metastable states. $J$. Phys. B: At. Mol. Phys., 9(15):2617, October 1976. ISSN 0022-3700.

[30] J. L. Dulaney, M. A. Biondi, and R. Johnsen. Electron-temperature dependence of the recombination of electrons with $\mathrm{O}_{4}^{+}$ions. Phys. Rev. A, 37(7):2539-2542, April 1988.

[31] Brian R. Eichelberger, Theodore P. Snow, and Veronica M. Bierbaum. Collision rate constants for polarizable ions. J. Am. Soc. Mass Spectrom., 14(5):501-505, May 2003. ISSN 1044-0305, 1879-1123.

[32] B Eliasson and U Kogelschatz. Basic data for modelling of electrical discharges in gases: Oxygen. Technical Report KLR 86-11C, Asea Brown Boveri, June 1986.

[33] B. Eliasson, M. Hirth, and U. Kogelschatz. Ozone synthesis from oxygen in dielectric barrier discharges. J. Phys. D: Appl. Phys., 20(11):1421, 1987.

[34] Nicole Eyet, Anthony Midey, Veronica M. Bierbaum, and A. A. Viggiano. Survey of the reactivity of $\mathrm{O}\left(a^{1} \Delta_{g}\right)$ with negative ions. J. Phys. Chem. A, 114(3):12701276, January 2010. ISSN 1089-5639, 1520-5215.

[35] F. C. Fehsenfeld, D. L. Albritton, J. A. Burt, and H. I. Schiff. Associativedetachment reactions of $\mathrm{O}^{-}$and $\mathrm{O}_{2}^{-}$by $\mathrm{O}_{2}\left({ }^{1} \Delta_{g}\right)$. Can. J. Chem., 47(10):17931795, May 1969. ISSN 0008-4042.

[36] M. R. Flannery. Electron-ion and ion-ion recombination. In Gordon W F Drake, editor, Handbook of Atomic, Molecular, and Optical Physics, pages 606-629. Springer, 1996.

[37] M. R. Flannery, K. J. McCann, and N. W. Winter. Cross sections for electron impact ionisation of metastable rare-gas excimers $\left(\mathrm{He}_{2}^{*}, \mathrm{Kr}_{2}^{*}, \mathrm{Xe}_{2}^{*}\right)$. J. Phys. B: At. Mol. Phys., 14(19):3789, 1981.

[38] A.I. Florescu-Mitchell and J.B.A. Mitchell. Dissociative recombination. Phys. Rep., 430(5-6):277-374, August 2006. ISSN 0370-1573.

[39] G. Fournier, R. Lucas, D. Pigache, and M. Lécuiller. Ozone balance in an electronbeam controlled discharge in oxygen. Bull. Am. Phys. Soc., 23(2):146-146, 1978. ISSN 0003-0503. WOS:A1978ER58900098.

[40] G Fournier, J Bonnet, J Fort, D Pigache, and M Lécuiller. Towards a possible industrial production of ozone with an electron-beam-controlled discharge. In Proceedings of the 4th International Symposium on Plasma Chemistry, pages 742747, Zurich, Switzerland, 1979.

[41] W Van Gaens and A Bogaerts. Kinetic modelling for an atmospheric pressure argon plasma jet in humid air. J. Phys. D: Appl. Phys., 46(27):275201, July 2013. ISSN 0022-3727, 1361-6463. 
[42] B.F. Gordiets, C.M. Ferreira, V.L. Guerra, J.M.A.H. Loureiro, J. Nahorny, D. Pagnon, M. Touzeau, and M. Vialle. Kinetic model of a low-pressure $\mathrm{N}_{2^{-}}$ $\mathrm{O}_{2}$ flowing glow discharge. IEEE Trans. Plasma Sci., 23(4):750-768, 1995. ISSN 0093-3813.

[43] F. J. Gordillo-Vázquez. Air plasma kinetics under the influence of sprites. J. Phys. D: Appl. Phys., 41(23):234016, December 2008. ISSN 0022-3727.

[44] Monika Gupta and K. L. Baluja. Electron collisions with an ozone molecule using the R-matrix method. J. Phys. B: At. Mol. Opt. Phys., 38(22):4057, November 2005. ISSN 0953-4075.

[45] S. Hadj-Ziane, B. Held, P. Pignolet, R. Peyrous, and C. Coste. Ozone generation in an oxygen-fed wire-to-cylinder ozonizer at atmospheric pressure. J. Phys. D: Appl. Phys., 25(4):677, 1992.

[46] G J M Hagelaar and L C Pitchford. Solving the Boltzmann equation to obtain electron transport coefficients and rate coefficients for fluid models. Plasma Sources Sci. Technol., 14(4):722-733, November 2005. ISSN 0963-0252, 1361-6595.

[47] L. Hatton. The T experiments: Errors in scientific software. IEEE Comput. Sci. Eng. Mag., 4(2):27-38, 1997.

[48] L. Hatton and A. Roberts. How accurate is scientific software? IEEE Trans. Softw. Eng., 20(10):785-797, 1994.

[49] Daiyu Hayashi and Kiyoshi Kadota. Efficient production of $\mathrm{O}^{-}$by dissociative attachment of slow electrons to highly excited metastable oxygen molecules. Jpn. J. Appl. Phys., 38(1R):225, January 1999. ISSN 1347-4065.

[50] Jin He and Yuantao T Zhang. Modeling study on the generation of reactive oxygen species in atmospheric radio-frequency helium-oxygen discharges. Plasma Process. Polym., 9(9):919-928, September 2012. ISSN 16128850.

[51] R. F. Heidner and D. Husain. A study of the collisional quenching of $\mathrm{O}\left(2^{1} D_{2}\right)$ by the noble gases employing time-resolved attenuation of atomic resonance radiation in the vacuum ultraviolet. Int. J. Chem. Kinet., 6(1):77-87, January 1974. ISSN 1097-4601.

[52] R. F. Heidner III, D. Husain, and J. R. Wiesenfeld. Kinetic study of electronically excited oxygen atoms, $\mathrm{O}\left(2^{1} D_{2}\right)$, by time-resolved atomic absorption spectroscopy in the vacuum ultra-violet $\left(\lambda=115.2 \mathrm{~nm}, \mathrm{O}\left(3^{1} D_{2}^{0} \leftarrow 2^{1} D_{2}\right)\right)$. Chem. Phys. Lett., 16(3):530-533, October 1972. ISSN 0009-2614.

[53] J.C. Helton and F.J. Davis. Latin hypercube sampling and the propagation of uncertainty in analyses of complex systems. Reliab. Eng. Syst. Safe., 81(1):23-69, July 2003. ISSN 09518320.

[54] David L. Huestis, Stephen W. Bougher, Jane L. Fox, Marina Galand, Robert E. Johnson, Julianne I. Moses, and Juliet C. Pickering. Cross sections and reaction rates for comparative planetary aeronomy. Space Sci. Rev., 139(1-4):63-105, July 2008. ISSN 0038-6308, 1572-9672. 
[55] Yasumasa Ikezoe. Gas Phase Ion-molecule Reaction Rate Constants Through 1986. Ion Reaction Research Group of the Mass Spectroscopy Society of Japan, 1987.

[56] Y. Itikawa, A. Ichimura, K. Onda, K. Sakimoto, K. Takayanagi, Y. Hatano, M. Hayashi, H. Nishimura, and S. Tsurubuchi. Cross sections for collisions of electrons and photons with oxygen molecules. J. Phys. Chem. Ref. Data, 18(1): 23-42, January 1989. ISSN 0047-2689, 1529-7845.

[57] Thomas Jaffke, Martina Meinke, Reza Hashemi, Loucas G. Christophorou, and Eugen Illenberger. Dissociative electron attachment to singlet oxygen. Chem. Phys. Lett., 193(1-3):62-68, May 1992. ISSN 0009-2614.

[58] B. H. Jeon. Determination of electron collision cross-sections for the oxygen molecule by using an electron swarm study. J. Korean Phys. Soc., 43(4):513525, October 2003. ISSN 0374-4884. WOS:000185973800012.

[59] Norman Lloyd Johnson and Samuel Kotz. Continuous Univariate Distributions: Distributions in Statistics, volume 1. Hougton Mifflin, 1970. ISBN 9780471446262.

[60] Harold S Johnston. Gas phase reaction kinetics of neutral oxygen species. Technical Report NSRDS-NBS-20, National Bureau of Standards, September 1968.

[61] K. N. Joshipura, B. K. Antony, and Minaxi Vinodkumar. Electron scattering and ionization of ozone, $\mathrm{O}_{2}$ and $\mathrm{O}_{4}$ molecules. J. Phys. B: At. Mol. Opt. Phys., 35 (20):4211, October 2002. ISSN 0953-4075.

[62] Konstantinos S. Kalogerakis, Richard A. Copeland, and Tom G. Slanger. Collisional removal of $\mathrm{O}_{2}\left(b^{1} \Sigma_{g}^{+}, \nu=2,3\right)$. J. Chem. Phys., 116(12):4877-4885, March 2002. ISSN 0021-9606, 1089-7690.

[63] Paul L. Kebabian and Andrew Freedman. Rare gas quenching of metastable $\mathrm{O}_{2}$ at 295 K. J. Phys. Chem. A, 101(42):7765-7767, October 1997. ISSN 1089-5639.

[64] Hugh P. Kelly. Many-body perturbation-theory calculation of atomic polarizabilities. Phys. Rev., 152(1):62, 1966.

[65] S. Kelly and M. M. Turner. Generation of reactive species by an atmospheric pressure plasma jet. Plasma Sources Sci. Technol., 23(6):065013, December 2014. ISSN 0963-0252.

[66] S. Kelly and M. M. Turner. Power modulation in an atmospheric pressure plasma jet. Plasma Sources Sci. Technol., 23(6):065012, December 2014. ISSN 0963-0252.

[67] R. D. Kenner and E. A. Ogryzlo. A direct determination of the rate constant for the quenching of $\mathrm{O}\left({ }^{1} \mathrm{~S}\right)$ by $\mathrm{O}_{2}\left(\mathrm{a}^{1} \Delta_{\mathrm{g}}\right)$. J. Photochem., 18(4):379-382, 1982. ISSN 0047-2670.

[68] Mark B. Knickelbein, Kenneth L. Marsh, Otho E. Ulrich, and George E. Busch. Energy transfer kinetics of singlet molecular oxygen: The deactivation channel for $\mathrm{O}_{2}\left(b^{1} \Sigma_{u}^{+}\right)$. J. Chem. Phys., 87(4):2392, August 1987. ISSN 00219606. 
[69] I. A. Kossyi, A. Yu Kostinsky, A. A. Matveyev, and V. P. Silakov. Kinetic scheme of the non-equilibrium discharge in nitrogen-oxygen mixtures. Plasma Sources Sci. Technol., 1(3):207, 1992.

[70] Kamal Kumar and Chih-Jen Sung. Autoignition of methanol: Experiments and computations. Int. J. Chem. Kinet., 43(4):175-184, April 2011. ISSN 05388066.

[71] Kinga Kutasi, Paulo A Sá, and Vasco Guerra. $\mathrm{O}_{2}$ dissociation in Ar-O 2 surfacewave microwave discharges. J. Phys. D: Appl. Phys., 45(19):195205, May 2012. ISSN 0022-3727, 1361-6463.

[72] Russ R. Laher and Forrest R. Gilmore. Updated excitation and ionization cross sections for electron impact on atomic oxygen. J. Phys. Chem. Ref. Data, 19(1): 277-305, January 1990. ISSN 0047-2689, 1529-7845.

[73] P. Langevin. Une formule fondamentale de théorie cinétique. Ann. Chim. Phys., 5:245-288, 1905.

[74] V Laporta, R Celiberto, and J Tennyson. Resonant vibrational-excitation cross sections and rate constants for low-energy electron scattering by molecular oxygen. Plasma Sources Sci. Technol., 22(2):025001, April 2013. ISSN 0963-0252, 13616595.

[75] S. A. Lawton and A. V. Phelps. Excitation of the $b^{1} \Sigma_{g}^{+}$state of $\mathrm{O}_{2}$ by low energy electrons. J. Chem. Phys., 69(3):1055-1068, 1978. ISSN 0021-9606, 1089-7690.

[76] Ralph Lehmann. An algorithm for the determination of all significant pathways in chemical reaction systems. J. Atmos. Chem., 47(1):45-78, January 2004. ISSN 0167-7764, 1573-0662.

[77] Valérie Léveillé and Sylvain Coulombe. Atomic oxygen production and exploration of reaction mechanisms in a $\mathrm{He}_{2} \mathrm{O}_{2}$ atmospheric pressure glow discharge torch. Plasma Process. Polym., 3(8):587-596, October 2006. ISSN 1612-8850, 1612-8869.

[78] C. Lifshitz, R. L. C. Wu, J. C. Haartz, and T. O. Tiernan. Associative detachment reactions of negative ions with $\mathrm{O}_{3}$. J. Chem. Phys., 67(5):2381, 1977. ISSN 00219606.

[79] H. V. Lilenfeld, P. A. G. Carr, and F. E. Hovis. Energy pooling reactions in the oxygen-iodine system. J. Chem. Phys., 81(12):5730-5736, December 1984. ISSN 0021-9606, 1089-7690.

[80] M. Lino da Silva, J. Loureiro, and V. Guerra. A multiquantum dataset for vibrational excitation and dissociation in high-temperature $\mathrm{O}_{2}-\mathrm{O}_{2}$ collisions. Chem. Phys. Lett., 531:28-33, April 2012. ISSN 00092614.

[81] D X Liu, P Bruggeman, F Iza, M Z Rong, and M G Kong. Global model of low-temperature atmospheric-pressure $\mathrm{He}+\mathrm{H}_{2} \mathrm{O}$ plasmas. Plasma Sources Sci. Technol., 19(2):025018, April 2010. ISSN 0963-0252, 1361-6595.

[82] Ding-Xin Liu, Ming-Zhe Rong, Xiao-Hua Wang, Felipe Iza, Michael G. Kong, and Peter Bruggeman. Main species and physicochemical processes in cold 
atmospheric-pressure $\mathrm{He}+\mathrm{O}_{2}$ plasmas. Plasma Process. Polym., 7(9-10):846865, October 2010. ISSN 16128850.

[83] D V Lopaev, E M Malykhin, and S M Zyryanov. Surface recombination of oxygen atoms in $\mathrm{O}_{2}$ plasma at increased pressure: II. vibrational temperature and surface production of ozone. J. Phys. D: Appl. Phys., 44(1):015202, January 2011. ISSN 0022-3727, 1361-6463.

[84] Daniil Marinov, Vasco Guerra, Olivier Guaitella, Jean-Paul Booth, and Antoine Rousseau. Ozone kinetics in low-pressure discharges: Vibrationally excited ozone and molecule formation on surfaces. Plasma Sources Sci. Technol., 22(5):055018, October 2013. ISSN 0963-0252, 1361-6595.

[85] A. H. Markosyan, A. Luque, F. J. Gordillo-Vázquez, and U. Ebert. Pumpkin: A tool to find principal pathways in plasma chemical models. Comp. Phys. Comm., 185(10):2697-2702, October 2014. ISSN 0010-4655.

[86] J.W. McConkey, C.P. Malone, P.V. Johnson, C. Winstead, V. McKoy, and I. Kanik. Electron impact dissociation of oxygen-containing molecules-a critical review. Phys. Rep., 466(1-3):1-103, September 2008. ISSN 03701573.

[87] B. Mennad, Z. Harrache, D. Amir Aid, and A. Belasri. Theoretical investigation of ozone production in negative corona discharge. Curr. Appl. Phys., 10(6):13911401, November 2010. ISSN 15671739.

[88] Anthony Midey, Itzhak Dotan, S. Lee, W. T. Rawlins, Mark A. Johnson, and A. A. Viggiano. Kinetics for the reactions of $\mathrm{O}^{-}$and $\mathrm{O}_{2}^{-}$with $\mathrm{O}_{2}\left(a^{1} \Delta_{g}\right)$ measured in a selected ion flow tube at $300 \mathrm{~K}$. J. Phys. Chem. A, 111(24):5218-5222, June 2007. ISSN 1089-5639, 1520-5215.

[89] Anthony Midey, Itzhak Dotan, and A. A. Viggiano. Temperature dependences for the reactions of $\mathrm{O}^{-}$and $\mathrm{O}_{2}^{-}$with $\mathrm{O}_{2}\left(a^{1} \Delta_{g}\right)$ from 200 to $700 \mathrm{~K}$. J. Phys. Chem. A, 112(14):3040-3045, April 2008. ISSN 1089-5639, 1520-5215.

[90] Thomas M. Miller. Atomic and molecular polarizabilities. In CRC Handbook of Chemistry and Physics, volume 77, pages 193-202. CRC Press, Boca Raton, 2000.

[91] Thomas M. Miller, Nicholas S. Shuman, and A. A. Viggiano. Behavior of rate coefficients for ion-ion mutual neutralization, 300-550 K. J. Chem. Phys., 136 (20):204306, 2012. ISSN 00219606.

[92] D D Monahan and M M Turner. Global models of electronegative discharges: critical evaluation and practical recommendations. Plasma Sources Sci. Technol., 17(4):045003, November 2008. ISSN 0963-0252, 1361-6595.

[93] Max D. Morris. Factorial sampling plans for preliminary computational experiments. Technometrics, 33(2):161-174, 1991.

[94] Sebastian Mosbach, Je Hyeong Hong, George P. E. Brownbridge, Markus Kraft, Soumya Gudiyella, and Kenneth Brezinsky. Bayesian error propagation for a kinetic model of n-propylbenzene oxidation in a shock tube. Int. J. Chem. Kinet., 46(7):389-404, July 2014. ISSN 1097-4601. 
[95] Tomoyuki Murakami, Kari Niemi, Timo Gans, Deborah O'Connell, and William G Graham. Chemical kinetics and reactive species in atmospheric pressure heliumoxygen plasmas with humid-air impurities. Plasma Sources Sci. Technol., 22(1): 015003, February 2013. ISSN 0963-0252, 1361-6595.

[96] R. K. Nesbet. Atomic polarizabilities for ground and excited states of C, N, and O. Phys. Rev. A, 16(1):1, 1977.

[97] J. C. Nickel, P. W. Zetner, G. Shen, and S. Trajmar. Principles and procedures for determining absolute differential electron-molecule (atom) scattering cross sections. J. Phys. E: Sci. Instrum., 22(9):730, September 1989. ISSN 0022-3735.

[98] W. L. Oberkampf and T. G. Trucano. Verification and validation in computational fluid dynamics. Prog. Aerosp. Sci., 38(3):209-272, 2002.

[99] William L. Oberkampf and Christopher J. Roy. Verification and Validation in Scientific Computing. Cambridge University Press, October 2010. ISBN 9780521113601.

[100] Gan Young Park, Yong Jun Hong, Hyun Woo Lee, Jae Yoon Sim, and Jae Koo Lee. A global model for the identification of the dominant reactions for atomic oxygen in $\mathrm{He} / \mathrm{O}_{2}$ atmospheric-pressure plasmas. Plasma Process. Polym., 7(3-4): 281-287, March 2010. ISSN 16128850, 16128869.

[101] Ganyoung Park, Hyunwoo Lee, Gyoocheon Kim, and Jae Koo Lee. Global model of $\mathrm{He} / \mathrm{O}_{2}$ and $\mathrm{Ar} / \mathrm{O}_{2}$ atmospheric pressure glow discharges. Plasma Process. Polym., 5(6):569-576, 2008. ISSN 1612-8869.

[102] H. Park and T. G. Slanger. $\mathrm{O}_{2}(X, \nu=8-22) 300 \mathrm{~K}$ quenching rate coefficients for $\mathrm{O}_{2}$ and $\mathrm{N}_{2}$, and $\mathrm{O}_{2}(X)$ vibrational distribution from $248 \mathrm{~nm} \mathrm{O} 3$ photodissociation. J. Chem. Phys., 100(1):287-300, January 1994. ISSN 0021-9606, 1089-7690.

[103] F. Penent, J. P. Grouard, R. I. Hall, J. L. Montmagnon, R. L. Champion, L. D. Doverspike, and V. A. Esaulov. Fundamental processes in collisions of $\mathrm{O}^{-}$with atoms and molecules; mechanisms of one- and two-electron loss. J. Phys. B: At. Mol. Phys., 20(22):6065, November 1987. ISSN 0022-3700.

[104] Z Lj Petrović, S Dujko, D Marić, G Malović, ž Nikitović, O Šašić, J Jovanović, V Stojanović, and M Radmilović-Ra?enović. Measurement and interpretation of swarm parameters and their application in plasma modelling. J. Phys. D: Appl. Phys., 42(19):194002, October 2009. ISSN 0022-3727, 1361-6463.

[105] A. V. Phelps and J. P. Molnar. Lifetimes of metastable states of noble gases. Phys. Rev., 89(6):1202, 1953.

[106] Arthur V. Phelps. Compilation of atomic and molecular data. http://jila.colorado.edu/avp/, 2005.

[107] Tina D. Poulsen, Peter R. Ogilby, and Kurt V. Mikkelsen. Polarizabilities of the first excited $\left(a^{1} \Delta_{g}\right)$ and ground $\left(X^{3}\right)$ states of molecular oxygen. J. Phys. Chem. $A, 102(45): 8970-8973$, November 1998. ISSN 1089-5639, 1520-5215. 
[108] J. M. Pouvesle, J. Stevefelt, F. W. Lee, H. R. Jahani, V. T. Gylys, and C. B. Collins. Reactivity of metastable helium molecules in atmospheric pressure afterglows. J. Chem. Phys., 83(6):2836, September 1985. ISSN 00219606.

[109] J. M. Pouvesle, A. Khacef, J. Stevefelt, H. Jahani, V. T. Gylys, and C. B. Collins. Study of two-body and three-body channels for the reaction of metastable helium atoms with selected atomic and molecular species. J. Chem. Phys., 88(5):3061, 1988. ISSN 00219606.

[110] J. L. Queffelec, B. R. Rowe, F. Vallée, J. C. Gomet, and M. Morlais. The yield of metastable atoms through dissociative recombination of $\mathrm{O}_{2}^{+}$ions with electrons. J. Chem. Phys., 91(9):5335, 1989. ISSN 00219606.

[111] S. A. Rangwala, S. V. K. Kumar, E. Krishnakumar, and N. J. Mason. Cross sections for the dissociative electron attachment to ozone. J. Phys. B: At. Mol. Opt. Phys., 32(15):3795, August 1999. ISSN 0953-4075.

[112] Shahid Rauf and Mark J. Kushner. Dynamics of a coplanar-electrode plasma display panel cell. I. Basic operation. J. Appl. Phys., 85(7):3460, 1999. ISSN 00218979 .

[113] W. T. Rawlins, G. E. Caledonia, and R. A. Armstrong. Dynamics of vibrationally excited ozone formed by three-body recombination. II. kinetics and mechanism. Journal of Chemical Physics, 87(9):5209, 1987. ISSN 00219606.

[114] Patrick J. Roache. Verification and Validation in Computational Science and Engineering. Hermosa Pub, 1998. ISBN 9780913478080.

[115] Christopher J. Roy and William L. Oberkampf. A comprehensive framework for verification, validation, and uncertainty quantification in scientific computing. Comput. Methods in Appl. Mech. Eng., 200(25-28):2131-2144, June 2011. ISSN 00457825 .

[116] M.V. Ruano, J. Ribes, A. Seco, and J. Ferrer. An improved sampling strategy based on trajectory design for application of the Morris method to systems with many input factors. Environ. Modell. Softw., 37:103-109, November 2012. ISSN 13648152.

[117] Yukinori Sakiyama, David B Graves, Hung-Wen Chang, Tetsuji Shimizu, and Gregor E Morfill. Plasma chemistry model of surface microdischarge in humid air and dynamics of reactive neutral species. J. Phys. D: Appl. Phys., 45(42):425201, October 2012. ISSN 0022-3727, 1361-6463.

[118] Andrea Saltelli, Marco Ratto, Stefano Tarantola, and Francesca Campolongo. Sensitivity analysis for chemical models. Chem. Rev., 105(7):2811-2828, July 2005. ISSN 0009-2665, 1520-6890.

[119] S P Sander, R R Freidl, J R Barker, D M Golden, M J Kurylo, P H Wine, J P D Abbatt, J B Burkholder, C E Kolb, G K Moortgat, R E Huie, and V L Orkin. Chemical kinetics and photochemical data for use in atmospheric studies. Technical Report JPL Publication 10-6, Jet Propulsion Laboratory, June 2011. 
[120] Keith Schofield. Rate constants for the gaseous interaction of $\mathrm{O}\left(2^{1} D_{2}\right)$ and $\mathrm{O}\left(2^{1} S_{0}\right)$ - a critical evaluation. J. Photochem., 9(1):55-68, 1978. ISSN 0047-2670.

[121] V. Schulz-von der Gathen, V. Buck, T. Gans, N. Knake, K. Niemi, St. Reuter, L. Schaper, and J. Winter. Optical diagnostics of micro discharge jets. Contr. Plasma Phys., 47(7):510-519, November 2007. ISSN 08631042, 15213986.

[122] K. Seiersen, J. Bak, H. Bluhme, M. J. Jensen, S. B. Nielsen, and L. H. Andersen. Electron-impact detachment of $\mathrm{O}_{3}^{-}, \mathrm{NO}_{3}^{-}$and $\mathrm{SO}_{2}^{-}$ions. Phys. Chem. Chem. Phys., 5(21):4814, 2003. ISSN 1463-9076, 1463-9084.

[123] A. A. Shepelenko, N. V. Kupryaev, and P. A. Mikheyev. Singlet delta oxygen concentration and the main process of its decrease in the afterglow of a DC discharge in oxygen flow. High Temperature, 50(1):137-144, February 2012. ISSN 0018-151X, 1608-3156.

[124] Jichun Shi and John R. Barker. Kinetic studies of the deactivation of $\mathrm{O}_{2}\left({ }^{1} \Sigma_{g}^{+}\right)$and $\mathrm{O}\left({ }^{1} D\right)$. Int. J. Chem. Kinet., 22(12):1283-1301, December 1990. ISSN 1097-4601.

[125] Rex T. Skodje, Alison S. Tomlin, Stephen J. Klippenstein, Lawrence B. Harding, and Michael J. Davis. Theoretical validation of chemical kinetic mechanisms: Combustion of methanol. J. Phys. Chem. A, 114(32):8286-8301, August 2010. ISSN 1089-5639, 1520-5215.

[126] T. G. Slanger and G. Black. Products of the $\mathrm{O}\left({ }^{1} \mathrm{~S}\right)-\mathrm{O}_{2}$ interaction. J. Chem. Phys., 68(3):998-1000, February 1978. ISSN 0021-9606, 1089-7690.

[127] T. G. Slanger and G. Black. The product channels in the quenching of $\mathrm{O}\left({ }^{1} S\right)$ by $\mathrm{O}_{2}\left(a^{1} \Delta_{g}\right)$. J. Chem. Phys., 75(5):2247, 1981. ISSN 00219606.

[128] T. G. Slanger and G. Black. Quenching of $\mathrm{O}\left({ }^{1} S\right)$ by $\mathrm{O}_{2}\left(a^{1} \Delta_{g}\right)$. Geophys. Res. Lett., 8(5):535-538, 1981. ISSN 1944-8007.

[129] Tom G. Slanger and Richard A. Copeland. Energetic oxygen in the upper atmosphere and the laboratory. Chem. Rev., 103(12):4731-4766, 2003.

[130] J. H. A. Sobral, H. Takahashi, M. A. Abdu, P. Muralikrishna, Y. Sahai, C. J. Zamlutti, E. R. de Paula, and P. P. Batista. Determination of the quenching rate of the $\mathrm{O}\left({ }^{1} D\right)$ by $\mathrm{O}\left({ }^{3} P\right)$ from rocket-borne optical $(630 \mathrm{~nm})$ and electron density data. J. Geophys. Res., 98(A5):7791-7798, 1993. ISSN 2156-2202.

[131] C. Soria, F. Pontiga, and A. Castellanos. Plasma chemical and electrical modelling of a negative DC corona in pure oxygen. Plasma Sources Sci. Technol., 13(1):95, 2004.

[132] D. Shane Stafford and Mark J. Kushner. $\mathrm{O}_{2}\left(\Delta_{1}\right)$ production in $\mathrm{He} / \mathrm{O}_{2}$ mixtures in flowing low pressure plasmas. J. Appl. Phys., 96(5):2451-2465, September 2004. ISSN 0021-8979, 1089-7550.

[133] Jeffrey I. Steinfeld, Steven M. Adler-Golden, and Jean W. Gallagher. Critical survey of data on the spectroscopy and kinetics of ozone in the mesosphere and thermosphere. J. Phys. Chem. Ref. Data, 16(4):911-951, October 1987. ISSN 0047-2689, 1529-7845. 
[134] J. Stevefelt, J. Boulmer, and J F. Delpech. Collisional-radiative recombination in cold plasmas. Phys. Rev. A, 12(4):1246-1251, October 1975.

[135] H. C. Straub, P. Renault, B. G. Lindsay, K. A. Smith, and R. F. Stebbings. Absolute partial cross sections for electron-impact ionization of $\mathrm{H}_{2}, \mathrm{~N}_{2}$, and $\mathrm{O}_{2}$ from threshold to $1000 \mathrm{eV}$. Phys. Rev. A, 54(3):2146-2153, September 1996.

[136] Daisuke Suzuki, Hidetoshi Kato, Mizuha Ohkawa, Kazutoshi Anzai, Hiroshi Tanaka, Paulo Limao-Vieira, Laurence Campbell, and Michael J. Brunger. Electron excitation of the Schumann-Runge continuum, longest band, and second band electronic states in $\mathrm{O}_{2}$. J. Chem. Phys., 134(6):064311, 2011. ISSN 00219606.

[137] Motomichi Tashiro, Keiji Morokuma, and Jonathan Tennyson. R-matrix calculation of electron collisions with electronically excited $\mathrm{O}_{2}$ molecules. Phys. Rev. A, 73(5):052707, May 2006.

[138] B. L. Upschulte, W. J. Marinelli, and B. D. Green. Reactions of $\mathrm{O}_{2}\left(a^{1} \Delta_{g}\right)$ with $\mathrm{O}^{-}$and $\mathrm{O}_{2}^{-}$. J. Phys. Chem., 98(3):837-842, January 1994. ISSN 0022-3654.

[139] Robert J Vidmar and Kenneth R Stalder. Computations of the power to sustain plasma in air with relevance to aerospace technology. Final Report AFRL-SRAR-TR-04-0123, Air Force Office of Scientific Research, 2004.

[140] B. L. Whitten, W. L. Morgan, and J. N. Bardsley. Monte-Carlo calculations of two- and three-body ionic recombination. J. Phys. B: At. Mol. Phys., 15(2):319, January 1982. ISSN 0022-3700.

[141] P. H. Wine, J. M. Nicovich, R. J. Thompson, and A. R. Ravishankara. Kinetics of $\mathrm{O}\left({ }^{3} P_{j}\right)$ reactions with hydrogen peroxide and ozone. J. Phys. Chem., 87(20): 3948-3954, September 1983. ISSN 0022-3654.

[142] Aijun Yang, Xiaohua Wang, Mingzhe Rong, Dingxin Liu, Felipe Iza, and Michael G. Kong. 1-D fluid model of atmospheric-pressure rf $\mathrm{He}+\mathrm{O}_{2}$ cold plasmas: Parametric study and critical evaluation. Phys. Plasmas, 18(11):113503, 2011. ISSN 1070664X.

[143] Judit Zádor, István Gy. Zsély, Tamás Turányi, Marco Ratto, Stefano Tarantola, and Andrea Saltelli. Local and global uncertainty analyses of a methane flame model. J. Phys. Chem. A, 109(43):9795-9807, November 2005. ISSN 1089-5639, $1520-5215$.

[144] V. Zhaunerchyk, W. D. Geppert, F. Österdahl, M. Larsson, R. D. Thomas, E. Bahati, M. E. Bannister, M. R. Fogle, and C. R. Vane. Dissociative recombination dynamics of the ozone cation. Phys. Rev. A, 77(2):022704, February 2008. 